Subsídios para a aplicação de métodos de geração de casos de testes baseados em máquinas de estados

\author{
Arineiza Cristina Pinheiro
}





\section{Subsídios para a aplicação de métodos de geração de casos de testes baseados em máquinas de estados}

\section{Arineiza Cristina Pinheiro}

Orientador: Prof. Dr. Adenilso da Silva Simão

Dissertação apresentada ao Instituto de Ciências Matemáticas e de Computação - ICMC-USP, como parte dos requisitos para obtenção do título de Mestre em Ciências - Ciências de Computação e Matemática Computacional. VERSÃO REVISADA 
Ficha catalográfica elaborada pela Biblioteca Prof. Achille Bassi e Seção Técnica de Informática, ICMC/USP, com os dados fornecidos pelo(a) autor(a)

Pinheiro, Arineiza Cristina
Subsidios para a aplicação de métodos de geração de
Casos de testes baseados em máquinas de estados /
Arineiza Cristina Pinheiro; orientador Adenilso da
Silva Simão. -- São Carlos, 2012.
79 p.
Dissertação (Mestrado - Programa de Pós-Graduação en
Ciências de Computação e Matemática Computacional) --
Instituto de Ciências Matemáticas e de Computação,
Universidade de São Paulo, 2012.
1. teste baseado em modelos. 2. máquinas de
estados finitos. 3. métodos de geração de casos de
teste. I. Simão, Adenilso da Silva, orient. II.
Título.


À Deus, em primeiro lugar, por ter me dado força e perseverança para a conclusão de mais uma etapa da minha vida.

Aos meus pais, Irene e Ariovaldo, por terem me apoiado e incentidado em minhas decisões. À minha irmã, Ariene, pela paciência e pela ajuda que sempre recebo. Aos meus avós, Yvone, Ariovaldo, Izabel e Marcílio "in memorian", pela constante torcida em cada conquista da minha vida.

Ao Bruno, pelo amor, comprensão e amizade. É muito importante poder contar sempre com a pessoa que amo.

Ao meu orientador, Prof. Dr. Adenilso da Silva Simão, pela confiança e orientação deste trabalho.

Aos meus 'velhos' amigos , Rayana, Júnior, Marília, Gabriel, Jeff, Jonas, Carol, Tatiana, Adriana e Fabiano, e aos meus 'novos' amigos feitos durante o mestado, Jerê, Vinicius, Thaís, Gustavo e Elis, que acompanharam de perto ou de longe meu trajeto até a conclusão deste trabalho.

Aos meus queridos amigos-irmãos, Joice, Juliana, Silvana e Rodolfo, pelas incertezas e realizações vividas durante o mestrado. A todos os meus amigos 'Labianos', Adriano, André, Lucas, Rafa, Marcão, David, Fabiano, Paulo, Gabriel, Harry, Draylson, Eduardo, Eliana, Maria e Vânia, pelas horas compartilhadas, tanto de trabalho quanto de comemorações. Em especial pela festa surpresa de aniversário realizada em 2010, com ajuda do meu querido orientador.

Aos funcionários do ICMC, pelo constante auxílio.

À todas as pessoas que contribuíram de alguma forma para a realização deste trabalho.

À CAPES e à FAPESP, pelo apoio financeiro. 

realização de atividades de teste é indispensável para a garantia da qualidade de um produto e para a identificação de defeitos, diminuindo custos de manutenção e evitando ao máximo o risco do cliente encontrar esses defeitos. Nessa linha, testes baseados em modelos têm se mostrado atrativos, pois o custo de geração de casos de testes e de correção de defeitos tende a ser menor. Devido à sua simplicidade conceitual e expressividade na descrição do comportamento de um sistema, um dos modelos mais usados e pesquisados na área de teste baseado em modelos são as Máquinas de Estados Finitos (MEFs). Por meio de MEFs e com apoio de ferramentas apropriadas, a geração de casos de testes para avaliar os comportamentos esperados de um sistema é automatizada, reduzindo tanto o custo da geração e da manutenção quanto as falhas humanas. Desta forma, a aplicabilidade de métodos de geração de casos de teste baseados em modelos no contexto de sistemas embarcados vem sendo investigada. O objetivo deste trabalho de mestrado consiste em investigar a aplicabilidade dos métodos de geração em cenários de teste reais, com foco em sistemas embarcados, identificando as dificuldades e limitações do processo, bem como os requisitos essenciais para a adequação dos métodos de geração propostos na literatura e de ferramentas de apoio à atividade de teste. O foco principal do projeto é a implementação de mecanismos que atendam aos requisitos levantados, visando a usabilidade, segurança e portabilidade da ferramenta. 
EST activities are essential to ensure the quality of products and identify faults to reduce maintenance costs and avoid that the client finds these faults. In this sense, model-based tests have been proved useful, because the cost of generating test cases and fault correction tend to be smaller. Due to its conceptual simplicity and expressiveness in describing the behavior of a system, Finite State Machines (FSM) have been used and researched in the model-based testing area. FSMs, employed with the support of appropriate tools, enable the generation of test cases in an automated way to assess the expected behavior of a system, reducing both the generation and maintenance costs and human failures. Thus, the applicability of test cases generation methods based on models in the context of embedded systems should be investigated. Test cases generation methods based on FSM are designed to derive test cases from the model. In this context, this work aims to investigate the applicability of generation methods in real-world scenarios, focusing embedded systems. It should identify the difficulties and limitations of the process, as well as the essential requirements for the adequacy of generation methods proposed in the literature and tools to support the test activity. The main focus of the project is the implementation of mechanisms that meet the elicited requirements in order to provide usability, security and tool portability. 
1 Introdução 1

1.1 Contextualização . . . . . . . . . . . . . . . . . . . . . 1

1.2 Motivação . . . . . . . . . . . . . . . . . . . . . . . 2

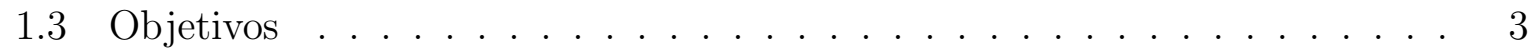

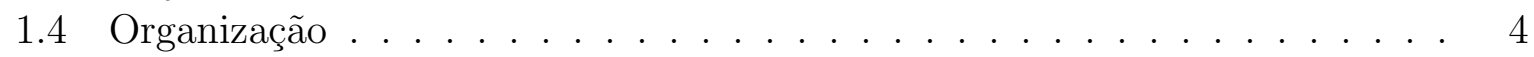

2 Teste Baseado em Modelos 5

2.1 Considerações Iniciais . . . . . . . . . . . . . . . . . . . . . . . . . . . . . . . . . . . . .

2.2 Teste de Software . . . . . . . . . . . . . . . . . . . . . 6

2.3 Técnicas de Teste . . . . . . . . . . . . . . . . . . . . . . . . . . . 8

2.4 Teste Baseado em Modelos . . . . . . . . . . . . . . . . . . . . . 11

2.5 Máquinas de Estados Finitos . . . . . . . . . . . . . . . . . 15

2.5.1 Propriedades e Características . . . . . . . . . . . . . . . 18

2.5.2 Testes Baseados em Máquinas de Estados . . . . . . . . . . . . . 18

2.6 Métodos de Geração de Casos de Testes . . . . . . . . . . . . . . . . . 20

2.6.1 Sequências Básicas . . . . . . . . . . . . . . . . . 20

2.6.2 Método TT . . . . . . . . . . . . . . . . . . . 22

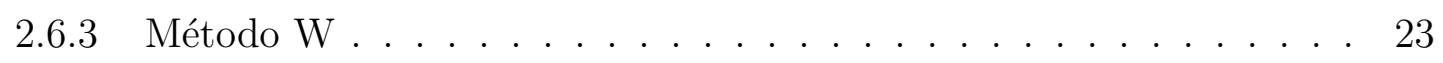

2.6 .4 Método Wp . . . . . . . . . . . . . . . . . 24

2.6.5 Método DS . . . . . . . . . . . . . . . . . . . . . . . . . . . . . . . 25

2.6.6 Método UIO . . . . . . . . . . . . . . . . . . . . . . . . . . . . . . . . . 27

2.6 .7 Método UIOv . . . . . . . . . . . . . . . . . . . . . . . . . . . 27

2.6 .8 Método HSI . . . . . . . . . . . . . . . . . . . . . . . . . . . . . . . . . . . . 28

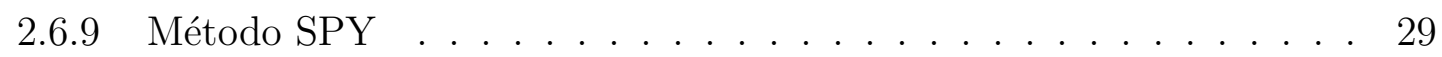

2.7 Considerações Finais . . . . . . . . . . . . . . . . . . . . 30

3 Sistemas Embarcados 33

3.1 Considerações Iniciais . . . . . . . . . . . . . . . . . . . . . . . . . . . . . . . . . . . . . . . . . 33

3.2 Fundamentos e Características . . . . . . . . . . . . . . . . 34

3.3 Projeto e Modelagem . . . . . . . . . . . . . . . . . . . . . 35

3.4 Teste de Software Embarcado . . . . . . . . . . . . . . . . 37

3.4 .1 Metodologia CoFI . . . . . . . . . . . . . . . . . . . 39

3.5 ITASAT . . . . . . . . . . . . . . . . . . . . . 42 
3.6 Considerações Finais . . . . . . . . . . . . . . . . . . . . . . . . . 44

4 JPlavisFSM $\quad 45$

4.1 Considerações Iniciais . . . . . . . . . . . . . . . . . . . . . . . 45

4.2 Contextualização . . . . . . . . . . . . . . . . . . . . . 46

4.3 JPlavisFSM: Contribuições . . . . . . . . . . . . . . . . . . . . . . . . . . . . . . . . . . . . 50

4.4 Aspectos de Implementação . . . . . . . . . . . . . . . . . . . . . . 53

4.5 Validação da JPlavisFSM . . . . . . . . . . . . . . . . . . . . 55

4.5.1 Estudo de Caso 1: Extensão com Novos Métodos . . . . . . . . . . 56

4.5.2 Estudo de Caso 2: Análise de Usabilidade . . . . . . . . . . . . . . 57

4.6 Considerações finais . . . . . . . . . . . . . . . . . . . . . 59

5 Estudo de Caso: ITASAT $\quad 61$

5.1 Considerações Iniciais . . . . . . . . . . . . . . . . . . . . . 61

5.2 Planejamento do Processo de Teste . . . . . . . . . . . . . . . 62

5.3 Identificação e Modelagem . . . . . . . . . . . . . . . . . . . . . . . . 62

5.4 Geração de Casos de Teste . . . . . . . . . . . . . . . . . . . . . 63

5.5 Análise dos Resultados . . . . . . . . . . . . . . . . . . . 66

5.6 Considerações Finais . . . . . . . . . . . . . . . . . . . 67

$\begin{array}{llr}6 & \text { Conclusões } & 69\end{array}$

6.1 Contribuições . . . . . . . . . . . . . . . . . . . . 70

6.2 Dificuldades e Limitações . . . . . . . . . . . . . . . . . . . . . . . . 71

6.3 Trabalhos Futuros . . . . . . . . . . . . . . . . . . . . 72

$\begin{array}{ll}\text { Referências Bibliográficas } & 73\end{array}$ 
2.1 Exemplo de MEF. . . . . . . . . . . . . . . . . . . . . 11

2.2 Exemplo de MEFE. . . . . . . . . . . . . . . . . . . . . . 12

2.3 Exemplo de Statechart. . . . . . . . . . . . . . . . . . . . . . 13

2.4 Exemplo da modelagem em SDL. . . . . . . . . . . . . . . . . 14

2.5 Modelos gerados pelas ferramentas Simulink e Stateflow. . . . . . . . . . 14

2.6 Exemplo de MEF. . . . . . . . . . . . . . . . . . . . . 15

2.7 MEF parcial, não-reduzida, não-determinística, não-inicialmente-conexa. $\quad$. 19

2.8 (a)Erro de Saída; (b)Erro de transferência. . . . . . . . . . . . . . . . . . 20

2.9 (a)Grafo- $X d ;$ (b)Grafo- $\beta \ldots \ldots \ldots \ldots \ldots$

2.10 Grafo- $\beta$ reduzido. . . . . . . . . . . . . . . . . . 26

2.11 Processo de geração de casos de teste do método SPY . . . . . . . . . . . 30

3.1 Desenvolvimento tradicional versus MDD. . . . . . . . . . . . . . . 38

3.2 Processo de aplicação da Metodologia CoFI. . . . . . . . . . . . . . . . . . 40

3.3 Arquitetura do ITASAT (Adaptado de (ITASAT, 2011)) . . . . . . . . . . . 43

4.1 MEF correspondente ao arquivo mef.les. . . . . . . . . . . . . . . . 46

4.2 Tela de métodos de geração de casos de teste da Plavis/FSM. . . . . . . . 48

4.3 Tabela de mutantes gerados. . . . . . . . . . . . . . . . . . . . . 49

4.4 Tela inicial da Ferramenta JPlavisFSM. . . . . . . . . . . . . . . . . . . . . 50

4.5 Sessão de Teste da Ferramenta JPlavisFSM. . . . . . . . . . . . . . . . . . 52

4.6 Análise de Mutantes da Ferramenta JPlavisFSM. . . . . . . . . . . . . . 53

5.1 Processo de desenvolvimento do estudo de caso. . . . . . . . . . . . . . . 62

5.2 MEFs do comportamento normal do CM Receiver. . . . . . . . . . . . . . . 64

5.3 MEFs do comportamento normal do CM Transmitter. . . . . . . . . . . . . 65 


\section{Lista de Tabelas}

2.1 Tabela de transição da MEF da Figura 2.6. . . . . . . . . . . . . . . . 16

2.2 DS: Saídas obtidas para a MEF da Figura 2.6. . . . . . . . . . . . . . 21

2.3 W: Saídas obtidas para a MEF da Figura 2.6. . . . . . . . . . . . . . . 22

4.1 Formato .les criado pelo editor de MEFs da Plavis/FSM. . . . . . . . . . . 47

4.2 Número de classes implementadas na JPlavisFSM. . . . . . . . . . . . . . . 54

4.3 Características das MEFs geradas nos trabalhos. . . . . . . . . . . . . . 59

5.1 Número de testes gerados por método para cada uma das MEFs. . . . . . . 66

5.2 Resumo dos testes. . . . . . . . . . . . . . . . . . 67 


\subsection{Contextualização}

As atividades de Validação, Verificação e Teste (VV\&T) são executadas para garantir a qualidade no desenvolvimento de software e, assim como as outras atividades de Engenharia de Software, devem ser conduzidas de forma sistemática, clara e rigorosa. O objetivo principal dessas atividades é facilitar a compreensão, aumentar a produtividade, diminuir os custos para quem desenvolve o software e atender aos padrões de qualidade. A realização de atividades de teste é indispensável para a garantia da qualidade de um produto e na identificação de defeitos o mais cedo possível, para diminuir custos de manutenção e evitar ao máximo o risco do cliente encontrar esses defeitos.

Por ser uma atividade onerosa do desenvolvimento de software, estudos teóricos e experimentais em teste de software têm sido conduzidos por grupos de pesquisas para identificar métodos eficazes e eficientes para aplicar os recursos disponíveis. Nessa linha, testes baseados em modelos têm se mostrado úteis, pois o custo de geração de casos de testes e de correção de defeitos tendem a ser menores. O Teste Baseados em Modelos consiste em uma técnica para geração automática de um conjunto de casos de testes, com entradas e saídas esperadas, utilizando modelos extraídos a partir dos requisitos do software (Binder, 2000). Devido à sua simplicidade conceitual e expressividade na descrição do comportamento de um sistema, um dos modelos mais usados e pesquisados na área de teste baseado em modelos são as Máquinas de Estados Finitos (MEFs). Por 
meio de MEFs e com apoio de ferramentas apropriadas, a geração de casos de testes para avaliar os comportamentos esperados de um sistema é automatizada, reduzindo tanto o custo da geração e da manutenção quanto as falhas humanas.

Nesse contexto, a ferramenta Plavis/FSM (Simão et al., 2005), desenvolvida no projeto Plavis $^{1}$ em parceria com pesquisadores do INPE, ICMC-USP, Unicamp, UFSCar, UEPG e Univem, tem como principal funcionalidade proporcionar a aplicação de métodos de geração baseados em MEFs nas atividades de teste. A ferramenta tem sido utilizada no grupo de pesquisa do ICMC-USP e na área de Engenharia de Gerenciamento de Sistemas Espaciais (GSE) da pós-graduação do INPE, em disciplinas de pós-graduação e trabalhos de mestrado. A Plavis/FSM oferece um ambiente que permite a familiarização com os conceitos importantes da área. Identificou-se, então, o interesse de ampliar o escopo de aplicação da ferramenta para apoiar o teste de sistemas reais.

Em parceria com o INPE e ITA, foi realizado um estudo de caso no projeto ITASAT (Sato et al., 2011), desenvolvido pelas instituições com apoio da Agência Espacial Brasileira, cujo objeto de pesquisa é o desenvolvimento e lançamento do satélite ITASAT-1 (Sato et al., 2011). A ideia consistiu em utilizá-lo como base para o levantamento das reais dificuldades de se aplicar teste baseado em MEFs em sistemas reais, contribuindo com a elaboração de novos cenários de teste para o projeto.

\subsection{Motivação}

Métodos de geração baseados em MEFs têm sido amplamente investigados e propostos na literatura (Chow, 1978; Fujiwara et al., 1991; Petrenko et al., 1993; Sabnani e Dahbura, 1988; Simão et al., 2009; Vuong et al., 1989). A formalidade provida pelas máquinas de estados proporciona a automatização do processo de geração de casos de testes, o que contribui na fase de seleção do conjunto de testes a ser aplicado ao sistema, reduzindo os esforços e guiando o processo de forma sistemática.

Com a possibilidade de automatizar o processo de geração de casos de teste, a disseminação da técnica de teste baseada em MEFs pode ser explorada para um conjunto maior de pessoas que, em princípio, não precisa possuir conhecimento prévio sobre métodos de geração. Ambientes de teste que proporcionem uma interface para o gerenciamento da atividade de teste baseada MEFs devem ser desenvolvidos com o intuito de facilitar o processo de teste de sistemas reais e de auxiliar no processo de ensino da técnica.

O desenvolvimento de software requer uma série de testes rigorosos, principalmente nas fases de teste de unidade e de integração antes que o produto venha a ser entregue para a

\footnotetext{
${ }^{1}$ http://www.labes.icmc.usp.br/plavis/index.html
} 
comercialização. Atualmente, a indústria de sistemas embarcados tem ganhado destaque, pois está em constante processo de mudança, seus produtos estão se tornando cada vez maiores, mais complexos e mais integrados. O software que compõe o sistema embarcado tem se tornado sofisticado e, frequentemente, tem substituido o hardware (Ebert e Salecker, 2009). Um software embarcado está cada vez mais presente no cotidiano das pessoas e desempenham as funções principais em equipamentos como carros, televisores digitais, aviões, entre outros, e, portanto, precisa ser bem testado.

Entretanto, apesar do software significar uma pequena parcela do sistema embarcado, a maior parte das falhas no sistema são causados pelo software e não pelo hardware (Seo et al., 2008). Aliar modelos formais como parte da atividade de projeto de software embarcado possibilita a utilização de métodos de geração de casos de testes baseados em máquinas de estados, sistematizando a modelagem dos artefatos de teste, agregando as vantagens de se evitar ambiguidades e falhas de interpretação de requisitos ao empregar modelos como documentos de especificação de sistemas.

\subsection{Objetivos}

O objetivo deste trabalho de mestrado consiste em prover subsídios para a aplicação de métodos de geração da casos de testes com a finalidade de investigar a aplicabilidade dos métodos de geração em um cenário de teste de sistemas reais, identificando as dificuldades e limitações do processo, bem como os requisitos essenciais para a adequação dos métodos de geração propostos na literatura. Visa-se implementar uma ferramenta de teste, que promova a manipulação das MEFs e a geração automatizada dos casos de testes baseada nos métodos encontrados na literatura, focando a portabilidade da ferramenta.

Esforços foram concentrados na evolução da ferramenta Plavis/FSM, implementando uma nova versão que visa a disponibilização de funcionalidades adicionais para auxiliar na atividade de modelagem e análise do conjunto de teste gerado. A ferramenta foi reformulada com o intuito de prover maior usabilidade e flexibilidade, características levantadas como essenciais para a nova versão. Como parte dos requisitos para a evolução da ferramenta foi utilizado o feedback fornecidos por alunos envolvidos com a ferramenta original na disciplina de pós-graduação de Verificação e Validação de Sistemas Espaciais oferecidas pelo INPE.

A nova ferramenta desenvolvida, denominada JPlavisFSM, agrega as funcionalidades existentes na versão antiga e disponibiliza novos recursos, como inclusão de métodos em tempo de execução e análise de completude do conjunto gerado pela ferramenta (Simão e Petrenko, 2010). Três estudos de caso foram conduzidos para analisar o desempenho da ferramenta desenvolvida e a aplicabilidade da técnica de teste baseado em MEFs. 
Nessa avaliação, foram explorados três contextos diferentes, sendo: (1) desenvolvedor de métodos de geração; (2) testador sem conhecimento na área de teste baseado em máquinas de estados; e (3) testador com conhecimento na área de teste baseado em máquinas de estados. Além disso, os estudos de casos foram realizados com o intuito de ampliar a coleta de dados sobre sistemas reais desenvolvidos na indústria, com foco no sistema embarcado do satélite universitário ITASAT. Para guiar a geração das MEFs durante o estudo de casos realizado com o ITASAT, foi aplicada a metodologia CoFI, proposta e empregada para contornar as dificuldades enfrentadas no contexto de sistemas aeroespaciais.

Os resultados apontam que o conhecimento prévio sobre a técnica de teste baseado em MEFs é relevante para o desempenho da atividade de teste mesmo com o apoio da ferramenta de teste, uma vez que a máquina de estado gerada na fase de modelagem determina a aplicabilidade do métodos de geração de casos de testes.

\subsection{Organização}

O restante deste trabalho está organizado da seguinte forma. No Capítulo 2, é apresentada uma visão geral sobre teste de software, com maior enfoque em teste baseado em modelos, citando os modelos existentes, em especial as máquinas de estados finitos e a sua aplicabilidade no teste de software. No Capítulo 3, é abordado o contexto de sistemas embarcados, exemplificando e definindo suas principais características, pertinentes a fase de projeto, modelagem e testes, além de apresentar o projeto ITASAT. No Capítulo 4, é apresentada a ferramenta JPlavisFSM, desenvolvida durante o presente trabalho. No Capítulo 5, é descrito o estudo de caso realizado com objetivo de avaliar a aplicabilidade de teste baseado em MEFs em cenários reais de um sistema embarcado. Por fim, no Capítulo 6, é feita uma síntese do contexto e objetivos do trabalho, exibindo as contribuições, limitações e os trabalhos futuros para a pesquisa. 


\section{Teste Baseado em Modelos}

\subsection{Considerações Iniciais}

Durante a realização da atividade de teste, um grande desafio é estabelecer exatamente quais são os objetivos do teste (Delamaro et al., 2007b). Para definir quais itens serão testados e como, uma especificação formal pode auxiliar o processo, uma vez que especificações não rigorosas podem apresentar ambiguidades e divergência de interpretações. Desta forma, a utilização de modelos formais para a especificação de sistemas, tanto na fase de desenvolvimento quanto na fase de teste, é um recurso que deve ser explorado.

O objetivo deste capítulo é apresentar os principais conceitos e técnicas de teste de software, com foco nas técnicas de teste baseadas em máquinas de estados finitos. $\mathrm{Na}$ Seção 2.2, são contextualizadaos a área de teste de software e os principais conceitos envolvidos. Na Seção 2.3, são discutidas as principais técnicas de teste de software encontradas na literatura. Na Seção 2.4, são apresentados alguns dos principais modelos empregados na teoria e na prática para a realização de teste baseado em modelos. Na Seção 2.5, são apresentadas a definição de máquina de estados e uma revisão sobre os principais conceitos que a envolvem, bem como as classes de erros possivelmente encontradas durante o desenvolvidmento da atividade de teste. Na Seção 2.6, são apresentados os principais métodos de geração de casos de testes discutidos na literatura. 


\subsection{Teste de Software}

Seguir métodos de desenvolvimento e utilizar ferramentas de engenharia de software podem ajudar no processo, porém não excluem a chance de defeitos no produto final. Desta forma, atividades de VV\&T podem ser realizadas a fim de minimizar os possíveis problemas no software. O objetivo dessas atividades é garantir tanto a conformidade do produto final com a sua especificação quanto a qualidade do processo envolvido. As atividades são basicamente divididas em estáticas e dinâmicas (Delamaro et al., 2007b). Atividades estáticas são as que não precisam de artefatos executáveis para serem realizadas, tais como inspeção de software e revisões técnicas. As atividades dinâmicas, por sua vez, necessitam de artefatos que possam ser executados para serem verificados. A atividade de teste se enquadra nessa segunda categoria.

O foco da atividade de teste é analisar o comportamento que o programa ou modelo venha a apresentar, confrontando-o com o determinado na sua especificação. Assim, um teste bem elaborado é aquele que encontra defeitos, uma vez que o fato de encontrar defeitos não garante que o software está correto. Em outras palavras, um bom conjunto de teste é aquele que leva o programa a falhar. Um conjunto é dito adequado quando cobre todos os requisitos do critério em questão. Nesse contexto, pode-se listar alguns dos principais termos usados em teste de software, como:

- Domínio de entrada - é o conjunto de todos os possíveis valores que podem ser utilizados para executar o programa $P$ ou sistema em teste (SUT - system under testing);

- Dado de teste - um elemento do domínio de entrada, ou seja, um valor de entrada do sistema;

- Caso de teste - é um par entrada/saída esperada de P. Um dado de teste juntamente com o resultado esperado do programa para aquele dado de teste;

- Conjunto de teste - também chamado de conjunto de casos de teste, é o conjunto de todos os casos de teste usados durante a atividade de teste em questão; e

- Oráculo - é o mecanismo de decisão utilizado para determinar se a saída obtida para um determinado teste corresponde à saída esperada, podendo ser uma ferramenta automatizada ou o próprio testador.

Na literatura é possível encontrar definições distintas para: (1) defeito, (2) engano, (3) erro e (4) falha. Segundo IEEE (1999), um defeito (fault) é definido como sendo um 
passo, processo ou definição de dados incorretos. Um engano (mistake) é a ação humana que resulta em um defeito. Um erro (error) decorre da execução de um defeito gerando um estado inconsistente ou inesperado no programa, como valores incorretos de variáveis, memória ou do apontador de instruções. Por fim, pode ocorrer uma falha (failure) no sistema em decorrência de um erro, que torna visível o problema para o observador por meio de um resultado inesperado do sistema.

O processo de teste pode ser planejado durante todo o ciclo de vida do projeto, desde a elaboração da especificação do projeto até a fase de manutenção. A atividade de teste deve ser desenvolvida em paralelo às demais atividades; assim, o processo de teste pode ter vários níveis, dependendo dos interesses da equipe responsável pelo projeto e da fase do desenvolvimento do software em que o teste poderá ser aplicado. As fases de teste podem ser classificadas da seguinte forma (Mathur, 2008).

Teste de Unidade, que tem como foco identificar defeitos nas menores unidades do programa (métodos, funções, procedimentos etc). Cada parte do programa deve ser isolada e testada a fim de mostrar que funciona individualmente; para isso, é necessária a implementação de drivers e stubs. O driver é o responsável por processar os dados de entrada e saída, fornecendo uma interface para a viabilização dos testes, processando os dados de entrada para fornecê-los como parâmetros ao métodos ou funções, e coletando os dados de saída para apresentá-los ao testador. Os stubs simulam as dependências da unidade foco do teste com outras unidades do sistema, como outros métodos ou funções que a unidade testada executa durante sua execução.

Teste de Integração, responsável por analisar a integração das unidades do programa, pois algumas situações imprevistas podem acontecer e levar a um erro na comunicação entre as unidades. Técnicas de teste funcional são empregadas nessa fase, havendo também iniciativas de se estender critérios estruturais e baseados em defeitos (Delamaro et al., 2007b).

Teste de Sistema, no qual se verifica os requisitos funcionais e não-funcionais do sistema, levando em conta características de hardware e banco de dados. Assim, como no teste de integração, o teste de sistema é de suma importância, uma vez que partes ou cenários de teste, até então simulados, podem ser testados de forma integral.

Teste de Aceitação, que se destina a verificar, junto ao usuário, a adequação aos requisitos estabelecidos.

Teste de Regressão, que é aplicado na fase de manutenção do sistema ou a cada nova versão do sistema entregue para teste.

Como o teste pode representar uma atividade onerosa para o projeto em desenvolvimento, algumas iniciativas podem ser tomadas a fim de contribuir para otimizar o tempo 
dedicado à execução dos testes, como o desenvolvimento e o uso de ferramentas que automatizem técnicas de teste ou que automatizem o processo de geração de dados de teste.

\subsection{Técnicas de Teste}

O objetivo das técnicas de teste é sistematizar o processo de definição de conjunto de teste, de forma a verificar a adequação do software à sua especificação, garantindo maior qualidade e segurança ao produto final. A atividade de teste pode ser realizada a partir de três técnicas principais (Delamaro et al., 2007b): (1) funcional; (2) estrutural; e (3) baseada em defeitos. Na técnica funcional, o teste é realizado tendo como base a especificação do programa, não havendo necessidade de possuir informações sobre a sua estrutura interna. Na técnica estrutural, tem-se como base a implementação para a seleção dos casos de teste a serem aplicados, requerendo a execução de partes ou de componentes elementares do programa. Na técnica baseada em defeitos, o teste é realizado a partir do conhecimento sobre defeitos típicos inseridos durante o processo de desenvolvimento de software.

Como o domínio de entrada de um programa pode ser infinito, faz-se necessário estabelecer um meio de utilizar um subconjunto reduzido que seja representativo e possua alta probalibilidade de revelar a presença de defeitos. Para isso, utiliza-se o conceito de teste de subdomínios, que objetiva dividir de maneira sistematizada o domínio de entrada e, então, selecionar os casos de teste de acordo com os subdomínios definidos.

Para identificar quais dados de entrada estão em cada subdomínio, as técnicas de teste definem algumas "regras", chamadas de critérios de teste, que determinam quais os requisitos de testes a serem satisfeitos, ou seja, qual grupo de casos de teste que deve ser executado para representar os respectivos subdomínios relevantes ao critério escolhido.

No teste funcional, ou caixa-preta, uma das formas de cobrir a maior parte do domínio de testes é realizar o critério de particionamento de equivalência. O objetivo desse critério é dividir o domínio de entrada do programa em classes de equivalência. De acordo com a especificação, subconjuntos do domínio de entrada são definidos de tal forma que possuam a propriedade de desencadear comportamento similar no programa quando executados. Deve-se eleger apenas uma entrada de cada um desses subconjuntos (classes) (Mathur, 2008). O cojunto de teste é formado pelas entradas selecionadas de cada classe.

Existe a opção de utilizar outro critério em conjunto ao particionamento de equivalência: o critério de análise do valor limite. O critério consiste em selecionar os casos de testes de forma que o valor limite de cada classe de equivalência seja explorado, sendo eles os valores que estão exatamente sobre e imediatamente acima ou abaixo dos limites da classe de equivalência (Fabbri et al., 2007). Essa técnica direciona a escolha dos casos 
de testes que irão representar as partições, aumentando as chances de se identificar problemas, uma vez que se observa que os casos de testes que exploram as condições limites têm maior probabilidade de encontrar defeitos (Fabbri et al., 2007).

Na técnica de teste estrutural, ou caixa-branca, existem duas classes de critérios (Barbosa et al., 2007): (1) baseados em fluxo de controle e (2) baseados em fluxo de dados. Pode-se citar como exemplos da classe baseada em fluxo de controle os critérios: todos-nós, todos-arcos e todos-caminhos. O critério todos-nós exige que cada linha de código, ou seja, cada nó definido seja executado pelo menos uma vez. O critério todos-arcos exige que cada desvio de fluxo de controle, isto é, cada aresta definida, seja executado pelo menos uma vez. Por fim, o critério todos-caminhos exige que todos os caminhos possíveis do programa sejam executados. No caso da existência de laços no código, o critério todos caminhos é infactível, pois o número de caminhos possíveis é infinito. Quanto à classe baseada em fluxo de dados, os critérios requerem que as interações envolvendo a manipulação de variáveis sejam testadas, como definições e subsequentes usos dessas definições. Dois dos principais critérios pertencentes a essa classe são (Mathur, 2008): (1) todas-definições, que requer que cada definição de variável seja executada pelo menos uma vez; e (2) todos-usos, que requer que todas as associações entre uma definição de variável e seus subsequentes usos sejam exercitadas pelos casos de teste, por meio de pelo menos um caminho livre de definição, que corresponde a um caminho em que a variável não é redefinida.

Maldonado (1991) define uma nova família de critérios baseados em fluxo de dados, chamada Potenciais-Usos. Tais critérios requerem que caminhos livres de definição em relação a qualquer nó $i$ que possua definição de variável e a qualquer variável $x$ definida em $i$ sejam executados, independentemente de ocorrer um uso de $x$ nesses caminhos (Barbosa et al., 2007). Pode-se citar como um dos critérios básicos da família Potenciais-Usos (Maldonado, 1991): todos-potenciais-usos, que requer que pelo menos um caminho livre de definição de uma variável definida em um nó $i$ para todo nó e todo arco possível de ser alcançado a partir de $i$ seja executado.

Por fim, na técnica baseada em defeitos, um dos critérios mais conhecidos é o teste de mutação. Segundo Mathur (2008), o critério pode ser utilizado como técnica caixa preta, quando realizada mutação de especificação e, no domínio de aplicações web, mutação de mensagens entre cliente e servidor. Por outro lado, ao considerar o critério de mutação que requer acesso a todo ou parte do código fonte, este é considerado como uma técnica caixa-branca.

Considerando um produto $P$, o artefato em teste que pode ser um programa ou um modelo, e um conjunto de testes $T$, a técnica consiste basicamente em avaliar a adequação do conjunto. Para isso, primeiramente, é executado o conjunto $T$ em $P$. Se ocorrer alguma 
falha, um defeito foi encontrado. Caso contrário, assume-se que algum erro pode existir e ainda não foi detectado.

Produtos com uma ou mais alterações são derivados a partir do produto original $P$, dando origem aos produtos $P_{1}, P_{2}, \ldots, P_{n}$, chamados de mutantes de $P$. Para gerar os mutantes são utilizados operadores de mutação, que são dependentes da linguagem analisada e determinam quais os tipos de mudanças sintáticas que podem ser realizadas no código. Os operadores de mutação tem por objetivo: (1) induzir mudanças sintáticas simples com base nos enganos típicos cometidos pelos desenvolvedores, como trocar o valor de uma constante; ou (2) forçar determinados objetivos de teste, como executar cada nó ou arco do produto (Delamaro et al., 2007a). O conjunto de teste $T$ é executado em cada um dos mutantes gerados. Nesta fase, o objetivo é "matar" todos os mutantes. Espera-se que, devido à alteração realizada, os mutantes possuam comportamento diferente do produto original, caracterizando um defeito.

Eventualmente, algum mutante e o produto original podem apresentar sempre o mesmo resultado, para qualquer caso de teste elaborado. Cabe ao testador verificar o código e determinar se há equivalência entre os produtos. Em caso afirmativo, o mutante é classificado como equivalente. A equivalência entre programas é um problema indecidível; sendo assim, não existe uma solução automatizada para o problema, tornando necessária a intervenção do testador para analisar os respectivos códigos e determinar se há ou não a equivalência. Muitas vezes, trata-se de uma atividade complexa e demorada. No caso de o produto ser um modelo, é possível determinar automaticamente a equivalência.

Após a execução dos mutantes e a análise de equivalência, é calculado o escore de mutação. O objetivo é determinar a adequação dos casos de teste utilizados em uma escala de 0 a 1 , fornecendo uma medida objetiva de quão próximo o conjunto está da adequação do critério. Dado o produto $P$ e o conjunto de teste analisado $T$, é calculado o escore de mutação $m s(P, T)$ como (Delamaro et al., 2007a):

$$
m s(P, T)=\frac{D M(P, T)}{M(P)-E M(P)}
$$

onde:

$D M(P, T)$ : número de mutantes mortos pelo conjunto de casos de teste $T$;

$M(P)$ : número total de mutantes gerados a partir do produto $P$; e $E M(P)$ : número de mutantes gerados que são equivalentes a $P$.

O escore de mutação é obtido a partir da razão entre o número de mutantes mortos pelo conjunto $T$ e o número de mutantes que se pode matar, dado pela diferença entre o número total de mutantes gerados e o número de mutantes classificados como equivalentes. Entretanto, além do problema da equivalência, outro grande problema para a aplicação 
do critério análise de mutantes está relacionado ao seu alto custo de execução, uma vez que o número de mutantes gerados pode ser muito grande, mesmo ao considerar software pequenos, o que dispende um alto tempo de execução (Delamaro et al., 2007a).

\subsection{Teste Baseado em Modelos}

Vários são os modelos que podem ser empregados para definição de sistemas computacionais. As diversas técnicas de modelagem encontradas na literatura diferem entre si pelo grau de formalismo proposto e mecanismos de modelagem disponibilizados. Cabe ao projetista, seja de testes ou do sistema, decidir qual o melhor modelo para representar o comportamento do software. Nesta seção, são apresentados alguns dos modelos encontrados na literatura. Como os modelos apresentados são extensões de MEFs, a seguir, é apresentada resumidamente a definição de MEF, no entanto, por ser o foco desse trabalho, a definição de MEF é retomada em detalhes na Seção 2.5.

Máquinas de Estados Finitos ou MEFs são modelos de máquinas hipotéticas compostas por um número finito de estados e transições que levam de um estado a outro. Somente um estado pode estar ativo por vez e as transições são atômicas, desencadeadas por um evento de entrada e gerando um evento de saída.

A Figura 2.1 apresenta um exemplo de uma MEF adaptado de (Chow, 1978). A MEF modela o comportamento de um extrator de comentários de uma linguagem de programação. Quando identificado o primeiro "*” nenhuma saída é gerada ( uull). Em seguida, todos os caracteres lidos, representados por " $v$ ", são lidos e armazenados em um buffer. Ao identificar o último "**, é retirado o caractere "*" do buffer e então é impresso seu conteúdo.

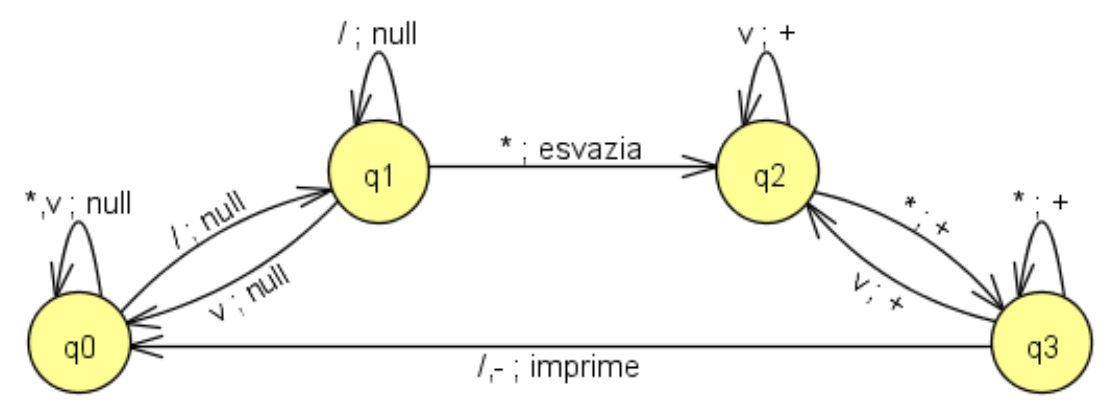

Figura 2.1: Exemplo de MEF.

Máquinas de Estados Finitos Estendidas são MEFs tradicionais que agregam novos conceitos, como o uso de transições condicionais e predicados. Esse novo artefato viabiliza a criação de transições dependentes de parâmetros, adicionando variáveis de controle: contadores ou variáveis que definem prioridades para as ocorrências de transições. Uma 
variação de MEFEs são as chamadas MEFs comunicantes (MEFC), que apresentam canais de comunicação para o relacionamento entre duas ou mais MEFs.

Pode-se definir uma MEFE como sendo uma MEF convencional responsável pela modelagem do fluxo de controle, acrescida de parâmetros de entrada e saída, variáveis de contexto, operações e predicados definidos sobre as variáveis de contexto e parâmetros de entrada, responsáveis pela modelagem do fluxos de dados do sistema (Petrenko et al., 2004).

Uma MEFE recebe entradas como parâmetros e calcula quais predicados podem ser satisfeitos, dado o estado atual. Os predicados indicam as transições possíveis, identificando qual transição deve ser habilitada e, então, executada. Com essa execução, a MEFE gera a resposta pertinente à transição realizada e atualiza as variáveis, movendo-se para outro estado. A Figura 2.2 exemplifica uma MEFE.

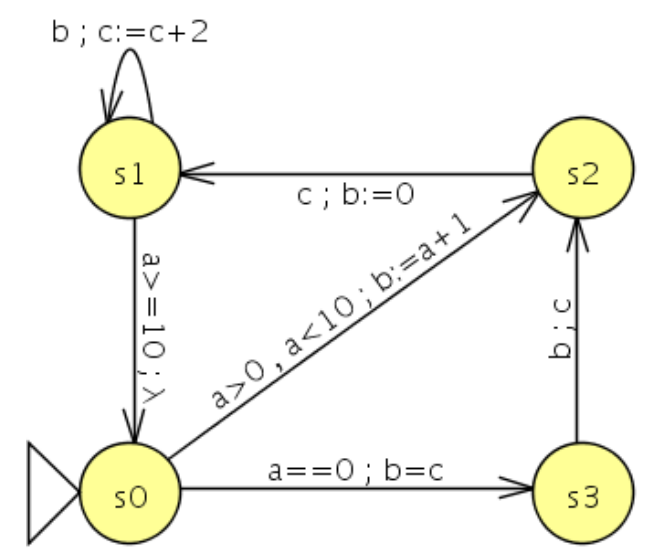

Figura 2.2: Exemplo de MEFE.

Statecharts, definidos por Harel (1987), são diagramas que representam o comportamento de entidades dinâmicas especificando suas respostas ao receberem eventos em instantes pré-definidos. Pode-se utilizar Statecharts para descrever o comportamento de classes, casos de uso, atores, subsistemas, operações ou métodos. Podem descrever sistemas completos por meio de abstrações como superestados e história, os quais são elementos fornecidos pelo modelo. Em alto nível, Statecharts representam uma máquina de estados. Estados e outros tipos de elementos, como pseudoestados, podem ser descritos pelos respectivos símbolos do modelo, enquanto transições são descritas por arcos direcionados que os interconectam. Estados também podem conter subdiagramas, característica opcional que define o conceito de superestados.

Os Statecharts configuram uma extensão das MEFs tradicionais, em que características de decomposição, ortogonalidade e broadcasting são incorporadas com o objetivo de viabilizar a construção de uma especificação de forma modularizada, uma vez que agrega independência aos subestados e permite modelar paralelismo. Na Figura 2.3 é apresentado 
um exemplo de Statechart em que é possível visualizar os principais elementos disponíveis no modelo: $S 1, S 2$ e $S 7$ representam superestados; a linha pontilhada representa a modelagem para paralelismo, ou seja, a submáquina representada pelos estados $S 3$ e $S 4$ são executadas em paralelo com a submáquina $S 5$; e o símbolo $H^{*}$ representa o elemento história, que indica que a transição do estado $S 8$ deve retornar ao último estado visitado antes do evento $a$ originado do superestado $S 2$.

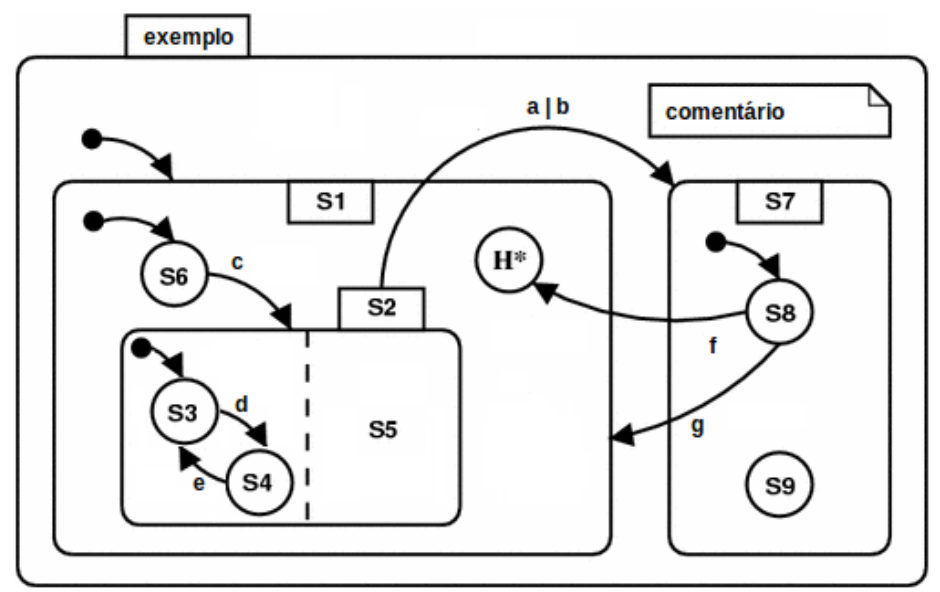

Figura 2.3: Exemplo de Statechart.

Specification and Description Language (SDL) é uma técnica de descrição formal definida e padronizada pela ITU-T (International Telecommunications Union-Telecom- munications Standardization Sector) (ITU-T, 1993, 2002). Criada para modelagem de sistemas de telecomunicações, SDL é utilizada para descrição formal de especificações de sistemas reativos e distribuídos.

Os elementos fornecidos pela SDL consistem em blocos, canais e tipos abstratos de dados, sendo que blocos se comunicam por canais. A SDL apresenta uma modelagem descrita por um conjunto de processos representados em formato de MEFs. Conceitos de objetos, como tipos e herança, foram incorporados a linguagem de forma a fornecer mecanismos para aumentar o escopo de sua aplicação. Como a linguagem possui natureza dinâmica e sintaxe bem definida, é possível executar o modelo gerado permitindo atividades de validação e simulação. A Figura 2.4 apresenta um exemplo de um modelo em SDL.

Apesar de alguns autores o referenciarem como modelo, na realidade, o Stateflow é uma ferramenta proprietária para modelagem gráfica de sistemas. Desenvolvida pela mesma empresa proprietária do Simulink e Matlab, o Stateflow pode ser considerado uma extensão dessas duas ferramentas, utilizando-o como ambiente de projeto para modelagem de sistemas baseados em máquinas de estados e diagramas de fluxos. A ferramenta provê elementos para descrição de hierarquia e paralelismo. 


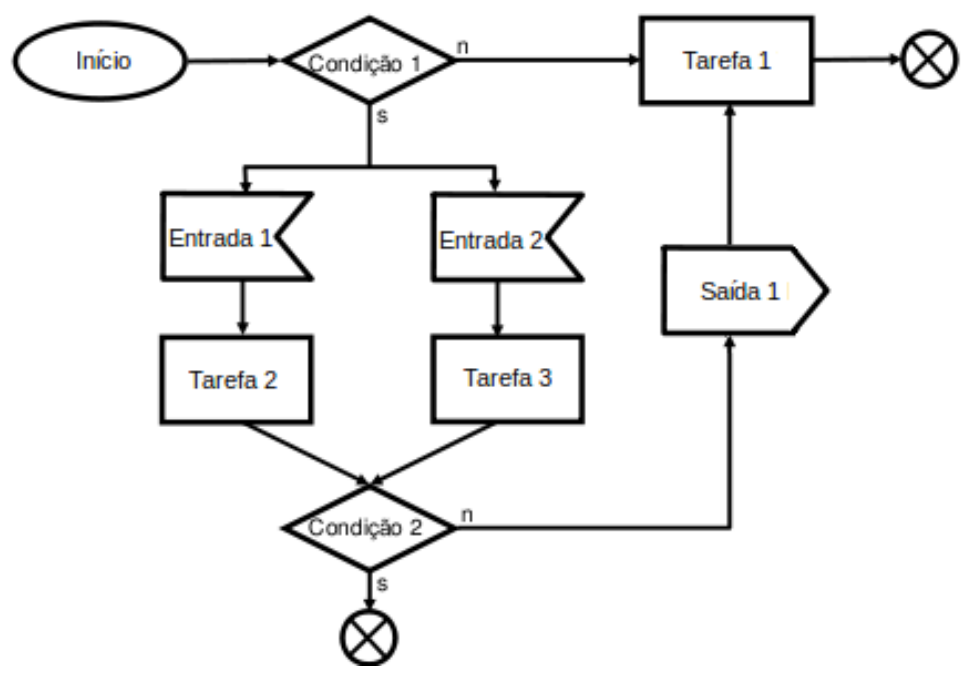

Figura 2.4: Exemplo da modelagem em SDL.

Segundo o site da ferramenta ${ }^{1}$, os modelos empregados no Stateflow consistem basicamente em Statecharts tradicionais que podem ser combinados com diagramas de fluxo, funções importadas do Matlab, funções de gráficos, tabelas verdade, operadores temporais, além de fornecer mecanismos de apoio à integração de códigos $\mathrm{C}$ externos. A ferramenta também apoia máquinas de estados finitos tradicionais. Dessa forma, o Stateflow agrega valores de vários modelos com o objetivo de prover maior flexibilidade para a modelagem de sistemas.

Na Figura 2.5, é apresentado um exemplo de modelos gerados a partir das ferramentas Simulink e Stateflow. O modelo gerado na ferramenta Simulink (Figura 2.5.(a)), baseado em componentes lógicos e eletrônicos, podem ser detalhados utilizando a ferramenta Stateflow, com a modelagem baseada em estados (Figura 2.5.(b)).

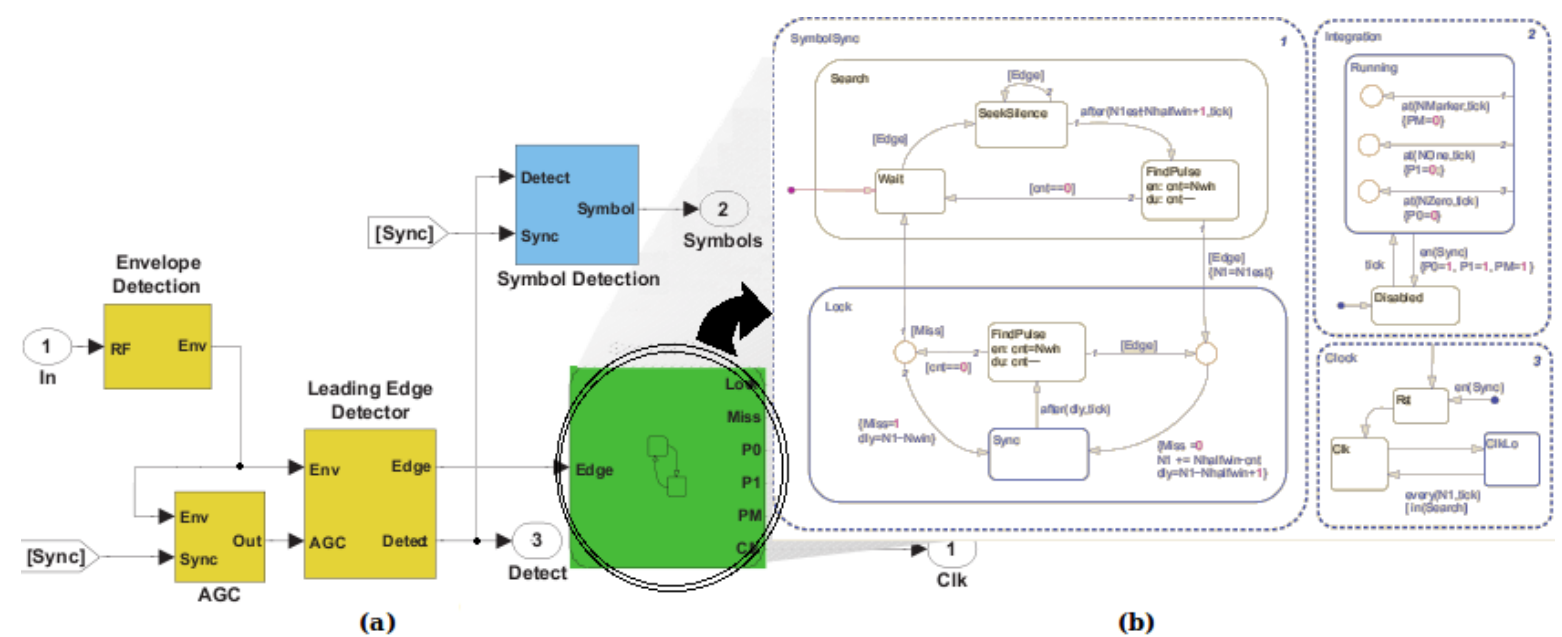

Figura 2.5: Modelos gerados pelas ferramentas Simulink e Stateflow.

\footnotetext{
${ }^{1}$ http://www.mathworks.com/products/stateflow/
} 


\subsection{Máquinas de Estados Finitos}

O conceito de máquina de estados finitos é apresentado em detalhes nesta seção por se tratar do modelo alvo dos estudos realizados durante o desenvolvimento deste trabalho de mestrado.

Uma máquina de estados finitos (MEF, do inglês finite state machine) é uma representação de uma máquina composta por estados e eventos, que correspondem a transições entre os estados. Uma transição é caracterizada por dois eventos: um de entrada e um de saída. A máquina pode estar em apenas um estado por vez. Ao ocorrer um evento de entrada, a máquina pode responder com um evento de saída e uma transição para outro estado (podendo ser para o mesmo estado).

Existem dois tipos de MEFs: (1) Mealy e (2) Moore. Na máquina de Mealy, os eventos de saída estão associados às transições, ou seja, ao ocorrer um evento de entrada, o evento de saída ocorre durante a mesma transição. Na máquina de Moore, os eventos de saída estão associados aos estados; sendo assim, o evento de saída ocorre ao final da transição, no seu estado destino. As máquinas diferem na forma de representação do evento de saída, mas para cada máquina de Mealy existe uma máquina de Moore correspondente. Para métodos de geração de sequências de teste, a máquina mais amplamente utilizada é a de Mealy, a qual será o foco deste trabalho.

A representação de uma MEF pode ser feita por um diagrama de estados, em que círculos representam os estados e arcos direcionados, as transições. Essa representação se assemelha a de um autômato finito com saídas. Outra representação possível é no formato de tabela de transição, em que os estados são representados por linhas e as entradas por colunas. Na Figura 2.6, é apresentada uma MEF de quatro estados e oito transições representada por um diagrama de estados e, na Tabela 2.1, é representado a mesma MEF em forma de tabela de transições.

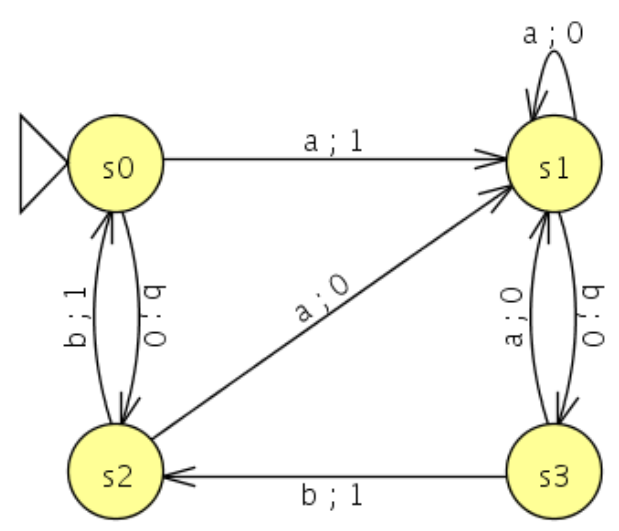

Figura 2.6: Exemplo de MEF. 
Tabela 2.1: Tabela de transição da MEF da Figura 2.6.

\begin{tabular}{|c||c|c||c|c|}
\hline \multicolumn{1}{|c||}{ MEF } & \multicolumn{2}{c||}{ Saída } & \multicolumn{2}{c|}{ Destino } \\
\hline Estado & Entrada & b & a & b \\
\hline \hline s0 & 1 & 0 & s1 & s2 \\
s1 & 0 & 0 & s1 & s3 \\
s2 & 0 & 1 & s1 & s0 \\
s3 & 0 & 1 & s1 & s2 \\
\hline
\end{tabular}

Formalmente, pode-se definir uma MEF (de Mealy e determinística) como uma tupla $M=\left(S, s_{0}, X, Y, D, \lambda, \delta\right)$, sendo:

- $S$ : conjunto finito não-vazio de estados;

- $s_{0}$ : estado inicial, tal que $s_{0} \in S$;

- $X$ : conjunto finito não vazio de símbolos de entrada;

- $Y$ : conjunto finito não vazio de símbolos de saída;

- $D$ : domínio da especificação, tal que $D \subseteq(S \times X)$;

- $\lambda$ : função de saída, tal que $\lambda: D \rightarrow Y$;

- $\delta$ : função de transição, tal que $\delta: D \rightarrow S$.

Considerando a MEF da Figura 2.6, tem-se que para o estado $s_{0}: \lambda\left(s_{0}, a\right)=1 \mathrm{e}$ $\lambda\left(s_{0}, b\right)=0$ (funções de saída) e $\delta\left(s_{0}, a\right)=s_{1}$ e $\delta\left(s_{0}, b\right)=s_{2}$ (funções de transição). Pode-se estender essas notações para sequências de entrada, considerando uma sequência de entrada $\alpha . a$ aplicada a partir do estado $s$, então $\delta(s, \alpha . a)=\delta(\delta(\mathrm{s}, \alpha), a)$ e $\lambda(s, \alpha . a)=$ $\lambda(s, \alpha) \cdot \lambda(\delta(\mathrm{s}, \alpha), a)$. Por exemplo, para o estado $s_{0}$, dada a sequência de entrada $a b b a$, temos $\lambda\left(s_{0}, a b b a\right)=1010$ e $\delta\left(s_{0}, a\right)=s_{1}$, que define uma sequência de entrada que antige o estado $s_{1}$ a partir do estado inicial, gerando a sequência de saída 1010. Outra notação empregada para representar as funções de saída e de transição é $s_{i}-x / y \rightarrow s_{j}$, que representa uma transição com entrada $x$ e saída $y$ do estado origem $s_{i}$ ao estado destino $s_{j}$, sendo $s_{i}, s_{j} \in S, x \in X$ e $y \in Y$. Para representar uma sequência finita de símbolos de entrada, pode-se utilizar a mesma notação sem a necessidade de representar a sequência de símbolos de saída obtidos, por exemplo, temos que $s_{0}-a b b a \rightarrow s_{1}$.

A notação $\alpha \beta$ representa a concatenação de duas sequências de entrada, sendo $\alpha, \beta$ $\in X^{*}$, em que $X^{*}$ representa todas as sequências do domínio de entrada. A notação $A B$ representa a concatenação de conjuntos, tal que $A B=\{\alpha \beta \mid \alpha \in A, \beta \in B\}$.

Dadas duas sequências $\alpha$ e $\beta$, $\alpha$ é dita prefixo de $\beta$, denotado $\alpha \leq \beta$, se $\beta=\alpha \omega$, para algum $\omega$. A sequência $\alpha$ é um prefixo próprio de $\beta$, denotado $\alpha<\beta$, se $\beta=\alpha \omega$, 
para algum $\omega \neq \varepsilon$, sendo que $\varepsilon$ representa a sequência vazia. Uma sequência de entrada é chamada de um caso de teste, ou apenas teste.

Um conjunto de casos de teste $T$ é um conjunto finito de sequências ou testes, tal que não existam duas sequências $\alpha, \beta \in T \operatorname{com} \alpha<\beta$. O conjunto de todas as sequências de entrada possíveis a partir do estado $s_{i}$ da MEF $M$ é denotado $\Omega_{M}\left(s_{i}\right)$. Caso deseje denotar o conjunto de sequências para $s_{0}$, pode-se omitir o estado, correspondendo apenas a $\Omega_{M}$.Para um conjunto de teste $T$, a notação pre $f(T)$ corresponde ao conjunto de todos os prefixos dos casos de testes contidos em $T$, isto é, pref $(T)=\{\alpha \mid \beta \in T, \alpha \leq \beta\}$.

Para executar cada sequência do conjunto de teste $T$ é necessário que a MEF esteja em seu estado inicial. Sendo assim, uma operação que leve corretamente a MEF de volta para o seu estado inicial antes que a próxima sequência venha a ser executada deve existir, o chamado reset confiável. Como é uma operação essencial para a aplicação das sequências de teste, o seu custo deve ser considerado, representando-o por meio do símbolo $r$ no início de cada sequência. O custo da execução de um caso de teste é medido pelo tamanho da sequência somado a operação de reset, assim, temos $\omega(\alpha)=|\alpha|+1$. Por exemplo, se um conjunto de teste é dado por $T=\{a a, b b b, b a b\}$, temos o conjunto final sendo $T^{\prime}=$ $\{r a a, r b b b, r b a b\}$ de tamanho 11 . O custo de execução do conjunto de testes $T$ é denotado $\omega(T)$, dado pela soma do tamanho de todas as sequências contidas em $T$.

Outras notações relativas ao contexto de MEF também são utilizadas. Dois estados, $s_{j}$ de $M$ e $t_{i}$ de $I$, sendo a MEF $I=\left(T, t_{0}, X, Y, C, \Lambda, \Delta\right)$, são ditos distinguíveis se existe uma seqüência de entrada $\gamma \in \Omega_{M}\left(s_{j}\right) \cap \Omega_{I}\left(t_{i}\right)$, chamada de sequência de separação, tal que $\lambda\left(s_{j}, \gamma\right) \neq \Lambda\left(t_{i}, \gamma\right)$. Duas MEFs $I$ e $M$ são ditas distinguíveis (ou distintas) se todo par de estados $\left(s_{i}, s_{m}\right)$, sendo $s_{i} \in S_{I}$ e $s_{m} \in S_{M}$, é distinguível.

Analogamente, considerando dois estados, $s_{i}$ e $s_{j}$ de $\mathrm{M}$, diz-se que são equivalentes se para todo $\alpha \in \Omega_{M}\left(s_{i}\right) \cap \Omega_{M}\left(s_{j}\right)$ se $\lambda\left(s_{i}, \alpha\right)=\lambda\left(s_{j}, \alpha\right)$. Também existe equivalência entre máquinas. $M$ é equivalente a outra MEF $I$ caso seus estados iniciais sejam equivalentes. Estendendo esse conceito para MEFs parcais, temos o conceito de quasi-equivalência. Dada a MEF parcial $I$ é dita quasi-equivalente a $M$ se $\Omega_{M} \supset \Omega_{I}$.

Um domínio de erro $\Im_{n}(M)$ é o conjunto de todas as implementações possíveis de M definidas sobre o alfabeto de entrada $X$. Similarmente, $\Im_{n}(M)$ denota o conjunto de todas MEFs completas definidas sobre o alfabeto de entrada $X$ com no máximo $n$ estados. $\mathrm{O}$ conjunto de teste $T$ é dito $n$-completo para a especificação $M$ se para todo $I \in \Im_{n}(M)$ tal que $I$ é distinguível de $M$, existe pelo menos uma sequência $\alpha \in T$ que distingue $I$ de $M$. Se $T$ possui uma única sequência, essa sequência é chamada de sequência de verificação (checking sequence). 


\subsubsection{Propriedades e Características}

MEFs possuem algumas propriedades importantes quanto a sua estrutura, como:

- Completude: uma MEF é dita completamente especificada, ou completa, se ela trata todas as entradas pertencentes ao domínio de entrada $(X)$ em todos os estados $(S)$, tal que $D=(S \times X)$. Caso contrário, a MEF é parcialmente especificada, ou parcial;

- Conectividade: uma MEF é fortemente conexa se para cada par de estados $\left(s_{i}, s_{j}\right)$ existe um caminho que leva $s_{i}$ a $s_{j}$, ou seja, existe alguma sequência de entrada que executa um caminho de transições com origem em $s_{i}$ e destino a $s_{j}$. Caso seja possível atingir todos os demais estados a partir do estado inicial, a MEF é dita inicialmente conexa;

- Determinismo: uma MEF é determinística quando há uma única transição para uma dada entrada e qualquer estado do conjunto que permita a transição para um próximo estado. Caso contrário, a MEF é dita não-determinística;

- Equivalência: um estado $s$ é dito equivalente a $s^{\prime}$, se para todo $\rho \in \Omega_{M}(s) \cap$ $\Omega_{M}\left(s^{\prime}\right), \lambda(s, \rho)=\lambda\left(s^{\prime}, \rho\right)$. Isto é, dois estados são equivalentes se não existe nenhuma sequência de entrada que, ao ser executada a partir dos respectivos estados, gere uma sequência de saída diferente. Utiliza-se a notação $s \approx s^{\prime}$ para estados equivalentes; $\mathrm{e}$

- Minimalidade: uma MEF é reduzida (ou minimal) se não existem dois estados equivalentes. Caso contrário, a MEF é dita não-reduzida.

Na Figura 2.6, pode-se observar um exemplo de MEF completa, reduzida, fortemente conexa e determinística. Na Figura 2.7, observa-se um exemplo de MEF: parcial, dado que o estado $s_{5}$ não trata o evento de entrada $b$; (2) não-reduzida, pois os estados $s_{1}$ e $s_{4}$ são equivalentes; (3) não-determinística, uma vez que o estado $s_{5}$ possui duas transições possíveis para o evento de entrada $a$; e (4) desconexa, pois não é possível alcançar o estado $s_{5}$ a partir de nenhum estado.

\subsubsection{Testes Baseados em Máquinas de Estados}

No contexto de teste de software, o teste baseado em máquinas de estados finitos tem o objetivo de confrontar uma MEF $M$ reduzida com $n$ estados com a MEF $I$, que corresponde a MEF implementada. Para tanto, a MEF I também deve ser uma MEF reduzida. 


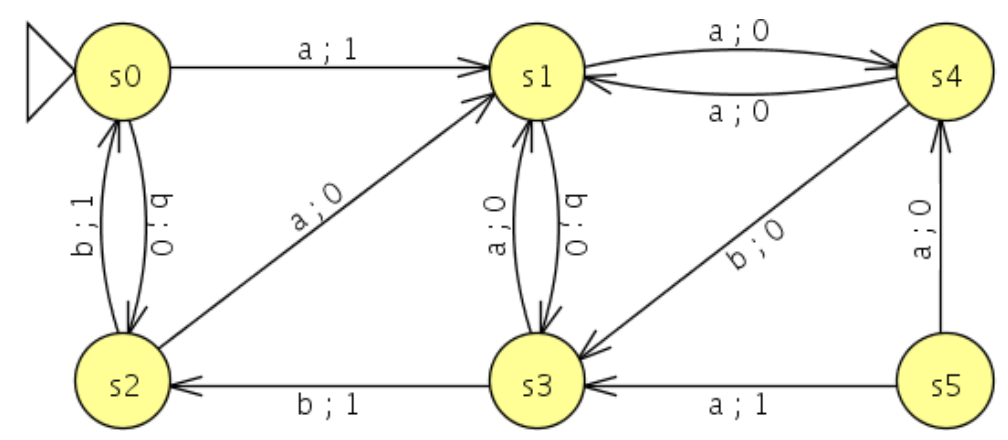

Figura 2.7: MEF parcial, não-reduzida, não-determinística, não-inicialmente-conexa.

A redução é uma característica importante uma vez que garante a inexistência de uma outra MEF equivalente, com $m$ estados, tal que $m \leq n$. De acordo com Chow (1978), uma MEF minimal $M$, que representa a versão correta da MEF especificada, se comparada com a MEF I, podem exibir os seguintes erros:

- Erros de saída: $I$ e $M$ diferem na saída obtida para um dado teste. Para tornar $I$ equivalente a $M$, deve-se modificar a função de saída de $I$.

- Erros de transferência: quando $I$ não é equivalente a $M$, e $I$ pode se tornar equivalente a $M$ ao alterar a função de transição de $I$.

- Erro de transição: termo geral para erro de saída e/ou de transferência.

- Erro de estado inicial: $I$ e $M$ não são equivalente. Porém basta alterar o estado inicial de $I$ para solucionar o erro.

- Estados extras: quando $I$ possui estados a mais do que $M$. Para tornar $I$ equivalente a $M$, basta modificá-la diminuindo o número de estados.

- Estados ausentes: erro oposto ao de estados extras, em que $I$ não é equivalente a $M$ por possuir um número menor de estados. Para torná-la equivalente a $M$, basta alterar $I$ acrescentando estados.

Na Figura 2.8, são exemplificados erros de saída e transferência, respectivamente, em relação a MEF apresentada na Figura 2.6, que possui a transição $s_{2}-b / 1 \rightarrow s_{0}$.

Para se identificar os erros descritos acima, uma opção seria a realização de teste exaustivo. O conjunto $X^{*}$, que representa todas as sequências de entradas possíveis, seria aplicado com o objetivo de verificar se as saídas de $I$ equivalem as saídas de $M$. Porém, é inviável realizar o teste exaustivo, uma vez que o conjunto $X^{*}$ é infinito.

Diversos métodos de geração de casos de testes têm sido propostos para a técnica de teste baseado em MEFs, com o objetivo de encontrar um conjunto de sequências que garanta a equivalência das MEFs. O método ideal seria aquele que gera o menor conjunto 


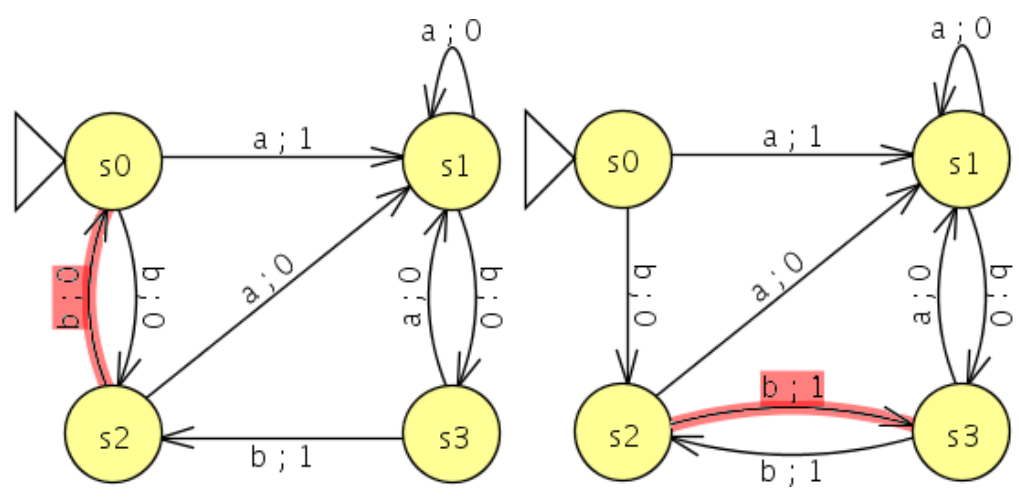

Figura 2.8: (a)Erro de Saída; (b)Erro de transferência.

de teste e que seja suficiente para revelar todos os possíveis erros de uma implementação. A Seção 2.6 apresenta alguns dos métodos de geração de casos de testes propostos para MEFs.

\subsection{Métodos de Geração de Casos de Testes}

Métodos de geração de casos de teste têm por objetivo verificar se uma implementação está correta em relação à especificação, por meio da execução de atividades de teste e validação em sistemas descritos por modelos (Fujiwara et al., 1991). Apesar de todos definirem procedimentos para a geração de testes, a principal diferença que os evidenciam é o custo da geração dessas sequências e a capacidade de detecção de defeitos (efetividade). Desta forma, deve-se levar em conta a relação custo-benefício de cada método. O foco principal consiste em promover a detecção do maior número possível dos defeitos existentes em uma implementação levando em conta o tamanho do conjunto gerado, para que esse fato não inviabilize a sua aplicação prática.

Como os métodos de geração de casos de testes (ou sequências de teste) são fortemente baseados em sequências básicas, primeiramente são apresentadas algumas das sequências importantes para a aplicação dos métodos tratados no decorrer desta seção.

\subsubsection{Sequências Básicas}

Sequências básicas possuem propriedades interessantes que são exploradas para a geração de conjuntos de teste. Algumas definem um caminho que passe por todos os estados pelo menos uma vez ou que execute todas as possíveis transições da MEF. Outras têm por objetivo garantir que, ao serem executadas na $\mathrm{MEF}$, possuam respostas diferentes para cada um de seus estados. Existem ainda sequências que levam a MEF para determinados estados. Exemplificando com base na Figura 2.6, as sequências mais citadas na literatura são: 
- State Cover $(Q)$ : é um conjunto de $n$ sequências de entrada (incluindo a sequência vazia $\varepsilon$ ), sendo $n$ o número de estados da MEF $M$, que ao serem executadas, a partir do estado inicial, terminam em cada um dos estado de $M$ uma vez. Para a Figura 2.6, um exemplo do conjunto State Cover seria: $Q=\{\varepsilon, a, b, a b\}$.

- Transition Cover $(P)$ : é um conjunto de sequências de entrada que exercitam cada uma das transições de $M$, a partir do estado inicial. O Transition Cover inclui o State Cover, pois para incluir todas as transições é necessário que todos os estados sejam visitados. Para a MEF de exemplo, temos: $P=\{\varepsilon, a, b, a b, b b, b a, a a, a b a, a b b\}$.

- Sequência de Separação $(S S)$ : são sequências que diferenciam um estado $s_{i}$ de outro estado $s_{j}$. Deve existir uma sequência $\alpha \in \Omega_{M}\left(s_{i}\right) \cap \Omega_{M}\left(s_{j}\right)$, tal que $\lambda\left(s_{i}, \alpha\right)$ $\neq \lambda\left(s_{j}, \alpha\right)$. Essas são as sequências básicas nas quais se baseiam os métodos de geração de casos de teste. Existem diversos tipos de sequências de separação, a serem descritas nos tópicos a seguir.

- Sequência de Distinção $(D S)$ : é uma sequência de separação $\alpha \in X^{*}$ em que a saída produzida por $M$ em resposta a $\alpha$ é diferente para cada estado $s \in S$. Assim como a SS, a DS pode não existir e não ser única. Para a MEF de exemplo, temos que $D S=\{b b b\}$. A Tabela 2.2 exibe as saídas obtidas quando aplicada a sequência a partir de cada um dos estado de $M$. Como pode-se observar, para diferenciar os estados $s_{2}$ e $s_{3}$ a sequência de entrada $b b$ é suficiente. Então, é possível minimizar a DS por estado $\left(D S_{i}\right)$, obtendo: $D S_{0}=\{b b b\}, D S_{1}=\{b b b\}, D S_{2}=\{b b\}$ e $D S_{3}=$ $\{b b\}$.

Tabela 2.2: DS: Saídas obtidas para a MEF da Figura 2.6.

\begin{tabular}{|c|ccc|}
\hline Estados & $\mathrm{b}$ & $\mathrm{b}$ & $\mathrm{b}$ \\
\hline \hline $\mathrm{s} 0$ & 0 & 1 & 0 \\
$\mathrm{~s} 1$ & 0 & 1 & 1 \\
$\mathrm{~s} 2$ & 1 & 0 & 1 \\
$\mathrm{~s} 3$ & 1 & 1 & 0 \\
\hline
\end{tabular}

- Sequência Única de Entrada e Saída $(U I O)$ : é uma sequência de entrada/saída única para cada estado $s_{i}$, que pode também não existir como as demais sequências de separação apresentadas. Com a aplicação da sequência UIO é possível distinguir o estado $s_{i}$ de qualquer outro estado, pois a saída produzida é específica do estado $s_{i}$. Uma sequência DS é uma UIO para todos os estados. Porém, como o objetivo é utilizar sequências menores, pode ser mais apropriado gerar UIOs, pois ,em geral, é possível obter sequências mais curtas. Para a MEF exemplo da Figura 2.6, temos: $U I O_{0}=\{a\}, U I O_{1}=\{b b b\}, U I O_{2}=\{b b\}$ e $U I O_{3}=\{b b\}$. 
- Conjunto de Caracterização $(W)$ : como $D S$ e $U I O$, o $W$ é utilizado para distinguir aos pares os estados de uma MEF. É um conjunto de sequências de entrada tal que, para dois estados distintos quaisquer $s_{j}$ e $s_{i}$, existe $\alpha \in W$ tal que $\lambda_{M}\left(\mathrm{~s}_{j}, \alpha\right)$ $\neq \lambda_{M}\left(\mathrm{~s}_{i}, \alpha\right)$. A união de todas as sequências UIO formam um conjunto $W$, assim como a $D S$ representa um $W$ unitário. Por sua vez, o $\mathrm{W}$ pode gerar um conjunto menor que as demais sequências descritas. Para a MEF de exemplo, temos: $W=$ $\{a, b b\}$. Como pode-se observar na Tabela 2.3, a sequência $b b$ apenas distingue os estados $s_{2}$ e $s_{3}$. Porém, ao aplicar em conjunto a sequência $a$, os estados $s_{0}$ e $s_{1}$ passam a ser distinguíveis, ou seja, geram saídas diferentes.

Tabela 2.3: W: Saídas obtidas para a MEF da Figura 2.6.

\begin{tabular}{|c|c|cc|}
\hline Estados & $\mathrm{a}$ & $\mathrm{b}$ & $\mathrm{b}$ \\
\hline \hline $\mathrm{s} 0$ & 1 & 0 & 1 \\
$\mathrm{~s} 1$ & 0 & 0 & 1 \\
$\mathrm{~s} 2$ & 0 & 1 & 0 \\
$\mathrm{~s} 3$ & 0 & 1 & 1 \\
\hline
\end{tabular}

- Conjunto de Identificação $\left(W_{p}\right)$ : é um subconjunto de W definido para cada estado $s_{i}$ de $M$ que distingue o estado $s_{i}$ dos demais, sendo $W_{i} \subseteq \Omega_{M}\left(s_{i}\right)$ o conjunto de seqüências de entrada definidas para o estado $s_{i}$, se para qualquer outro estado $s_{j}$ existe $\alpha \in W_{i} \cap \Omega_{M}\left(s_{j}\right)$ tal que $\lambda_{M}\left(s_{i}, \alpha\right) \neq \lambda_{M}\left(s_{j}, \alpha\right)$. Por exemplo, para a MEF da Figura 2.6, a sequência $a$ distingue o estado $s_{0}$ de todos os demais, então, $W_{0}=\{a\}$. Da mesma forma, a sequência de entrada $b b$, distingue tanto o estado $s_{2}$ quanto $s_{3}$, sendo $W_{2}=W_{3}=\{b b\}$. Porém, o estado $s_{1}$ não é distinguível apenas com a sequência $a$ ou com $b b$, mas é distinguível com o conjunto $W_{1}=\{a, b b\}$.

- Conjunto de Identificadores Harmonizados $\left(H_{i}\right)$ : é um conjunto de identificadores de estados tal que, para dois estados quaisquer $s_{i}, s_{j} \in S, i \neq j$, existe $\alpha \in$ $H_{i}$ e $\gamma \in W_{j}$ que têm um prefixo comum $\beta$ tal que $\beta \in \Omega_{M}\left(s_{i}\right) \cap \Omega_{M}\left(s_{j}\right)$ e $\lambda_{M}\left(s_{i}\right.$, $\beta) \neq \lambda_{M}\left(s_{j}, \beta\right)$. Sendo assim, temos para a MEF da Figura 2.6: $H_{0}=\{a, b\}, H_{1}=$ $\{b b\}, H_{2}=\{a, b\}$ e $H_{3}=\{b b\}$.

\subsubsection{Método TT}

O método Transition Tour (TT), proposto por Naito e Tsunoyama (1981), consiste em construir uma sequência que percorra pelo menos uma vez todas as transições de uma MEF. Sidhu e Leung (1989) definem uma transition tour como sendo uma sequência de teste que pode ser gerada simplesmente aplicando entradas aleatórias em uma MEF, a partir do estado inicial, até que todas as transições tenham sido cobertas, finalizando no estado inicial. Porém, como a geração é aleatória, muitas sequências redundantes 
podem ser geradas. Assim, métodos de redução devem ser aplicados para eliminar as redundâncias presentes na sequência final.

O problema de se encontrar a menor solução para o método TT é NP-complexo, correspondendo ao problema do carteiro chinês misto (Aho et al., 1988). Para se encontrar uma solução, são utilizadas heurísticas de busca que correspondem a processos incrementais de pesquisa. O objetivo é encontrar o máximo ou o mínimo da função matemática que descreve formalmente o problema, chamada de função objetivo. A partir de uma possível solução escolhida de modo aleatório, busca-se por uma nova solução que possua melhores resultados que a anterior, selecionando-a. O processo se repete até que seja identificada a solução ótima ou uma solução considerada satisfatória pelo membro responsável pela busca. Para se encontrar a melhor solução seria necessário aplicar a técnica de força bruta, explorando todas as possibilidades, o que é impraticável devido à natureza exponencial do problema.

O método TT pode ser aplicado em MEF com as seguintes propriedades: determinísticas, fortemente conexas e completamente especificadas. Como o método gera uma única sequência de entrada, apenas é necessária uma operação de reset ao início do teste. Uma transition tour para a MEF apresentada na Figura 2.6 é $T_{T T}=\{$ raababbabbbbb $\}$ de tamanho 13.

\subsubsection{Método W}

Um dos métodos mais difundidos para a geração de sequências de testes, o método Automata Theoretic ou, como ficou mais conhecido, Método W foi proposto por Chow (1978). O nome atribuído ao método originou-se devido à referência feita por Chow (1978) ao conjunto de caracterização, utilizado pelo método, como conjunto W.

O método $\mathrm{W}$ pode ser considerado o método clássico e precursor da área, uma vez que a maioria dos trabalhos seguintes foram baseados no método W. Uma restrição quanto ao método é em relação à sua aplicabilidade, que exige que a MEFs sejam: determinísticas, completas, inicialmente conexas e minimais.

O método W se baseia nos conjuntos W (conjunto de caracterização) e P (transition cover). A partir do conjunto $W$, é gerado um novo conjunto $W^{\prime}$ que contém um conjunto de sequências capaz de identificar qual é o estado testado da máquina. Para isso, é necessário estimar o número de estados que a MEF I (implementação) tem a mais do que a MEF $M$ (especificação). Considerando $n$ o número de estado da MEF $M$, estima-se $m$ como sendo o número de estados para a MEF I. Sendo assim, temos:

$$
W^{\prime}=\bigcup_{i=0}^{m-n}\left(X^{i} W\right),
$$


em que $X^{0}=\{\varepsilon\}$ e $X^{i}=X \cdot X^{i-1}$. Para o caso $n=m$, temos que $W=W^{\prime}$.

Definido o conjunto $W^{\prime}$, as sequências obtidas são concatenadas com o conjunto P, isto é, $T_{W}=P . W^{\prime}$. Logo, ao obter as sequências de teste, estas são executadas uma a uma na máquina, gerando as respectivas saídas que serão analisadas a procura de inconsistências entre as MEFs. Como é um método completo (Chow, 1978), caso nenhuma falha ocorra, pode-se afirmar que a MEF I está adequada a especificação.

Para o exemplo da MEF $M$ da Figura 2.6, considerando o caso $n=m$, temos: $W^{\prime}=W$ $=\{a, b b\}, P=\{\varepsilon, a, b, a b, b b, b a, a a, a b a, a b b\}$ e $T_{W}=\{a, b b, a a, a b b, b a, b b b, a b a, a b b b, b b a, b b b b, b a a$, babb,aaa,aabb,abaa,ababb,abba,abbbb\}. Porém, como dito anteriormente, o conjunto de teste é formado apenas por sequências que não sejam prefixo de outras. Desta forma, pode-se reduzir o conjunto de teste $T_{W}$ para: $T_{W}=\{a a a, b a a, b b a, a a b b, a b a a, a b b a, b a b b, b b b b$, $a b a b b, a b b b b\}$ de tamanho 39. Considerando as operações de reset, temos: $T_{W}=\{$ raaa,rbaa, rbba, raabb,rabaa,rabba, rbabb,rbbbb,rababb, rabbbb\} de tamanho final 49.

\subsubsection{Método Wp}

O método W parcial (Wp), do inglês partial W, foi proposto por Fujiwara et al. (1991) como uma melhoria do método W. A partir do conjunto W é criado o conjunto de identificação $W_{i}$, que extrai um subconjunto do conjunto $\mathrm{W}$ capaz de identificar cada estado da MEF, dependendo do estado final $s_{i}$ que foi alcançado pela sequência. Desta forma, o método Wp se baseia nos conjunto $Q$ (state cover), $P$ (transition cover) e $W_{i}$, sendo realizado em duas fases:

- Fase 1: gerar as sequências formadas por r.Q.W

- Fase 2: gerar as sequências formadas por $r \cdot R \otimes W$, em que $R=P \backslash Q$ e

$R \otimes W=\bigcup_{p \in R}\{p\} . W_{i}$ tal que $i$ é definido pelo estado final da execução da sequência $p$.

Para a utilização do método Wp, a MEF deve apresentar as propriedades: determinística, completa, inicialmente conexa e minimal. Da mesma forma que o Método W, o Wp foi provado ser completo e por concatenar as sequências com um subdomínio de W na segunda fase, gera um conjunto final $T$ menor.

Para a MEF da Figura 2.6, temos: $Q=\{\varepsilon, a, b, a b\}, P=\{\varepsilon, a, b, a b, b b, b a, a a, a b a, a b b\}$, $W_{0}=\{a\}, W_{1}=\{a, b b\}, W_{2}=\{b b\}$ e $W_{3}=\{b b\}$. Assim na fase 1, temos: $T_{F 1}=$ $\{a a, b a, b b, a b a, a b b b\}$. Na fase 2 , são gerados os conjuntos: $R=\left\{b b_{0}, b a_{1}, a a_{1}, a b a_{1}, a b b_{2}\right\}$, em que os índices de cada sequência indicam o estado final atingido por cada uma delas; e $T_{F 2}=\{b b a, b a a, b a b b, a a a, a a b b, a b a a, a b a b b, a b b b b\}$. Ao final, é realizada a união de $T_{F 1}$ com 
$T_{F 2}$, eliminando as sequências que são prefixos e inserindo a operação de reset antes de cada sequência selecionada, temos: $T_{W p}=\{$ rbba, rbaa, raaa, rbbb,rbabb,raabb, rabaa, rababb, rabbbb\} de tamanho 43.

\subsubsection{Método DS}

O método DS é baseado na sequência de distinção DS e foi proposto inicialmente por Hennie (1964), seguido por várias propostas de melhorias: Gönnenc (1970), Ural et al. (1997), Hierons e Ural (2002), Hierons e Ural (2006). Hennie (1964) propõe a utilização de sequências SS para gerar uma sequência de verificação em conjunto com a DS. Gönnenc (1970) apresenta a opção de se utilizar grafos para a geração das sequências. Os demais trabalhos foram desenvolvidos com o intuito de diminuir o tamanho da sequência de verificação, utilizando a modelagem baseada em grafos proposta por Gönnenc (1970).

A aplicabilidade do método é condicionada a existência da sequência DS, uma vez que nem todas as MEFs a possuem. Além disso, o método DS só é aplicável em MEFs: determinísticas, completas, fortemente conexas e minimais. Por outro lado, o método também é completo e é composto por duas partes:

1. A sequência $\alpha$, que verifica todos os estados da máquina;

2. E a sequência $\beta$, que avalia todas as transições.

As sequências $\alpha$ e $\beta$ são concatenadas para formar uma sequência de verificação. Para gerar a sequência $\alpha$, é construído um grafo chamado grafo- $X d$, aplicando em cada um dos estados da MEF a sequência DS. A sequência $\alpha$ é gerada percorrendo o grafo sem repetir as arestas, utilizando sequências de transferência, se necessário. Para que cada transição da MEF seja verificada, é gerada a sequência $\beta$, que consiste na concatenação de transições seguida pela DS, recorrendo a sequências de transferências, se necessário. A sequência $\beta$ é gerada a partir de um grafo, denominado grafo- $\beta$. Neste grafo, as arestas tem o objetivo de representar sequências do tipo $x . D S$, para todo $x \in X$. A geração da sequência $\beta$ se dá a partir da cobertura de todas as arestas do grafo. Na Figura 2.9 é apresentado o grafo- $X d$ e o grafo- $\beta$ para a MEF da Figura 2.6.

Extraindo a sequência $\alpha$ do grafo- $X d$, temos: DS ligando o estado $s_{0}$ ao estado $s_{2}$, marcando os dois estados como reconhecidos; DS do estado $s_{2}$ para o $s_{0}$, que já está marcado como reconhecido; DS do estado $s_{0}$ para o $s_{2}$, para garantir que a MEF retorna para o mesmo estado; a sequência de transferência $a$ que leva a MEF ao estado $s_{1}$, marcando-o como reconhecido; DS partindo do estado $s_{1}$ para o estado $s_{0}$; DS para confirmar a repetição do caminho; sequência de transferência $a b$ para o estado $s_{3}$, marcando-o como 

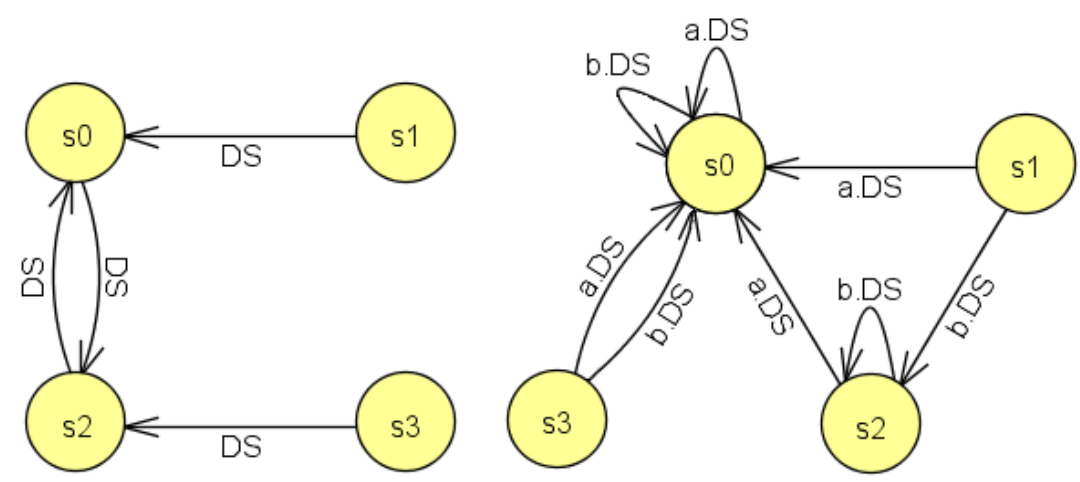

Figura 2.9: (a)Grafo- $X d$; (b)Grafo- $\beta$.

reconhecido; e, finalmente, DS do estado $s_{3}$ para o estado $s_{2}$. Desta forma, temos: $\alpha=$ $\{b b b b b b b b b$ a $b b b b b b a b b b b\}$.

Considerando que a sequência- $\alpha$ já foi aplicada e, portanto, todos os estados já foram verificados, duas reduções podem ser realizadas no grafo- $\beta$. A primeira refere-se à última transição da aplicação da DS. Por exemplo, aplicando-se DS ao estado $s_{0}$ a MEF passa pelos estados $s_{2}, s_{0}$ e $s_{2}$. A última transição pode ser descartada, pois essa verificação já foi realizada na construção da sequência- $\alpha$. Deste modo, a transição de $s_{0}$ com a entrada $b$ pode ser retirada do grafo- $\beta$. De modo análogo, a transição de $s_{2}$ com a entrada $b$ pode ser retirada do grafo.

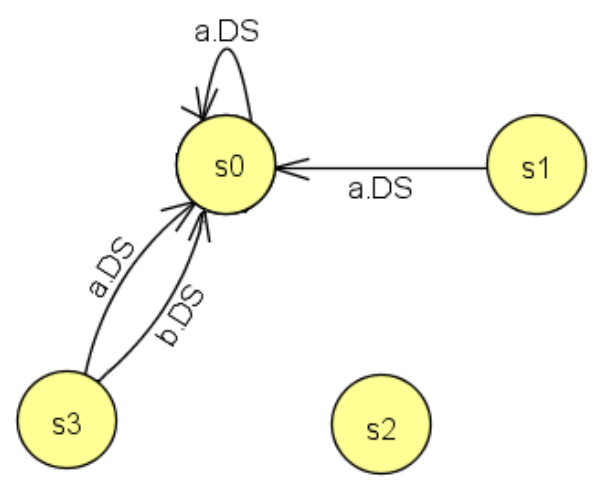

Figura 2.10: Grafo- $\beta$ reduzido.

A segunda redução refere-se à última transição da sequência incluída para transferir os estados de origem. A seqüência $a$ ligou o estado $s_{2}$ ao estado $s_{1}$, então a transição de $s_{2}$ com a entrada $a$ pode ser removida do grafo- $\beta$. Do mesmo modo, a sequência $a b$ ligou o estado $s_{2}$ ao estado $s_{3}$, passando pelo estado $s_{1}$. Sendo assim, a transição de $s_{1}$ com a entrada b também pode ser retirada. O grafo- $\beta$ reduzido é ilustrado na Figura 2.10.

Percorrendo o grafo- $\beta$ reduzido, obtem-se a sequência- $\beta$ : $\{a b b b a b a b b b a b \quad b b b b a$ $a b b b\}$. O conjunto final resultante da aplicação do método DS é: $T_{D} S=\{r b b b b b b b b b a b$ bbbbbabbbbabbbababbbabbbbbsabbb\} de tamanho 43. 


\subsubsection{Método UIO}

O método UIO foi originalmente proposto por Sabnani e Dahbura (1988) como um método completo. Porém, Vuong et al. (1989) apresentaram um contra-exemplo que desmostrou que o método UIO não garante a cobertura completa de defeitos para todas as MEFs. O método é baseado em sequências UIO e é realizado em apenas uma fase, correspondente à fase 2 do método W.

Da mesma forma que o método $\mathrm{W}$, a aplicabilidade do método UIO está restrita existência das sequências UIO e à MEFs que sejam: determinísticas, inicialmente conexas, completas e minimais. A fase de geração do conjunto de teste é definida por:

- Gerar as sequências formadas por r.P $\otimes U I O$, em que $P \otimes U I O=\bigcup_{p \in P}\{p\} . U I O_{i}$ tal que $i$ é definido pelo estado final da execução da sequência $p$.

Para exemplificar o método UIO, considerando a MEF da Figura 2.6 temos: $P$ $=\left\{\varepsilon_{0}, a_{1}, b_{2}, a b_{3}, b b_{0}, b a_{1}, a a_{1}, a b a_{1}, a b b_{2}\right\}$, em que os índice apresentados nas sequências correspondem ao estado final alcançado por cada uma, $U I O_{0}=\{a\}, U I O_{1}=\{b b b\}$, $U I O_{2}=\{b b\}$ e $U I O_{3}=\{b b\}$. Após a fase de geração do conjunto de teste, eliminando as sequências que são prefixos e inserindo a operação de reset, obtem-se $T_{U I O}$ $=\{r b b b, r b b a, r b a b b b, r a a b b b, r a b a b b b, r a b b b b\}$ de tamanho 33 .

Outros métodos que utilizam a sequência UIO como sequência de separação foram propostos, mas também não garantem a cobertura completa de defeitos. Apenas no trabalho proposto por Vuong et al. (1989) houve a preocupação de se estabelecer uma prova formal para uma melhoria do atual método UIO, chamado de Método UIOv, a ser trabalho a seguir.

\subsubsection{Método UIOv}

Como uma variação do método UIO, o método UIOv (UIO variation) foi proposto por Vuong et al. (1989). A solução apresentada inclui uma fase a mais no processo de geração de testes, em que seriam aplicada todas as sequências UIO a todos os estados pelo menos uma vez, ou seja, a sequência $U I O_{i}$ será aplicada em cada estado $s_{j}$ atingido a partir do conjunto $Q$, tal que $i=\{0 . . n\}$ e $j=\{0 . . n\}$. Desta forma, o método UIO difere do método UIOv na aplicação da primeira fase do processo:

- Fase 1: gerar as sequências formadas por r.Q.U, em que $U$ correspondem a união de todas as sequências UIO 
- Fase 2: gerar as sequências formadas por r.P $\otimes U I O$, em que $P \otimes U I O=$ $\bigcup_{p \in P}\{p\} . U I O_{i}$ tal que $i$ é definido pelo estado final da execução da sequência $p$.

Devido a esse novo processo que foi definido a fim de prover cobertura completa para defeitos em MEFs, o método UIOv pode ser considerado um caso especial do método Wp. Isso se torna verdade quando o conjunto $W_{i}$ possui somente uma sequência simples (UIO) para cada estado $s_{i}$ da MEF, tornando o método Wp equivalente ao método UIOv.

Para a MEF da Figura 2.6, temos: $Q=\{\varepsilon, a, b, a b\}, P=\left\{\varepsilon_{0}, a_{1}, b_{2}, a b_{3}, b b_{0}, b a_{1}, a a_{1}, a b a_{1}\right.$, $\left.a b b_{2}\right\}$, em que os índice apresentados nas sequências correspondem ao estado final alcançado por cada uma, na primeira fase, $U I O_{0}=\{a\}, U I O_{1}=\{b b b\}, U I O_{2}=\{b b\}$ e $U I O_{3}$ $=\{b b\}$. Assim, na primeira fase obtem-se $T_{F 1}=\{a, b b b, b b, b b, a a, a b b b, a b b, a b b, b a, b b b b, b b b, b b$, $a b a, a b b b b, a b b b, a b b b\}$ e $T_{F 2}=\{b b a, b a b b b, a a b b b, a b a b b b, a b b b b\}$. Desta forma, ao final de todo o processo de união e redução temos: $T_{U I O v}=\{r b b b b, r b b a, r b a b b b, r a a b b b, r a b a b b b, r a b b b b\}$ de tamanho 34 .

\subsubsection{Método HSI}

O método HSI (Petrenko et al., 1993), assim como a maioria dos métodos propostos, foi proposto como uma melhoria para o método W. Além de gerar conjuntos de teste completos, o método apresenta um grau de aplicabilidade maior do que os demais métodos, pois pode ser aplicado tanto em MEFs completas quanto em MEFs parciais. Desta forma, o método consegue cobrir um número maior de especificações com um custo menor quando comparado com o método W.

Fazendo um paralelo entre os métodos Wp e HSI, ambos tem sequências de separação por estado que possuem o objetivo de distinguir o estado $s_{i}$ dos demais. Desta forma, a diferença entre os conjuntos $W_{i}$ e $H_{i}$ está na forma como são construídos. Enquanto $W_{i}$ é obtido a partir do conjunto $W$, o $H_{i}$ é construído a partir de sequências de separação que distinguem cada par de estados da MEF. O método HSI consiste basicamente na aplicação das fases:

- Fase 1: gerar as sequências formadas por $r . Q \otimes H S I$, em que $Q \otimes H S I=$ $\bigcup_{q \in Q}\{q\} \cdot H_{i}$ tal que $i$ é definido pelo estado final da execução da sequência $q$.

- Fase 2: gerar as sequências formadas por r.P $\otimes H S I$, em que $P \otimes H S I=$ $\bigcup_{p \in P}\{p\} . H_{i}$ tal que $i$ é definido pelo estado final da execução da sequência $p$.

Com relação à MEF da Figura 2.6, temos: $Q=\left\{\varepsilon_{0}, a_{1}, b_{2}, a b_{3}\right\}, P=\left\{\varepsilon_{0}, a_{1}, b_{2}, a b_{3}, b b_{0}\right.$, $\left.b a_{1}, a a_{1}, a b a_{1}, a b b_{2}\right\}, H_{0}=\{a, b\}, H_{1}=\{b b\}, H_{2}=\{a, b\}$ e $H_{3}=\{b b\}$. Desta forma, temos 
na primeira fase $T_{F 1}=\{a, b, a b b, b a, b b, a b b b\}$ e $T_{F 2}=\{a, b, a b b, b a, b b, a b b b, b b a, b b b, b a b b, a a b b$, $a b a b b, a b b a, a b b b\}$. Ao final do processo obtem-se o cojunto de teste $T_{H S I}=\{r b b a, r b b b, r b a b b$, raabb,rababb,rabba,rabbb\} de tamanho 34 .

\subsubsection{Método SPY}

O método SPY (Simão et al., 2009) foi proposto para viabilizar a geração de conjuntos de teste para MEFs com estados extras. Os demais métodos são capazes de gerar testes para máquinas com estados extras, chamados conjuntos $m$-completos, em que a especificação possui $n$ estados e a implementação possui $m$ estados, tal que $m \geq n$. O problema da geração de testes $m$-completos está na necessidade de se incluir cada sequência do chamado conjunto de travessia (traversal set), que contém todas as sequências com $m-n+1$ símbolos de entrada.

O processo de geração de teste é incremental, baseado nos conjuntos $Q$ e $H_{i}$. O método começa determinando o conjunto State Cover mínimo $(Q)$. Então, os testes em $Q$ são estendidos pelos identificadores de estado $\left(H_{i}\right)$ apropriado. O método itera até que o conjunto de testes torne-se uma transition cover para a MEF M.

O método SPY é gerado de forma semelhante ao método HSI; porém, difere no modo de geração das sequências por ser capaz de identificar melhores condições para incrementar as sequências já calculadas. O processo pode ser ilustrado por uma árvore, que tem como raiz o estado inicial da MEF e gera folhas para as possíveis entradas do domínio, atingindo os estados destinos em seus nós. Na Figura 2.11, é ilustrada a árvore gerada para o cálculo das sequências de teste com relação à MEF da Figura 2.6.

Para a construção da árvore, temos: $Q=\left\{\varepsilon_{0}, a_{1}, b_{2}, a b_{3}\right\}$ como os nós iniciais e $H_{0}=$ $\{a, b\}, H_{1}=\{b b\}, H_{2}=\{a, b\}$ e $H_{3}=\{b b\}$ adicionados ao final de cada respectivo estado. O objetivo seguinte é acrescentar o transition cover para que todas as transições sejam cobertas. Realizando o processo de geração incremental do método SPY, temos que os nós sinalizados com um quadrado (estado s3) são correspondentes ao nó sinalizado com uma estrela, identificado inicialmente pelo state cover, uma vez que todos precedem o estado $s 1$ e são atingidos pela entrada $b$.

Pode-se executar a verificação da transição $(s 3, b)$ a partir de qualquer um destes três nós. Neste caso, o estado $s_{2}$ é atingido. Deve-se, então, aplicar $H_{2}=\{a, b\}$ no nó $s_{2}$ para confirmá-lo. Para minimizar o conjunto, foi escolhido o nó mais a direita, pois, caso contrário, existiria a necessidade de se incluir uma nova sequência de teste ao conjunto, uma vez que uma nova sequência seria gerada na árvore pela transição $(s 3, b a)$. Ao incluir a sequência no nó mais a direita, o nó folha passa a ser a entrada $a$ e a sequência $b a b b$, 


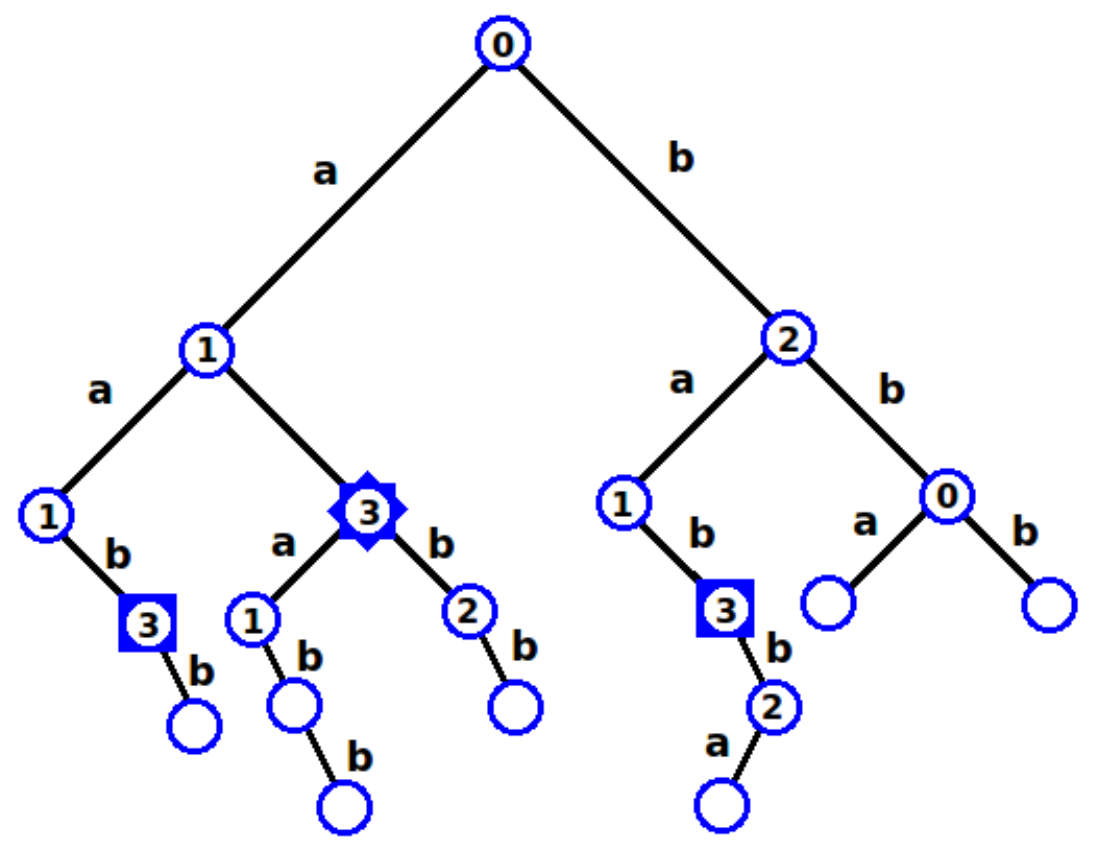

Figura 2.11: Processo de geração de casos de teste do método SPY.

obtida até o iteração anterior passa a ser prefixo da nova (babba). Desta forma o conjunto final gerado é $T_{S P Y}=\{r b b a, r b b b, r b a b b a, r a a b b, r a b a b b, r a b b b\}$ de tamanho 30 .

\subsection{Considerações Finais}

Nesse capítulo, foram apresentados os principais temas e conceitos da área de teste de software, apresentando alguns dos principais critérios das técnicas funcional, estrutural e baseada em defeitos. Foram apresentadas vantagens e desvantagens de cada uma das técnicas. Algumas fases da atividade de teste também foram abordadas, descrevendo a sua aplicabilidade em cada uma das fases correspondentes no processo de desenvolvimento. Foi apresentado também, o atual cenário de teste baseado em máquinas de estados, apresentando os métodos mais conhecidos na literatura (TT, W, Wp, DS, UIO, UIOv e HSI) e o método SPY mais recentemente proposto. Foram apresentados os métodos de geração de casos de testes aplicáveis de acordo com as propriedades das MEFs e com capacidade de detecção completa de defeitos, com exceção do método UIO.

As vantagens do teste baseado em modelos é a possibilidade de se conduzir testes com a possibilidade de se reduzir a ambiguidade pertinentes à especificação de sistemas e auxiliar na elaboração criteriosa de outros artefatos necessários para a condução das atividades de desenvolvimento e teste. Outra vantagem é a possibilidade de automatizar parte do processo de teste, por meio da implementação de algum dos métodos existentes para geração de casos de testes citados. Porém, os métodos apresentados são aplicáveis a um pequeno conjunto de MEFs. Neste sentido, uma linha de pesquisa está relacio- 
nada a flexibilização dos métodos, a fim de adaptá-los ou estende-los para atender MEFs não-completas ou não-determinísticas, por exemplo.

No próximo capítulo é apresentada uma introdução sobre as principais caracterísiticas de sistemas embarcados, com foco na atividade de teste de software embarcado. 
CAPÍTULO 2. TESTE BASEADO EM MODELOS 


\section{Sistemas Embarcados}

\subsection{Considerações Iniciais}

Sistemas embarcados encontram-se amplamente difundidos no cotidiano das pessoas, de forma que, muitas vezes, passam despercebidos. Estão presentes no cenário médico, automobilístico, aeroespacial, doméstico etc. Podem-se citar como exemplos: marca-passo, sistemas de monitoramento cardíaco, GPS, injeção eletrônica, satélites, forno de micro-ondas e celulares.

Segundo Kang et al. (2005), as funcionalidades adicionadas na maioria das aplicações embarcadas têm crescido em número e complexidade, aumentando os custos e o tempo de desenvolvimento dos sistemas, o que reforça a necessidade de testes elaborados e criteriosos. Desse modo, sistemas embarcados tornaram-se foco de muitas pesquisas que visam a entender e estabelecer quais características que os distinguem dos sistemas tradicionais e, consequentemente, quais as suas implicações.

O desenvolvimento de sistemas embarcados envolve um projeto coordenado de software e hardware dedicado (Kang et al., 2005; Tian et al., 2009). As funcionalidades que necessitam de flexibilidade e recursos são preferencialmente desenvolvidas em software e as que necessitam de desempenho, em hardware. O presente trabalho tem como objetivo investigar a aplicabilidade dos métodos de geração baseados em MEFs no contexto do teste de software de sistemas reais. Para isso, foi selecionado o software embarcado do módulo de comunicação do computador de bordo do satélite universitário ITASAT ??. 
Sendo assim, o objetivo deste capítulo consiste em abordar o cenário de software embarcado, para elucidar a influência das características que cercam sistemas embarcados quanto às fases de projeto e, principalmente, teste de software.

Na Seção 3.2, são apresentadas noções básicas sobre sistemas embarcados. Na Seção 3.3, são apresentadas algumas das características sobre o projeto de software. Na Seção 3.4, é discutido como se aplicam as técnicas de Teste de Software no cenário dos sistemas embarcados. Na Seção 3.5, é apresentado um exemplo de projeto de sistema embarcado, o satélite universitário ITASAT, em desenvolvimento no Instituto Tecnológico de Aeronáutica (ITA).

\subsection{Fundamentos e Características}

Em países desenvolvidos, existem em média 30 microprocessadores por pessoa, sendo que 98\% dos microprocessadores produzidos no mundo são destinados a aplicações embarcadas (Ebert e Jones, 2009). Apesar de amplamente difundidos, sistemas embarcados não possuem uma definição única, uma vez que representam uma ampla gama de sistemas. Assim, é possível encontrar diferentes definições na literatura, como: (1) computador de propósito específico que é utilizado dentro de um dispositivo (Kang et al., 2005); (2) parte de um produto com o qual um usuário final não interage ou controla diretamente (Tian et al., 2009); (3) sistema de processamento de informações que é incorporado em um produto maior e que normalmente não é diretamente visível para o usuário (Marwedel, 2006); ou (4) sistema controlado eletronicamente em que software e hardware são combinados (Sung e Choi, 2002). Porém, pode-se observar que todas as definições convergem para um sistema que é composto por um software que controla um hardware dedicado. Na literatura é possível encontrar características comuns a grande maioria dos sistemas embarcados, que os diferem dos demais tipos de sistemas. Segundo Marwedel (2006) e Tian et al. (2009), alguns exemplos das principais características são:

- Integram tecnologias mecânicas e eletrônicas com software, como a utilização de sensores e atuadores que realizam a leitura e o controle de um ambiente - real ou virtual - a ser processado;

- Frequentemente possuem requisitos de tempo-real, ou seja, o comportamento correto do sistema é dependente do tempo de resposta. Um requisito de tempo-real pode ser dito forte se o não cumprimento dessa restrição levar a uma falha grave, o que em sistemas críticos significa prejuízos;

- Devem ser tolerantes a falha, isto é, o seu comportamento deve ser sempre controlado, mesmo durante possíveis falhas, garantindo robustez ao sistema; 
- Possuem recursos limitados, como espaço de memória e fonte de energia, o que leva a uma necessidade de se prover um gerenciamento eficiente dos recursos disponíveis;

- Possuem natureza reativa. Sistemas reativos apresentam iteração continua com o ambiente e execução em ritmo pré-definido, segundo os estímulos externos ou internos (Marwedel, 2006).

Berger (2001) reforça o fato de que as implicações de uma falha de software de um sistema embarcado é muito mais severa do que em sistemas convencionais, do tipo desktop, uma vez que muitos sistemas embarcados estão diretamente ligados a atividades de alto risco, como sistemas aéreos e médicos. Além disso, muitos também operam em condições ambientais extremas. Sendo assim, as atividades de projeto e, principalmente, de teste devem ser criteriosas e elaboradas, uma vez que o software não pode ser muito facilmente reparado ou alterado. Para Ebert e Salecker (2009), deve-se assumir a situação extrema de que se está considerando o software falho por definição, em que o objetivo deve ser minimizar as chances de falha e controlar as eventuais ocorrências.

Diversas características devem ser avaliadas antes de se iniciar o processo de implementação de um sistema embarcado. Características como desempenho, segurança e gerenciamento de recursos são de fundamental importância e devem guiar o projeto e o desenvolvimento do sistema, bem como as atividades de teste de forma a garantir a qualidade necessária ao produto final.

\subsection{Projeto e Modelagem}

O desenvolvimento de software para sistemas embarcados representa um grande desafio para o engenheiro de software devido à sua alta complexidade (Ebert e Jones, 2009). A principal fonte de complexidade é o grande número de interações sutis e muitas vezes inesperadas entre as diversas partes desses sistemas, que têm suas funcionalidades representadas por estados e eventos gerados por sensores e atuadores que fazem a leitura do ambiente processado.

Discussões sobre a utilização de práticas formais de projeto são temas recorrentes no domínio de sistemas embarcados. Isso se deve ao fato de que muitas aplicações embarcadas são críticas por natureza, o que obriga os desenvolvedores a empregar métodos formais e sistematizados de projeto que focam na qualidade do produto final. Segundo Ebert e Jones (2009), alguns exemplos das práticas utilizadas incluem:

- Automatização de análise de código estático para a memória, desempenho e segurança; 
- Projeto e teste orientados a modelos (MDD e MDT);

- Linhas de produto como meio de controlar variantes;

- Modelagem matemática para atender requisitos de confiabilidade e consumo de energia, e realizar análise de desempenho;

- Técnicas formais de inspeção de código;

- Métodos ágeis como Scrum e feature-driven design;

- Componentes desenvolvidos explicitamente para reúso

Como primeiro passo, estabelecer formalmente quais são os requisitos a serem atendidos é de suma importância, uma vez que é necessário verificar se a especificação está completa e se há ausência de contradições. Outra vantagem da formalização é que, na fase de projeto, modelos formais viabilizam a derivação de implementações a partir da especificação de modo sistemático e, em alguns casos, automatizada. Portanto, a linguagem de descrição escolhida deve ser capaz de representar propriedades como (Marwedel, 2006): (1) hierarquia, comportamental (estados e eventos) ou estrutural (composição física do sistema); (2) orientação a estados, que determinam quais possíveis respostas do sistema para determinadas entradas; (3) tratamento de eventos, dada a natureza reativa de sistemas embarcados; e, (4) legibilidade, tanto por parte dos desenvolvedores quanto por máquinas (automação).

A utilização de modelos computacionais para especificar sistemas embarcados tem sido amplamente difundida. Segundo Marwedel (2006), modelos computacionais possuem as seguintes características: (1) definem componentes, sendo que procedimentos, processos, funções e MEFs são exemplos de componentes; (2) definem protocolos de comunicação, ou seja, os mecanismos pelos quais os componentes podem interagir entre si; (3) podem definir compartilhamento de informação, isto é, quais componentes tem acesso a informações de outros componentes.

Vários são os modelos passíveis de serem empregados na especificação de sistemas embarcados, como Statecharts e SDL (Marwedel, 2006). Porém, como dito na Seção 2.4, a maioria desses modelos são variações de MEFs, chamadas MEF comunicantes. Esse modelo é o empregado nos Statecharts, StateFlow e SDL. Kang et al. (2005) apresentam outro possível modelo chamado CFSM (Co-design finite state machine), em que difere das MEFs tradicionais por modelar eventos síncronos e assíncronos. MEFs são modelos relativamente simples mas com grande expressividade, uma vez que se adequam ao comportamento fortemente baseado em estados e eventos. A utilização de modelos pode ser explorada na fase de desenvolvimento e também na fase de testes, como artefato para 
a derivação de casos de testes, sendo que, no caso de MEFs, essa derivação pode ser automatizada.

\subsection{Teste de Software Embarcado}

Assim como a fase de projeto, a fase de teste possui grandes desafios no domínio de software embarcado. Devido às características de sistema reativo, crítico e de tempo-real, é necessário que os testes realizados possam garantir condições suficientes para o funcionamento adequado do sistema. Segundo Causevic et al. (2010), nota-se uma falta mais proeminente da disponibilidade de uma infra-estrutura para testes adequados no domínio de sistemas embarcados, mas esta deficiência não parece afetar significativamente o tempo disponível para testes.

Em um recente estudo sobre os atuais aspectos de teste de software no cenário industrial, foi realizada uma pesquisa qualitativa e quantitativa sobre a satisfação das equipes em relação às atuais atividades de teste desenvolvidas e às atividades consideradas ideais em seus respectivos projetos (Causevic et al., 2010). Em geral, há uma preferência por um teste mais rigoroso em todos os níveis, particularmente visíveis no teste funcional em nível de sistema. No domínio de embarcados torna-se notável também a convergência de opiniões pela necessidade de se aumentar a carga de testes de desempenho, uma prática que é apontada atualmente como insuficiente.

A pesquisa levanta pontos interessantes quanto ao grau de satisfação das equipes em relação às atuais práticas de teste adotadas. O maior grau de insatisfação foi obtido em relação à atual necessidade de se escrever casos de teste após ou durante a codificação do sistema. O segundo maior grau de insatisfação é em relação a prática de se iniciar a implementação do sistema antes mesmo da fase de projeto ter sido finalizada. Assim, pode-se identificar a tendência de se elaborar testes durante a fase de projeto, baseando-se em documentos definidos durante a elicitação de requisitos e discussão com os interessados no projeto (clientes, desenvolvedores e testadores).

É possível identificar a necessidade de reforçar técnicas de teste funcional e de desempenho quanto ao domínio de embarcados, explorando a automatização de testes e o desenvolvimento de ferramentas que apoiem às necessidades do domínio, uma vez que a pesquisa aponta o interesse por ferramentas open source, além do uso de ferramentas proprietárias desenvolvidas pela própria equipe responsável pelo sistema a ser desenvolvido.

A área de teste de software possui uma ampla gama de técnicas e critérios com aplicações nas mais diversas fases do desenvolvimento. Porém, ao se focar em um domínio específico, como o de embarcados, é relevante estudar quais as técnicas que poderiam ser mais eficientes e adequá-las ao novo cenário caso se identifique a necessidade. No sentido 
de atender as expectativas levantadas anteriormente, quanto à prática de se realizar o projeto dos casos de teste em paralelo ao projeto do sistema, antes mesmo de se iniciar a fase de implementação, foi observada uma linha de pesquisa que investiga a utilização de modelos tanto na fase de projeto quanto na fase de teste. Essa técnica é denominada teste baseado em modelos (MBT - model-based testing).

Nesse contexto, pode-se aplicar a técnica de MBT em conjunto com a técnica MDD, que envolve linguagens visuais de modelagem e ferramentas de suporte. O paradigma aplica o conceito de separar a especificação de um sistema dos detalhes de sua implementação, isto é, como o sistema irá utilizar as capacidades de uma plataforma específica para operar (Martinez et al., 2009).

Segundo Conrad et al. (2005), o processo de MDD, assim como o processo tradicional, começa com uma fase de requisitos, em que os requisitos da funcionalidade a ser realizada estão sendo especificados textualmente. A abordagem MDD caracteriza-se pela implantação de modelos integrados executáveis para especificação, projeto e implementação, utilizando a modelagem baseada em diagramas de blocos e máquinas de estado estendidas, como nas ferramentas Matlab / Simulink / Stateflow.

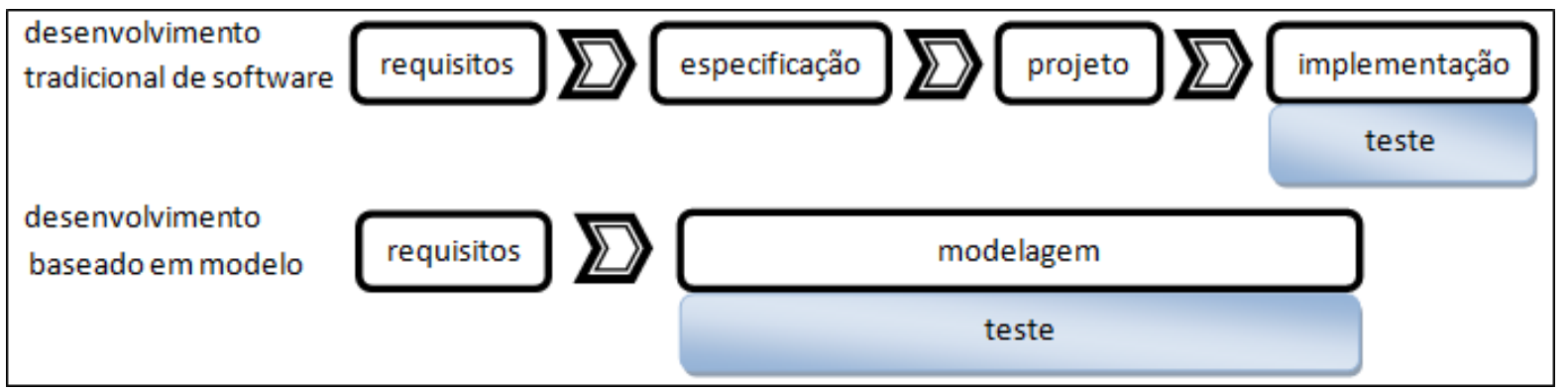

Figura 3.1: Desenvolvimento tradicional versus MDD.

Um modelo executável do software é desenvolvido nas primeiras fases do projeto, que tanto é passível de simulação quanto de testes. Este modelo executável é usado em todo o processo de desenvolvimento, o que guia o processo de codificação do software embarcado, podendo ser manual ou automático. Na prática, essa evolução no processo de desenvolvimento seria refletida em uma evolução do modelo funcional obtido, a partir de um primeiro modelo lógico, para um modelo de implementação e a sua posterior transformação em código. Em relação ao desenvolvimento de software tradicional, onde as fases estão claramente separadas, o desenvolvimento baseado em modelo mostra que as fases de especificação, projeto e implementação devem ser conduzidas de forma muito mais criteriosa e unificada (Figura 3.1, adaptada de Conrad et al. (2005)). A utilização de modelos de forma integral, ou seja, na fase de desenvolvimento e teste, facilita um desenvolvimento altamente consistente e eficiente (Conrad et al., 2005). 
Entretanto, um ponto a ser levantado é que a palavra modelo representa uma enorme gama de opções na literatura, como abordado na Seção 2.4. Para o domínio de sistemas embarcados, existem modelos específicos atualmente difundidos na industria, como o método de classificação em árvore (classification-tree method) utilizado no sub-domínio de sistemas automotivos (Conrad et al., 2005). Por outro lado, como sistemas embarcados são fortemente baseados em estados e frequentemente modelados com ferramentas que suportam Stateflow e Statechart, alguns autores discutem a possibilidade de utilizá-los também como modelos de teste.

Borcsok et al. (2009) propõe um ambiente de verificação automatizada para sistemas embarcados modelados com a ferramenta Simulink. Porém, além de adotar o modelo que descreve os componentes eletrônicos envolvidos no sistema, a ferramenta proposta aplica o critério de análise de valor limite da técnica de teste funcional para as entradas e saídas descritas no modelo. Na linha de MBT baseado em MEFs, Srivastava e Singh (2009) propõem modelar sistemas embarcados como máquinas de estados, definindo um modelo baseado em falhas. O modelo define três categorias de falhas: (1) saída desconectada, em que uma das saídas do sistema não foi corretamente conectada, o que não impede o evento de externar o resultado esperado; (2) entrada desconectada, em que nenhum evento é gerado quando ocorre o estímulo externo; (3) entradas redirecionadas, em que um evento é redirecionado a outro estado que não o estado correto. A partir dessas categorias, é aplicado o conceito de teste de mutação e de geração de casos de teste baseada em MEFs. As categorias geradas podem ser entendidas como operadores de mutação que seriam pertinentes ao domínio de sistemas embarcados, segundo Srivastava e Singh (2009).

A técnica de MBT pode ser útil e eficiente para o cenário de sistemas embarcados, considerando-se o número de trabalhos que abordam o tema. Pode-se observar que sistemas embarcados são frequentemente entendidos como sistemas reativos baseados em estados, eventos e saídas, o que pode ser de grande interesse exportar esse entendimento para a atividade de teste de software, como forma de se promover a validação do software, além de servir como base para futuros teste de integração hardware-software. Porém, como a modelagem de um sistema não é uma atividade trivial, a seguir é apresentada a Metodologia CoFI, proposta para guiar o processo de modelagem em MEFs.

\subsubsection{Metodologia CoFI}

A CoFI (Conformance and Fault Injection) (Ambrosio et al., 2005) é uma metodologia que orienta a atividade de teste funcional. A metodologia foi proposta para apoiar as necessidade da validação de software espacial, definindo passos para a criação de casos de teste para software e sistemas reativos de forma sistemática. O objetivo principal é auxilar 
o testador a definir modelos baseados em MEFs que representem o comportamento do sistema (ou subsistema) em teste (SUT).

A decomposição do comportamento do SUT em MEFs é realizada por meio da definição de serviços que podem ser considerados como funções do sistema do ponto de vista do usuário. Cada serviço é descrito por (pelo menos) uma MEF que representa o comportamento frente às possíveis falhas do sistema. Desta forma, modelos são criados para mapear os seguintes comportamentos: (1) normal (sem falhas); (2) frente a falhas especificadas; (3) frente a entradas inesperadas; e (4) frente a falhas de hardware as quais disparam a execução de mecanismos de tolerância a falhas. Na Figura 3.2, pode-se observar as três fases necessárias para execução da metodologia CoFI, descrita a seguir.
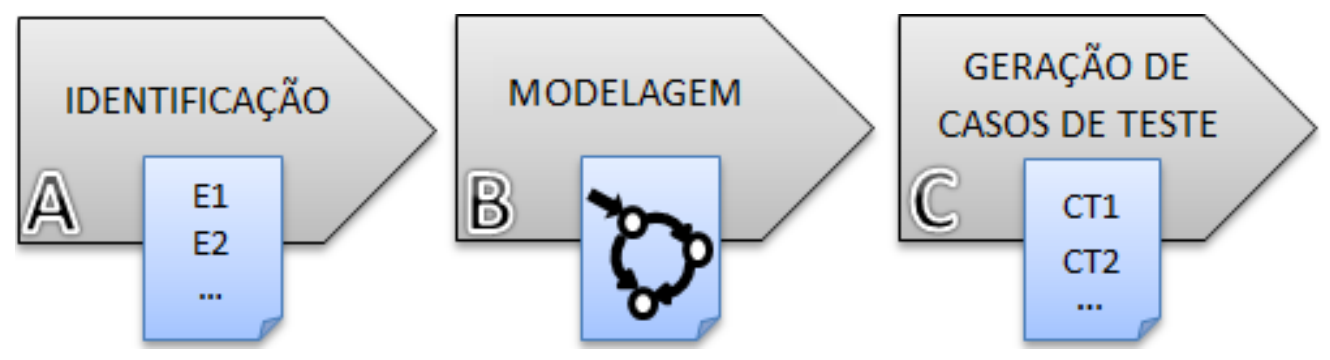

Figura 3.2: Processo de aplicação da Metodologia CoFI.

\section{Fase A. Identificação}

Na fase de identificação, o testador, baseado na espeficicação, deve identificar:

- Serviços que o usuário pode reconhecer e utilizar no SUT;

- Falhas de hardware que podem acontecer;

- Facilidades e restrições das ferramentas de teste que apoiam a execução dos testes no SUT;

- Pontos de controle e observação;

- Eventos (entradas) e ações (saídas).

O testador deve compreender o comportamento funcional do SUT, como um teste caixa-preta. A informação deve ser extraída por meio de documentos de especificação, como documento de requisitos e casos de uso, diagramas de sequência e interface, entre outros.

É necessário identificar todos os possíveis eventos e ações do SUT que podem ser executados e observados pelo testador. Estes eventos e ações devem ser abstraídos como entradas e saídas do sistema. Falhas físicas devem ser consideradas quando os testes 
envolvem o hardware dedicado no sistema embarcado; porém, a metodologia CoFI pode ser aplicada somente para modelar o software, na fase de teste de unidade. As facilidades e restrições do SUT devem ser consideradas para evitar a modelagem de eventos que não podem ser habilitados durante a execução dos testes.

\section{Fase B. Modelagem}

Na fase de modelagem, para cada serviço identificado, o testador deve elaborar modelos parciais para quatro tipos de comportamentos. No primeiro modelo, o comportamento normal do SUT deve ser definido com base nas sequências de eventos normalmente esperadas, ou seja, no seu funcionamento padrão. Para isso, o testador deve identificar o modo normal de funcionamento do SUT e quais os eventos e as ações esperadas para este caso.

No segundo modelo, deve-se modelar as exceções especificadas. O testador deve reconhecer as exceções mencionadas nos documentos de especificação, como timeouts e comandos errados que estão definidos em eventos esperados no contexto de utilização do SUT, chamados de eventos de exceção. Para o projeto do modelo, é necessário estender o modelo normal, modelando as entradas que representam as exceções em novas transições e excluindo as transições conhecidas no modelo normal. Algumas das transições do modo normal devem ser preservadas de modo a manter a conectividade da nova MEF, que deve possuir o mesmo estado inicial e final definidos no modelo normal.

O terceiro modelo corresponde ao de entradas inesperadas ou 'caminhos furtivos'. O objetivo deste modelo é prever comportamentos inesperados, isto é, descrever o que a MEF deve fazer se uma entrada acontecer em um estado em que ela não está definida. O testador deve utilizar a MEF original como base, escrevendo-a de forma tabular (estado versus evento) e preencher os espaços em brancos com o comportamento correto (ou esperado). Em alguns casos, não há como modelar nenhum comportamento possível; então, cabe ao testador analisar a melhor opção, como definir um comportamento 'vazio' ou ignorar a ocorrência de um evento.

Por fim, o modelo de tolerância a falhas deve modelar as possíveis falhas físicas que podem afetar o SUT, quando os testes sistêmicos envolvem hardware. Para cada falha física, o testador deve adaptar a MEF normal incluindo o novo evento de falha e excluindo as demais transições conhecidas, sempre preservando a conectividade da MEF.

Ao final do processo, uma coleção de MEFs que representam o comportamento da SUT é obtida. O próximo passo corresponde à geração de casos de teste a partir desta coleção.

\section{Fase C. Geração de Casos de Teste}

A fase de geração de casos de teste pode ser apoiada por ferramentas de teste que geram automaticamente as sequências de teste. Alguns experimentos que exploravam a 
aplicação da CoFI utilizaram como apoio à geração das sequências de teste a ferrramenta Condado (Pontes et al., 2009). Para o presente trabalho, foi investigada a aplicabilidade da ferramenta JPlavisFSM, desenvolvida no contexto deste projeto de mestrado a ser apresentada na Seção 4.3.

\subsection{ITASAT}

Para investigar a aplicabilidade dos métodos de geração baseados em MEFs no contexto de sistemas reais, com foco em sistemas embarcados, foi estudado o módulo de comunicação do satélite ITASAT-1 da Missão ITASAT, descrito em detalhes nesta seção.

A Missão ITASAT é parte de um programa financiado pela Agência Espacial Brasileira (AEB) no contexto da Ação 4934 para "Desenvolvimento e Lançamento de Satélites Tecnológicos de Pequeno Porte" e desenvolvido pelo Instituto Tecnológico Aeronáutico (ITA) em parceria com outras universidades brasileiras. O projeto conta com o ITA como membro responsável pela implementação do satélite e com o Instituto Nacional de Pesquisas Espaciais (INPE) como membro responsável por prover apoio técnico e infraesturura de laboratórios.

O ITASAT-1 (Sato et al., 2011) é um satélite universitário que tem como objetivo executar testes experimentais com cargas úteis (payloads) levadas pelo satélite, como1: um transponder digital de coleta de dados (DCS - Data Collection System); um sistema para determinação de atitude (tomada de decisão) baseado em girometros MEMS (Micro Electro Mechanical Systems); um experimento térmico que irá monitorar o comportamento térmico do satélite e um Tubo de Calor (Heat Pipe) experimental denominado TUCA (TUbo de CAlor); e um experimento de comunicações ISL/FoX (Inter Satellite Link/FoX) entre ITASAT-1 e um satélite universitário da Universidade de Tecnologia de Berlin (TU Berlin), que deverá ser lançado juntamente com o satélite ITASAT-1.

A arquitetura do satélite é composta por cinco subsistemas principais: estrutura mecânica (MSS - Mechanical Structure System); controle térmico (TCS - Thermal Control System); potência elétrica (EPS - Electrical Power System); controle de atitude e manipulação de dados (ACDH - Attitude Control and Data Handling); e telemetria e telecomando (TMTC - Telemetry \& Telecommand).

O Módulo de Comunicação é um dos subsistemas mais críticos para o sucesso do satélite. Seu funcionamento envolve as atividades de receber telecomandos das estações terrenas e enviar telemetrias coletadas pelas cargas úteis e pelos demais sensores presentes no satélite. É responsabilidade do Módulo de Comunicação gerenciar as cargas,

\footnotetext{
${ }^{1}$ Dados extraídos de: http://www.fab.mil.br/portal/capa/index.php?mostra=7014
} 
colocando-as em modo de sobrevivência (survival mode) em situações críticas. Por se tratar de um subsistema importante para a missão, foram concentrados esforços para a elaboração de testes para o Módulo de Comunicação. A arquitetura do satélite ITASAT-1 é ilustrada na Figura 3.3. Nesta figura, observa-se a estrutura de hardware do ACDH e o subsistema do módulo de comunicação, foco do estudo de caso.

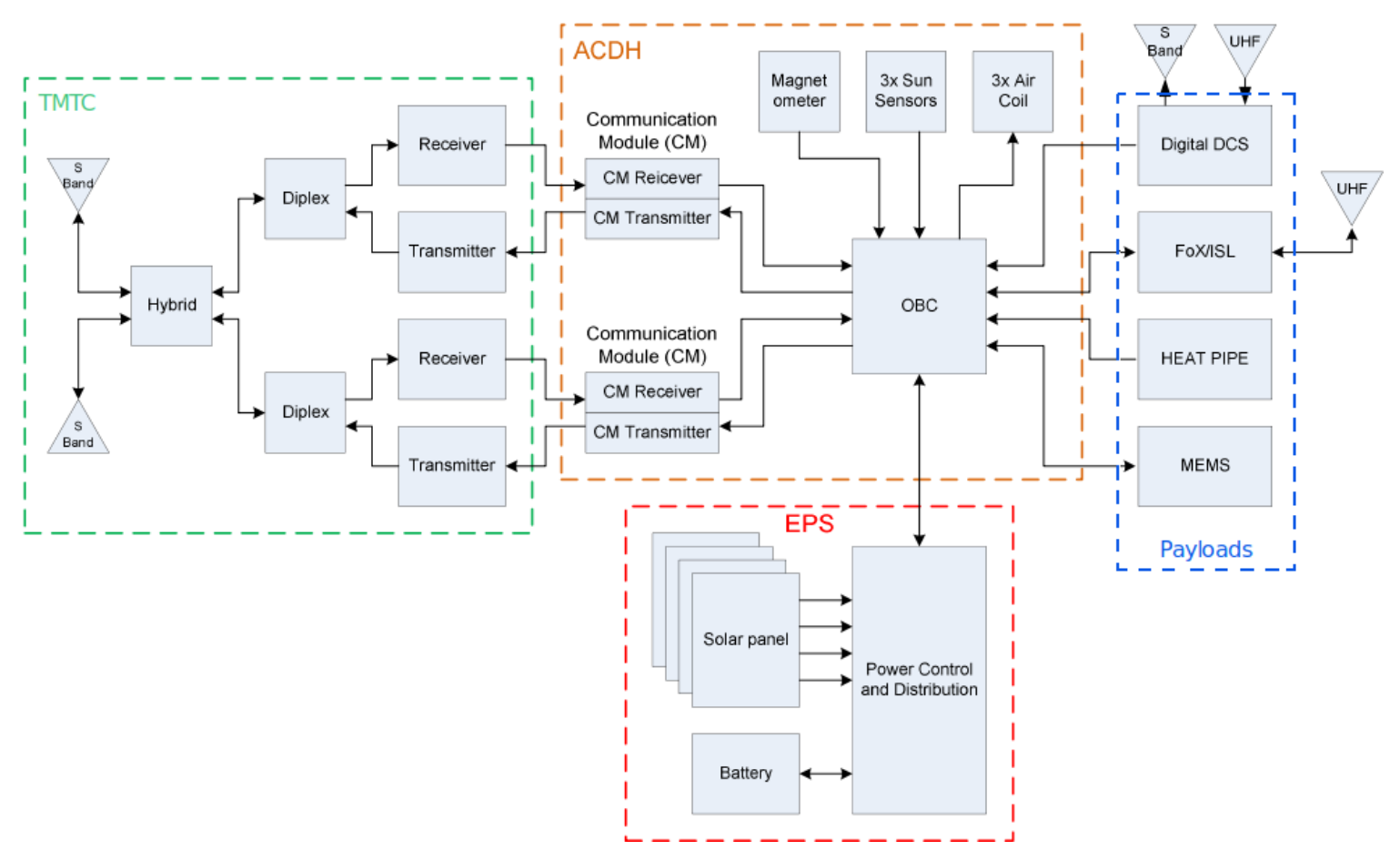

Figura 3.3: Arquitetura do ITASAT (Adaptado de (ITASAT, 2011)).

A interação do subsistema ACDH com o subsistema TMTC, EPS e cargas úteis consistem em:

- O TMTC recebe telecomandos (TC) da estação terrestre e os transmite para o $\mathrm{ACDH}$;

- O ACDH monitora o estado do satélite, gera telemetrias (TM) e os envia para o TMTC, que transmite as informações para a estação terrestre;

- $\mathrm{O} \mathrm{ACDH}$ gerencia as operações das cargas úteis;

- $\mathrm{O}$ ACDH recebe energia do EPS.

O foco do estudo de caso realizado com o ITASAT-1 consiste em colaborar com a atividade de teste do software do Módulo de Comunicação (Comunication Module), que é composto por duas partes: o software do CM Receiver e do CM Transmitter. Devem ser desenvolvidas MEFs a partir da documentação fornecida que modelem o comportamento 
de ambas as partes. A ferramenta JPlavisFSM foi utilizada para edição das MEFs e criação dos casos de teste.

\subsection{Considerações Finais}

Neste capítulo, foi realizada uma contextualização sobre sistemas embarcados, apresentando algumas definições encontradas na literatura e as principais características desse tipo de sistema. Foram apresentadas algumas das dificuldades encontradas para a padronização dos métodos e processos realizados durante a fase de projeto e teste do software. Porém, a sistematização dos processos de desenvolvimento e, principalmente, testes são de suma importância para a segurança dos usuários, uma vez que a criticidade envolvida na maioria desses sistemas é um fator a ser considerado.

No próximo capítulo é apresentada a ferramenta JPlavisFSM desenvolvida durante este trabalho de mestrado, contextualizando o projeto Plavis que deu origem a ferramenta Plavis/FSM, utilizada como base para o desenvolvimento da nova versão e discutindo as principais contribuições implementadas na JPlavisFSM. 


\subsection{Considerações Iniciais}

Como parte da proposta inicial deste projeto, a ferramenta JPlavisFSM foi desenvolvida com o objetivo de prover um ambiente gráfico para edição de MEFs e geração automatizada de casos de testes. A ferramenta Plavis/FSM ${ }^{1}$ foi utilizada como base para a nova versão, fornecendo os requisitos mínimos que deveriam ser implementados e quais deveriam ser otimizados. Outros requisitos foram identificados a partir de feedbacks de usuários que utilizaram a JPlavis/FSM na disciplina Validação e Verificação de Sistemas Espaciais do curso de pós-graduação em Engenharia e Tecnologia Espaciais do INPE.

Na Seção 4.2, a ferramenta Plavis/FSM é contextualizada, apresentando os recursos fornecidos nesta versão. Na Seção 4.3, são descritas as contribuições realizadas para a nova versão JPlavisFSM, exibindo o novo ambiente e suas novas funcionalidades. Na Seção 4.4, são discutidos em detalhes alguns aspectos de implementação da nova versão da ferramenta.

\footnotetext{
${ }^{1}$ http://www.labes.icmc.usp.br/plavis/
} 


\subsection{Contextualização}

A ferramenta de teste Plavis/FSM foi desenvolvida pela iniciativa do projeto de mesmo nome (PLAVIS - Plataforma para Validação e Integração de Software em Sistemas Espaciais), com o objetivo de disponibilizar mecanismos de geração automática de casos de testes a partir de MEFs (Simão et al., 2005). O projeto foi realizado em parceria com pesquisadores do Instituto Nacional de Pesquisas Espaciais (INPE) e das universidades: ICMC/USP, UFSCar, UEPG, Unicamp e Univem.

A Plavis/FSM foi desenvolvida em plataforma web e corresponde à integração de três outras ferramentas: (1) Proteum/FSM, que aplica o critério de análise de mutantes para MEFs; (2) MEGASET, que disponibiliza uma implementação do Método W e (3) CONDADO, que provê o Método Switch-Cover, além das implementações dos métodos State Counting e UIO, que geram sequências de teste para MEFs.

Para iniciar a utilização da ferramenta é necessário criar um projeto de teste. Na tela inicial, é possível escolher a opção Project para criar um novo projeto de teste, configurar formatos de visualização (Settings), voltar a página inicial (Home) ou sair da ferramenta (Logout).

Criado o projeto, a ferramenta é redirecionada a uma segunda tela, que permite a elaboração de testes para uma dada MEF. O primeiro passo é informar qual a MEF alvo dos testes a serem criados. No menu Source é possível fornecer um arquivo em um formato pré-definido pela ferramenta. Caso o usuário deseje construir a MEF pela ferramenta, ela dispõe de um editor em que é possível entrar com os estados e os eventos, gerando uma figura com a representação gráfica da MEF para que o usuário possa acompanhar a sua edição. É possível também exportar a MEF criada no editor nos formatos das ferramentas CONDADO, MEGASET e Plavis/FSM. Na Figura 4.1 é ilustrada a MEF gerada pelo editor, correspondendo ao arquivo mef.les da ferramenta Plavis/FSM descrito na Tabela 4.1

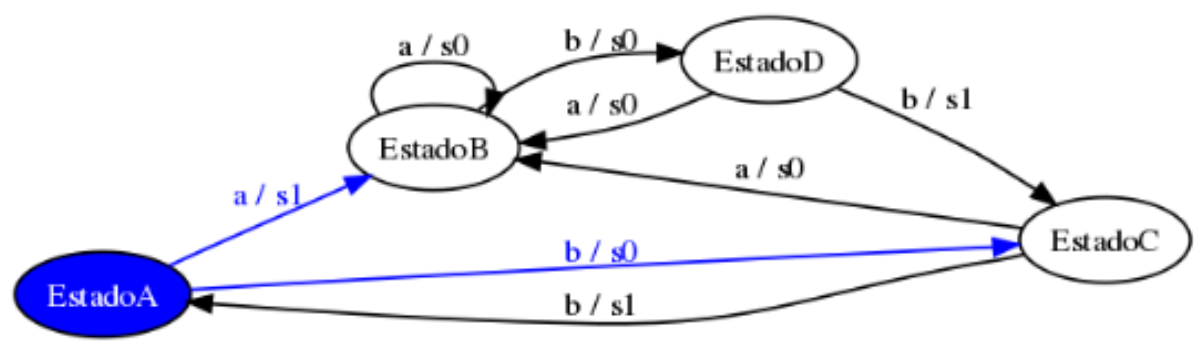

Figura 4.1: MEF correspondente ao arquivo mef.les. 
Tabela 4.1: Formato .les criado pelo editor de MEFs da Plavis/FSM.

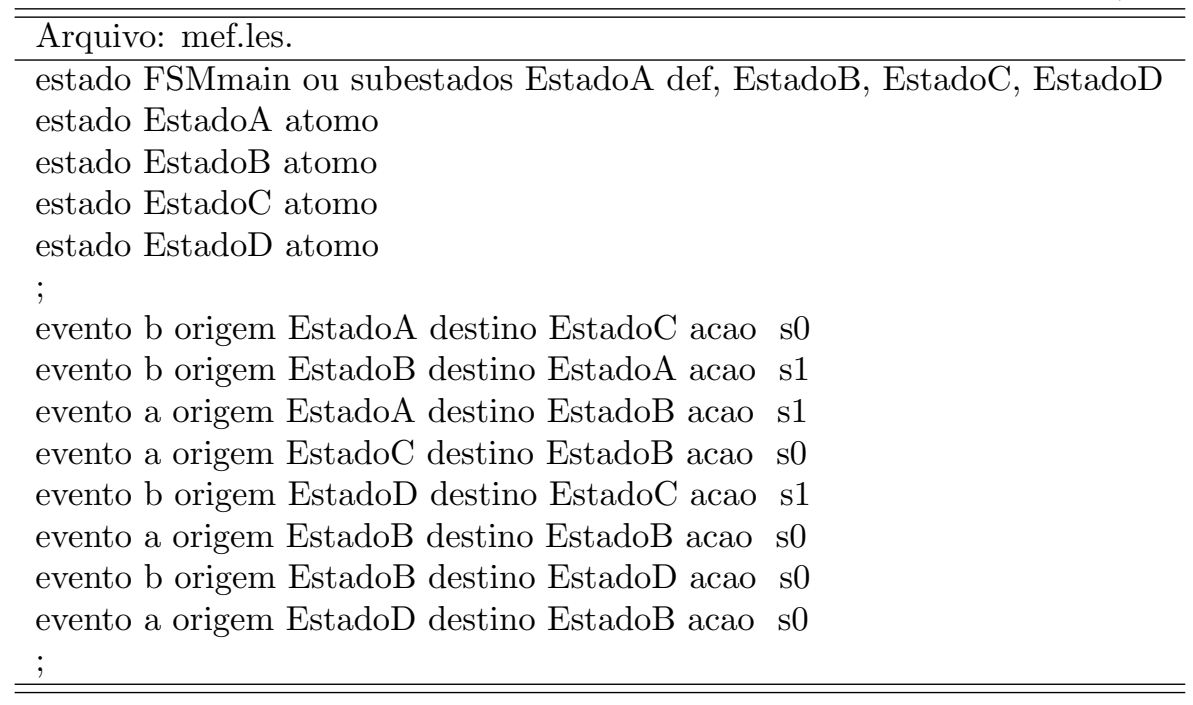

Definida a MEF de trabalho, o usuário deve escolher quais operadores de mutação que serão aplicados. Para o contexto de MEFs foram definidos nove operadores de mutação, sendo (Fabbri et al., 1999):

- OutAlt: saída trocada. Altera a saída gerada de um evento pelas demais saídas existentes;

- OutDel: saída faltando. Este operador remove o símbolo de saída associado a cada evento;

- StaDel: estado faltando. Suprime um estado, fazendo uma junção de dois estados em um único, desde que exista um arco conectando os mesmos, redirecionando todos os eventos pertinente aos estados antigos ao estado novo;

- TraArcDel: arco faltando. Este operador exclui um arco da MEF;

- TraDesStaDel: destino trocado. É alterado o estado destino associado a cada um dos eventos pelos demais estados existentes na MEF;

- TraEveAlt: evento trocado. É trocado cada evento da MEF pelos demais eventos existentes;

- TraEveDel: evento faltando É excluído um evento por vez que provoque a transição entre dois estados;

- TraEveIns: evento extra. É incluído, em cada arco da MEF, cada um dos outros eventos existentes que não provoca a transição entre os estados relacionados ao arco considerado; e 
- TraIniStaDel: alteração do estado inicial da MEF, de forma que em cada mutante um dos outros estados passa a ser o estado de inicialização.

O usuário pode escolher quais operadores deseja utilizar e então finaliza a edição do projeto da MEF. O próximo passo é criar sessões de teste em que se deve determinar qual o número de mutantes por operador que será incluído. O usuário pode escolher qual o método de geração de casos de teste ele deseja utilizar, sendo: (1) manual, incluindo um único caso de teste por vez (Include Teste Case) ou vários a partir de um arquivo (Import Test Cases From File); (2) método W (Import W Test Cases); (3) State Count (Import State Count Test Cases); (4) a partir da ferramenta CONDADO (Import Condado Test Cases); e (5) método UIO (Import UIO Test Cases). Na Figura 4.2 é ilustrado a interface da ferramenta.

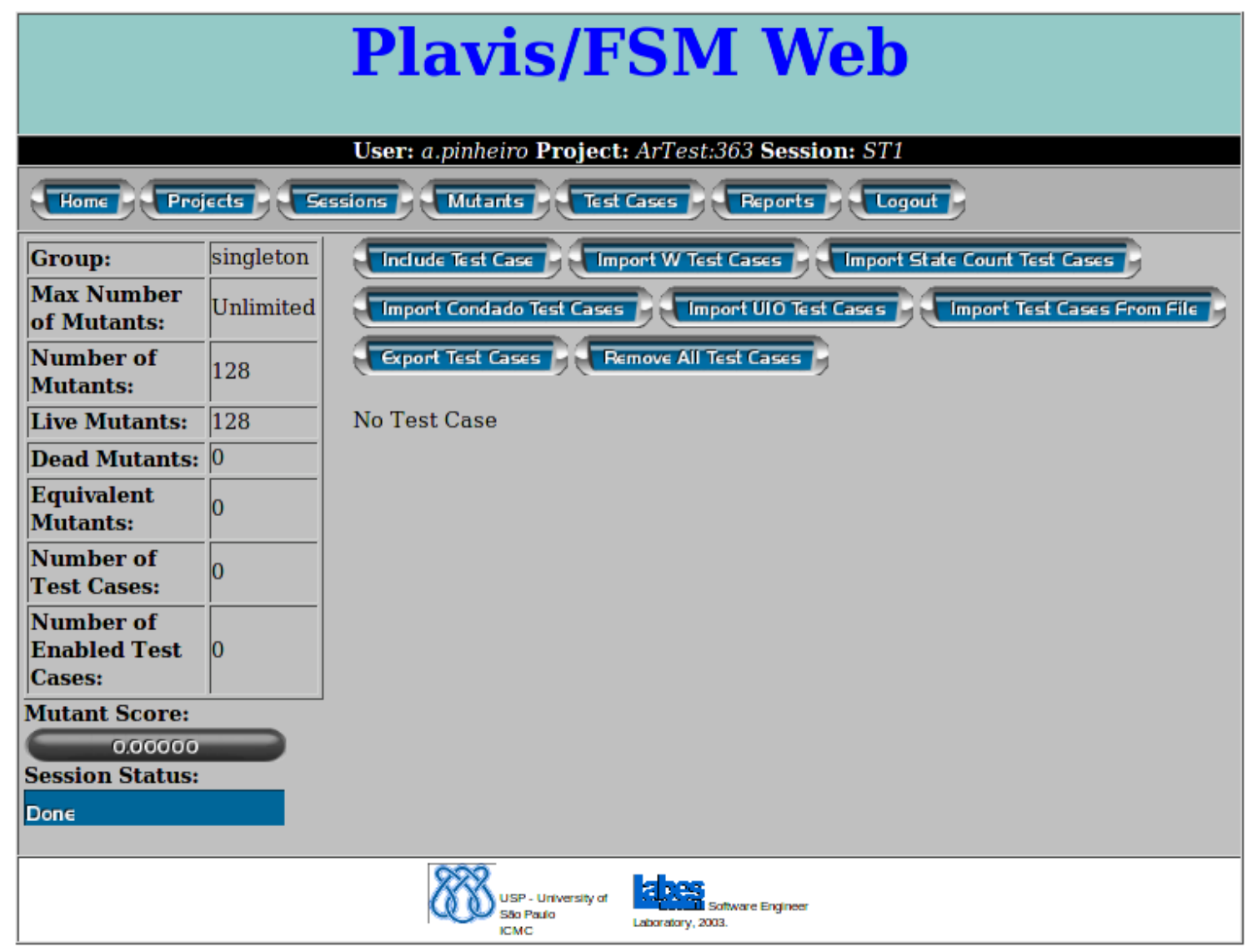

Figura 4.2: Tela de métodos de geração de casos de teste da Plavis/FSM.

O número de mutantes gerados foi de 128 (Figura 4.2) para a MEF descrita na Figura 4.1, que possui 4 estados e 8 transições. Após a geração dos mutantes, a ferramenta viabiliza a verificação de todos os mutantes gerados em uma tabela. O testador pode analisar cada uma das mutações realizadas, podendo elaborar um caso de teste específico 


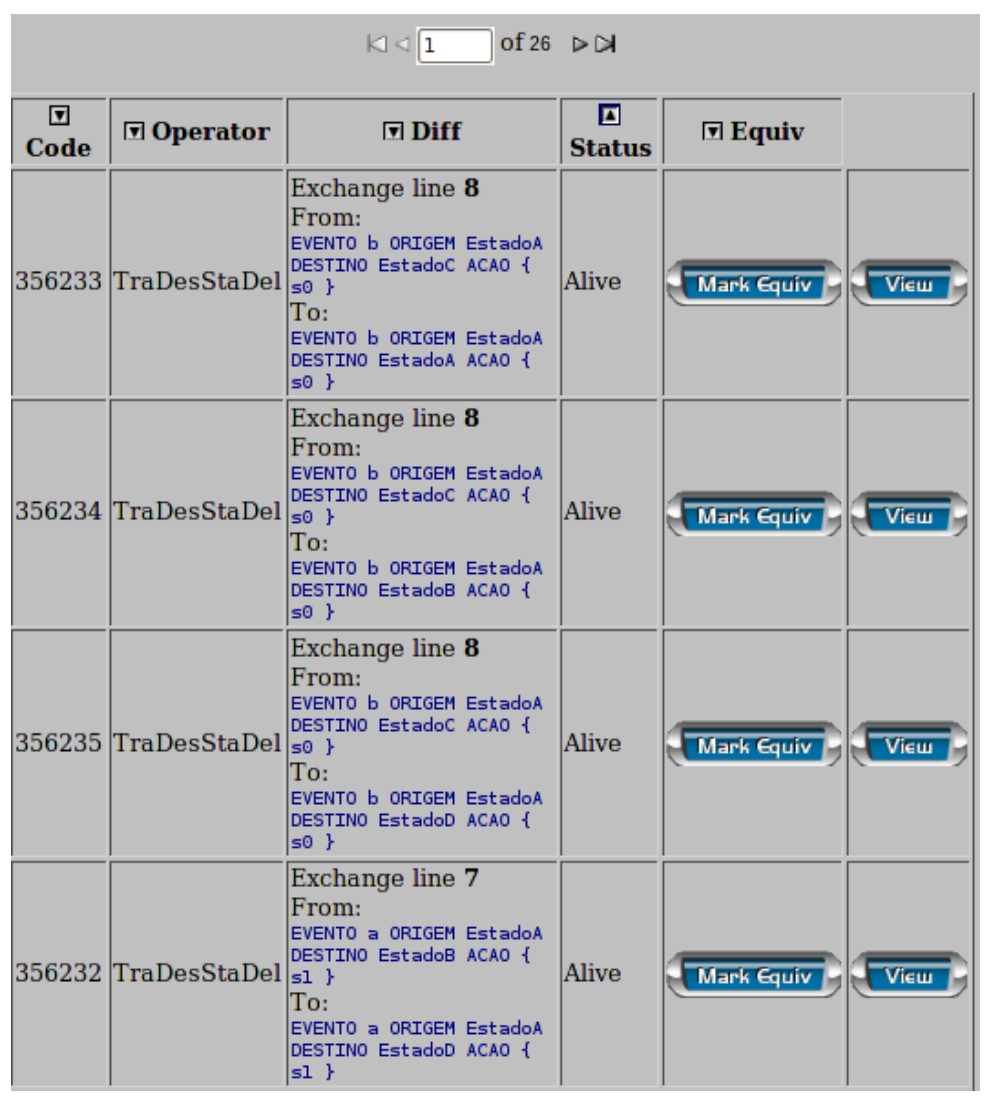

Figura 4.3: Tabela de mutantes gerados.

para matá-lo ou marcá-lo como equivalente, se for o caso (Figura 4.3). O testador ainda tem a opção de visualizar graficamente o mutante.

A ferramenta possui vários recursos que facilitam a aplicação do critério de análise de mutantes aliada a métodos de teste baseado em modelos. Algumas melhorias podem ser propostas de forma a aumentar a usabilidade da ferramenta e disponibilizar mais recursos ao testador, como a inclusão de novos métodos de geração de casos de teste, mais flexíveis quanto às propriedades das MEFs, uma interface de edição de MEFs mais intuitiva e mensagens de erro para o usuário.

A interface de edição de MEFs na Plavis/FSM, por exemplo, é composta por campos onde o usuário deve entrar com os estados e as transições em modo texto. A partir dos dados fornecidos, a ferramenta desenha automaticamente a MEF, não permitindo a escolha do posicionamento dos estados. Caso o usuário digite alguma configuração não permitida, como o nome de um estado composto apenas por números, a ferramenta não notifica o usuário e a MEF não é gerada. A falta de feedback para o usuário representa um dos principais problemas da Plavis/FSM.

Outra limitação relevante consiste na falta de apoio para análise das propriedades estruturais das MEFs. Quando a MEF é gerada corretamente, não é possível analisar se as propriedades de minimalidade e completude são atendidas, o que impede a execução 
de alguns métodos como o W. Nenhuma mensagem sobre a adequação das MEFs implementadas na ferramenta é apresentada ao usuário, o que limita o entendimento da não geração de casos de testes.

\subsection{JPlavisFSM: Contribuições}

A nova versão da ferramenta de teste, denominada JPlavisFSM, foi desenvolvida em Java como aplicativo para desktop, visando maior portabilidade da ferramenta e facilidade de instalação, uma vez que a versão anterior necessitava estar instalada em um servidor para acesso online. Na Figura 4.4, é apresentada a interface gráfica da nova ferramenta JPlavisFSM.

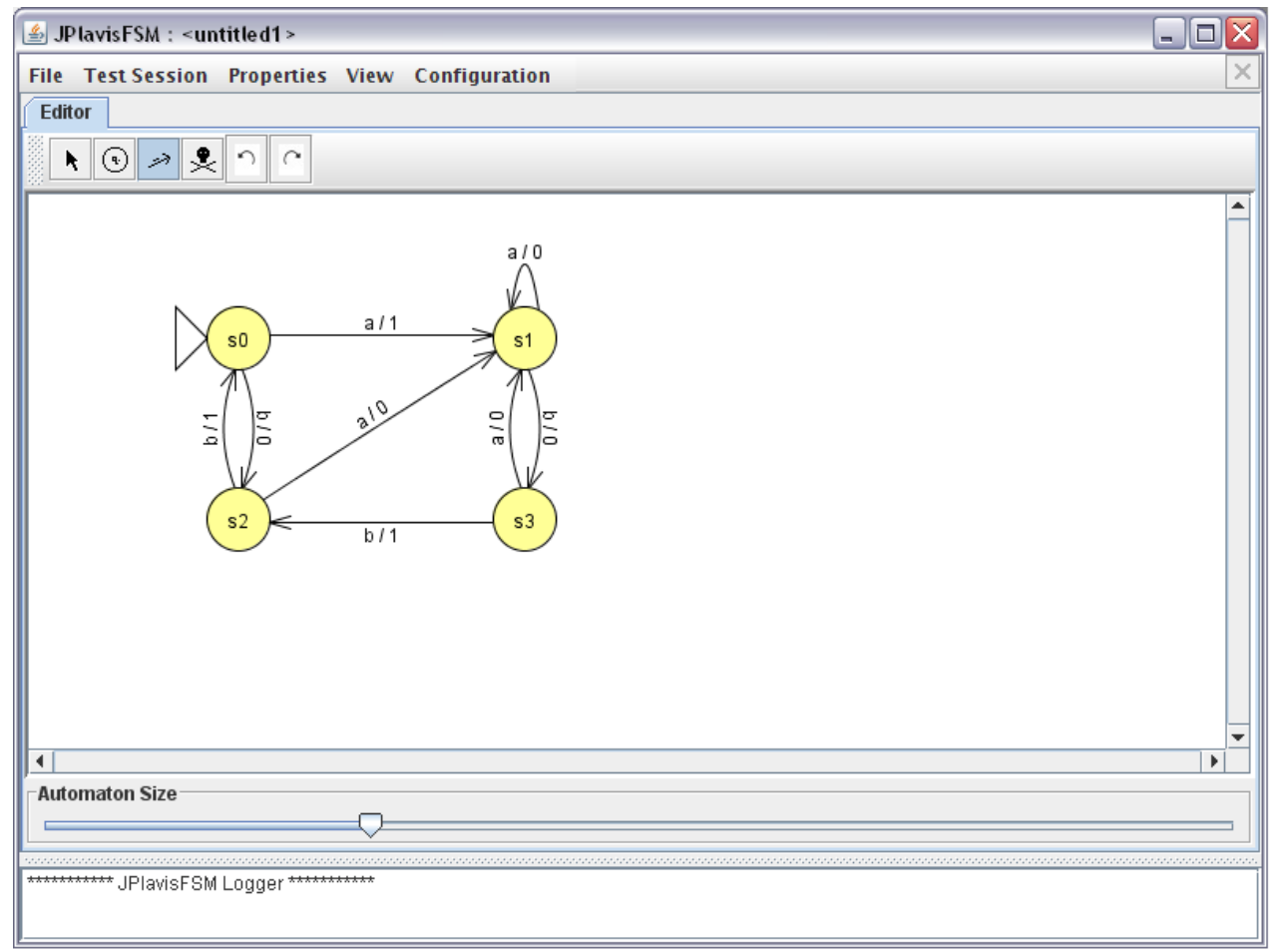

Figura 4.4: Tela inicial da Ferramenta JPlavisFSM.

Melhorias foram propostas para a nova versão. Uma nova interface de edição de MEF foi disponibilizada na ferramenta. Para isso, algumas ferramentas que proviam uma interface gráfica dinâmica para o apoio a construção de MEFs foram estudadas. Inicialmente, foram identificadas as ferramentas JFlap, Fizzim e Qfsm. A ferramenta Fizzim $^{2}$, desenvolvida em Java e Perl, é open source e permite a geração de código em Verilog para especialistas. A $\mathrm{Qfsm}^{3}$ é desenvolvida em $\mathrm{C}++$ e possibilita a geração de

\footnotetext{
${ }^{2}$ http://www.fizzim.com/

${ }^{3}$ http://qfsm.sourceforge.net/
} 
código em baixo nível, como VHDL e Verilog, e alto nível, como Java e C++; permite também a colaboração no desenvolvimento, mas não consiste em uma ferramenta open source. A ferramenta JFlap ${ }^{4}$, utilizada para ensino de autômatos, linguagens formais e MEFs, é desenvolvida em Java e open source. Por ser uma ferramenta voltada para o contexto educacional, a JFlap possui uma interface mais clara e simples em comparação com as demais. Optou-se, então, por integrar parte da interface de edição da ferramenta JFlap, por se tratar da opção que se adequa aos interesses do projeto da JPlavisFSM, em que o usuário deve receber respostas diretas quanto a suas ações.

Outra melhoria consistiu na disponibilização de um menu Properties que possibilita verificar as propriedades estruturais das MEFs criadas na ferramenta, como: (1) a existência de não-determinismo (Highlight Nondeterminism); (2) a existência de transições espontâneas, ou seja, sem a necessidade da ocorrência de um evento de entrada (Highlight $\lambda$-Transitions); (3) se a MEF é completamente especificada, evidenciando os estados incompletos (Highlight Partially Specified States); (4) se a MEF é inicialmente conexa, apontando quais os estados não podem ser alcançados a partir do estado inicial (Highlight Inicially Disconnected States); e, (5) se a MEF é reduzida, indicando quais estados (aos pares) são equivalentes entre si (Highlight Equivalent States (unreduced FSM)).

Novas funcionalidades foram implementadas, como: importar métodos de geração externos à ferramenta e analisar se o conjunto de teste gerado é completo. Como forma alternativa de análise do conjunto de teste gerado foi incorporada da ferramenta $n$-Complete (Simão e Petrenko, 2010). Na versão anterior (Plavis/FSM), a única forma de análise consistia na aplicação do critério de mutação, re-implementado na nova versão da ferramenta.

Na JPlavisFSM, os métodos disponíveis são: W, UIO, HSI, SPY, HSI-compl e SPY-compl e Switch-Cover, como é apresentado na Figura 4.5.

Os métodos 'HSI-compl' e 'SPY-compl' correspondem aos métodos originais HSI e SPY, respectivamente. A diferença consiste no pré-processamento da MEF especificada na ferramenta para torná-la completamente especificada, isto é, para cada par (estado,entrada) que não possui uma transição especificada é adicionada uma transição para o próprio estado com saída vazia. Essa funcionalidade, denominada 'auto-completar', foi implementada inicialmente para o método $\mathrm{W}$, com o objetivo de aumentar o conjunto de MEFs em que ele pudesse ser aplicado, uma vez que o método W só é aplicável a MEFs completas, determinísticas, inicialmente conexas e minimais. Porém, identificou-se que algumas MEFs implementadas na JPlavisFSM não possuem sequências de separação e, por consequência, não podem ser consideradas MEFs minimais. Como em alguns casos não existe a possibilidade de se reduzir as MEFs geradas durante o processo de modelagem, decidiu-se por disponiblizar a opção de se auto-completar as MEFs para a tentativa

\footnotetext{
${ }^{4}$ http://www.jflap.org/
} 


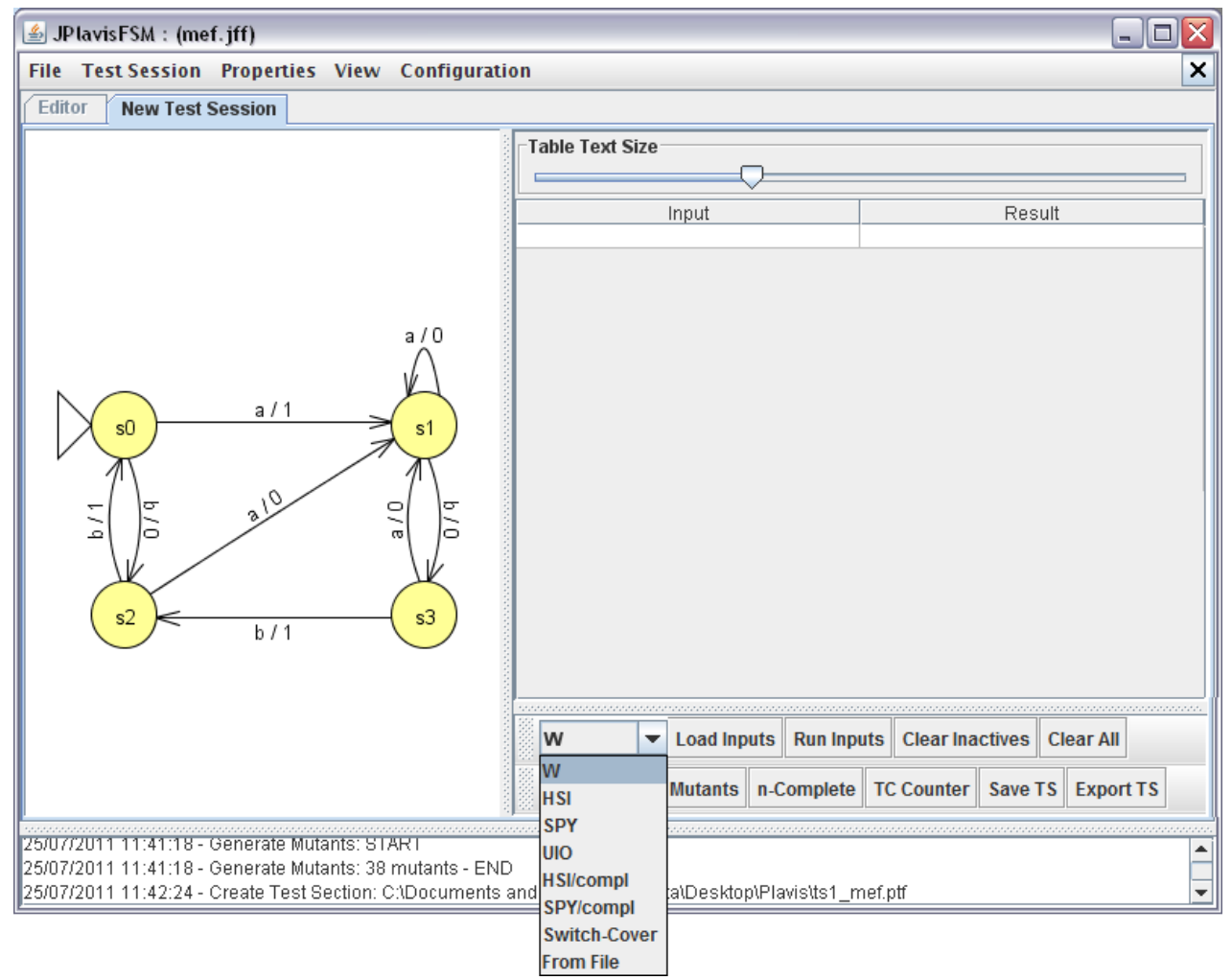

Figura 4.5: Sessão de Teste da Ferramenta JPlavisFSM.

de se especificar MEFs reduzidas, viabilizando a aplicação dos método HSI e SPY em um número maior de MEFs. A execução da funcionalidade auto-completar, por sua vez, não garante que a MEF final gerada será minimal.

Outras melhorias implementadas foram: (1) exportar sessão de teste, para análise externa do conjunto de entradas e saídas obtidas; (2) contador de sequências de teste, que indica o número de testes ativos, inativos e o total; (3) relatório da análise de mutantes, que indica o número de mutantes gerados por operador de mutação e a respectiva quantidade de mutantes mortos para o conjunto de teste gerado na sessão de teste.

No estudo do projeto Plavis/FSM, observou-se que um dos operadores de mutação definidos por (Fabbri et al., 1999), quando aplicados a MEFs parcialmente especificadas, gerava MEFs 'quasi-equivalentes' (Petrenko e Yevtushenko, 2005). O operador 'TraEveIns' insere uma transição com uma entrada não especificada na MEF original, ou seja, são geradas MEFs equivalentes à original exceto pela inclusão de uma nova transição. Como os métodos de geração se baseiam na MEF original para gerar os casos de teste, nenhum caso de teste é gerado para executar caminhos não especificados. O conjunto gerado por qualquer método completo não é capaz de atingir escore de mutação igual a 1.0. Na Figura 4.6, é exibida a área destinada para análise do critério de mutação.

Neste caso, cabe ao testador analisar a relevância dos mutantes gerados, se é possível ou não executar a transição incluída nas novas MEFs. Por decisão de projeto, optou-se 


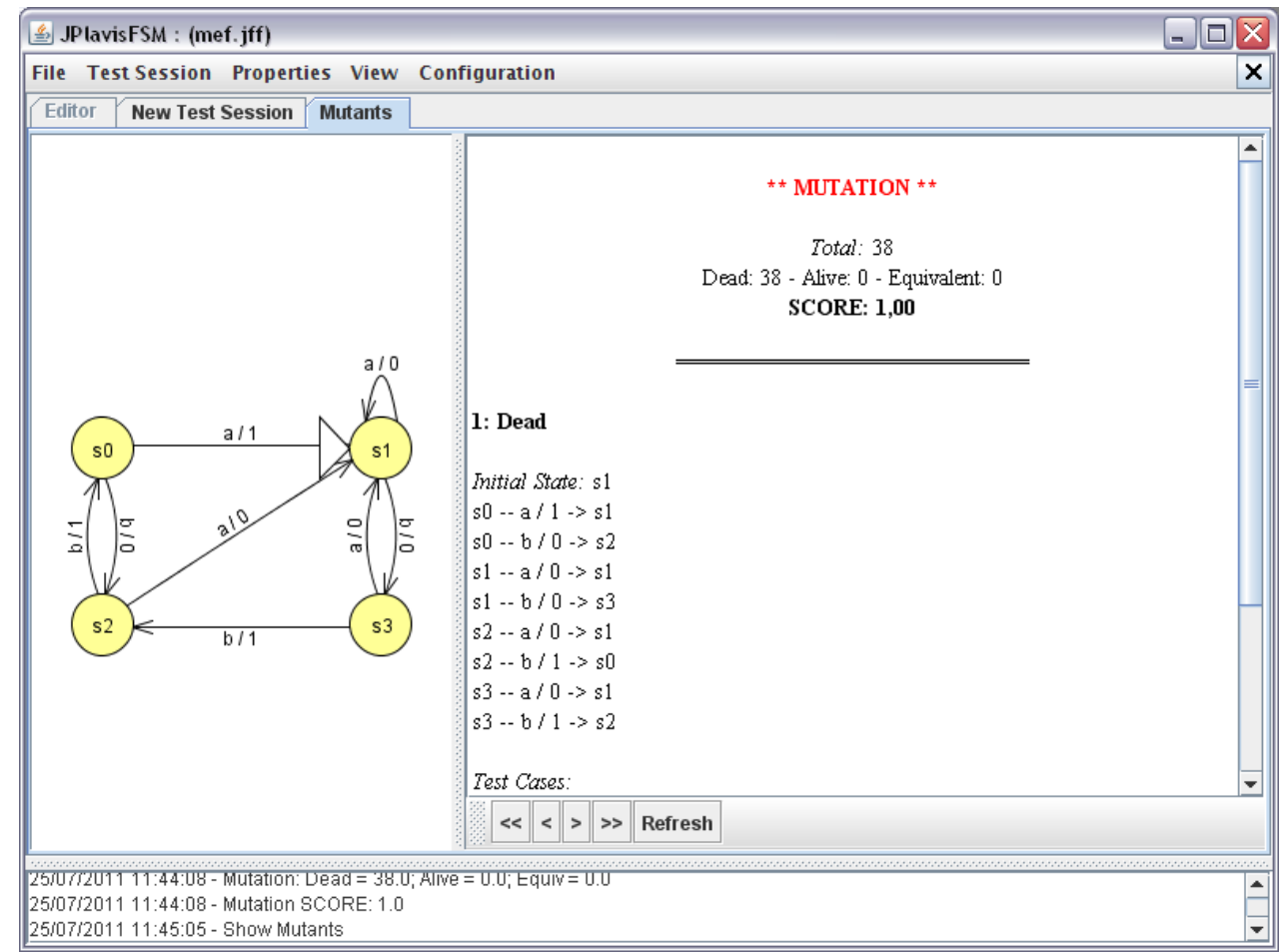

Figura 4.6: Análise de Mutantes da Ferramenta JPlavisFSM.

por deixar o operador ativo na JPlavisFSM, deixando a cargo do testador analisar a expressividade dos resultados gerados. Estudos de casos foram executados com o objetivo de validar a ferramenta e são apresentados no Capítulo 5. Durante a realização dos estudos de caso, defeitos foram corrigidos, o que aumentou a confiabilidade e a robustez da ferramenta.

Um documento com o manual de usuário da ferramenta está em elaboração e deverá ser publicado junto a biblioteca do ICMC como relatório técnico. A versão atual do documento pode ser encontrada em http://www.icmc.usp.br// arineiza/ManualJPlavisFSM.pdf.

\subsection{Aspectos de Implementação}

Para a implementação da nova versão da ferramenta, JPlavisFSM, optou-se por incorporar a ferramenta JFlap. O JFlap é uma ferramenta Open Source que começou como uma série de ferramentas do Rensselaer Polytechnic Institute por volta de 1990, com o objetivo de auxiliar na experimentação de linguagens, incluindo tópicos formais, autômatos finitos não determinísticos, máquinas de Turing multi-fitas e análise de vários tipos de gramáticas ${ }^{5}$.

Na versão 7.0 do JFlap, a qual foi utilizada para a integração, existem 8 pacotes com mais de 400 classes que desempenham funções, como gerenciamento da interface gráfica,

\footnotetext{
${ }^{5}$ Dados extraídos de http://www.jflap.org/
} 
gerenciamento dos autômatos e das gramáticas. Para a JPlavisFSM, foram utilizadas as funcionalidades de GUI e de gerenciamento de MEFs de Mealy. Para a adaptação do JFlap, foram implementadas adaptações em classes existentes e novos pacotes e classes para que fosse possível integrar as funcionalidades previstas para a JPlavisFSM. Foi integrado também o Método $\mathrm{W}$, composto por dois pacotes com um total de 17 classes java. Na Tabela 4.2, são exibidas o número de classes implementadas por pacote durante o projeto e o total de linhas implementadas por pacote.

Tabela 4.2: Número de classes implementadas na JPlavisFSM.

\begin{tabular}{|c||c|c|}
\hline Pacotes & Classes Novas & Número de Linhas \\
\hline \hline JFlap & 15 & 3581 \\
Método W & 1 & 136 \\
Mutantes & 3 & 424 \\
\hline
\end{tabular}

Grande parte das novas classes no pacote do JFlap foram implementadas com o intuito de adaptar a interface gráfica existente para as atuais necessidades da JPlavisFSM e outras 3 classes existentes foram adaptadas a fim de prover novos botões e menus. Em especial, as classes (CompletenessDetector, ConectivityDetector e MinimalDetector) foram implementadas para viabilizar a análise das propriedades estruturais das MEFs (Completude, Conectividade e Minimalidade). As classes LoadInputsAction e RunInputsAction têm o objetivo de gerenciar a geração de sequências de entradas de teste e sequências de saídas esperadas, respectivamente. A primeira administra a escolha dos métodos pelo usuário e disponibiliza os resultados gerados; a segunda executa as sequências de testes contra a MEF principal e também seus mutantes, gerando as saídas esperadas e o escore de mutação obtido.

No pacote de Mutantes, implementado para a JPlavisFSM, foi definida a estrutura dos operadores de mutação, segundo (Fabbri et al., 1999). Três novas classes foram definidas para a geração dos mutantes: Status, que define o estado do mutante (vivo, morto ou equivalente); Mutant, responsável pela estrutura de um mutante (transições e estado inicial), além de armazenar dados sobre seu estado, bem como os casos de testes que o mataram e qual operador de mutação o gerou; e MutantsCreator, que implementa os operadores de mutação para MEFs.

Devido à estrutura definida para MEFs, os operadores OutDel e TraEveDel não foram implementados, uma vez que cada transição é definida com uma única entrada e uma única saída. O operador OutDel determina a exclusão de um operador de saída associado a cada evento; porém, para a estrutura utilizada, não existe transição sem saída. Por sua vez, o operador TraEveDel remove um evento de entrada da transição; porém não há transição sem entrada. Desta forma, não faz sentido remover uma entrada ou uma 
saída da transição, sendo enquivalente a aplicar o operador ArcDel, em que a transição é removida.

Para minimizar o armazenamento de dados gerados durante a análise de mutantes, optou-se por gerenciar em dois arquivos de texto as informações pertinentes à sessão de teste. O arquivo que representa a sessão, com extensão .ptf (Plavis Tool Format), contém o conjunto de casos de teste gerado na ferramenta e o respectivo separador de sequências empregado. Em um segundo arquivo, é armazenado o número de mutantes gerado e os respectivos índices dos casos de testes que os mataram.

Foi necessário implementar um algoritmo que garantisse a geração dos mutantes em uma ordem fixa para que não houvesse a necessidade de armazenar o mutante gerado e seu respectivo status para verificações futuras, uma vez que a estrutura que armazena as transições do mutante é clonada de modo aleatório. Como resultado, apenas um arquivo texto com extensão .ptsf (Plavis Test Session Format) é gerado por sessão de teste. Cada linha contém o estado do mutantes, indicado pelo número 0 quando o mutante está vivo e 1, quando está morto. No caso do mutante estar morto, é acrescentado, na mesma linha, os índices dos casos de teste que o mataram. O número de linhas do arquivo corresponde ao número de mutantes gerados.

Ao acessar uma sessão de teste anteriormente criada, a ferramenta recupera os dados salvos e os apresenta ao usuário, sem a necessidade de re-executar a análise dos mutantes. A análise apenas é ativada quando o usuário atualiza a tabela de sequências de testes e aciona a opção para executá-la.

\subsection{Validação da JPlavisFSM}

Para validar a ferramenta JPlavisFSM, foram conduzidos dois estudos de caso. O primeiro estudo de caso, descrito na Seção 4.5.1, foi desenvolvido durante a disciplina de graduação SSC0722 - Métodos e Técnicas para Análise e Projeto de Sistemas Reativos, no Instituto de Ciências Matemáticas e de Computação (ICMC/USP), sob supervisão do Prof. Dr. Adenilso da Silva Simão. O objetivo consistiu em avaliar a ferramenta JPlavisFSM quanto ao desempenho da funcionalidade de importar métodos de geração externos à ferramenta e como essa funcionalidade poderia ser explorada como apoio ao ensino de teste baseado em MEFs.

O segundo estudo de caso, descrito na Seção 4.5.2, foi desenvolvido durante a disciplina CSE-207-4 Validação e Verificação de Sistemas Espaciais do programa de pós-graduação do INPE, ministrada pela Prof ${ }^{a}$. Dr ${ }^{a}$. Ana Maria Ambrosio. Neste caso, o intuito foi avaliar a usabilidade da ferramenta JPlavisFSM diante de diversos contextos, uma vez que os usuários eram membros efetivos da indústria que possuiam conhecimento prático 
sobre desenvolvimento e teste de sistemas reais e que estavam adquirindo conhecimento sobre a técnica de teste baseada em MEFs.

\subsubsection{Estudo de Caso 1: Extensão com Novos Métodos}

Para a disciplina de graduação, uma versão inicial da ferramenta JPlavisFSM foi disponibilizada aos alunos para que a utilizassem como apoio a um dos trabalhos propostos. O enunciado do trabalho especificava que, em grupos, os alunos deveriam implementar, em Java, o método W para MEFs. O programa deveria executar um arquivo de entrada com a especificação da MEF e ter como saída um arquivo com as sequências de teste geradas pelo método $\mathrm{W}$.

A utilização da ferramenta tinha por objetivo apoiar o teste do método implementado pelos alunos. A princípio, a ferramenta fornece ao usuário um ambiente gráfico para a geração das MEF que a traduz automaticamente para um formato texto que deve ser utilizado pelo método. A execução do método, então, é acionada pela ferramenta no momento de carregar as sequências de entrada. A JPlavisFSM espera pela geração do arquivo de saída do método com as sequências de testes e as exibe na interface gráfica. Cabe ao aluno avaliar a corretude do conjunto de testes gerado por seu método; para isso, a ferramenta disponibiliza a ferramenta de análise $\mathbf{n}$-Complete que avalia se o conjunto atendia a essa propriedade. Além disso, a JPlavisFSM provê uma implementação do método W para que o aluno tivesse uma base de comparação para o seu método.

Como parte do trabalho, os alunos deveriam avaliar a JPlavisFSM e sugerir melhorias, caso as identificassem. Em resumo, foram apontados:

- Avaliação (Pontos positivos):

1. Familiaridade com a interface de edição de MEFs;

2. Apoio para análise das propriedades estruturais das MEFs;

3. Auxílio na validação do método implementado;

- Sugestões:

1. Incluir a opção para salvar os resulados gerados;

2. Abrir área de ediçao de MEFs em branco;

3. Mostrar que a MEF não possui estados incompletos;

4. Gerar as entradas automaticamente, definindo os caracteres de entrada e o tamanho máximo na entrada;

5. Permitir flexibilidade na linguagem usada para métodos externos. 
Como a interface de edição de MEFs foi importada da ferramenta JFlap, utilizada em outras disciplinas, muitos alunos possuiam familiaridade com as funcionalidades de desenho. Para a execução do trabalho, a análise das propriedades estruturais das MEFs foi explorada durante a fase de criação das MEFs para teste do método, facilitando a identificação de MEFs que não atendiam os requisitos necessários para a geração de casos de teste com o método $\mathrm{W}$.

Como resultado, os alunos foram capazes de desenvolver suas próprias implementações do método W e integrá-las na ferramenta. A partir da integração, os alunos obtinham uma pré-avaliação da corretude de suas implementações ao utilizar os recursos de análise do conjunto de teste gerado. A validação do conjunto gerado foi guiada a partir da comparação do conjunto gerado pelo método W da JPlavisFSM e pela execução da opção n-Complete, o que transmitia segurança ao usuário sobre a qualidade da sua implementação.

Quanto às sugestões de melhorias, as opções para salvar os resultados gerados e abrir área de edição de MEFs em branco foram incorporadas à ferramenta. As demais sugestões foram postergadas em função da continuidade do desenvolvimento da ferramenta, que priorizou a implementação das demais funcionalidades presentes na versão original Plavis/FSM e outras funcionalidades classificadas como essenciais, como análise de mutantes e adição de novos métodos de geração.

A ferramenta mostrou-se bastante útil como artefato de apoio ao ensino da técnica de teste baseada em MEFs e, por outro lado, a utilização na disciplina mostrou que a funcionalidade que permite importar métodos externos a ferramenta fornece flexibilidade à ferramenta, uma vez que permite adaptar sua lista de métodos disponíveis para uso de acordo com a necessidade do usuário.

\subsubsection{Estudo de Caso 2: Análise de Usabilidade}

O estudo de caso desenvolvido almejou analisar a usabilidade da ferramenta JPlavisFSM. Para isso, foi selecionado um grupo de alunos da disciplina CSE-207-4 Validação e Verificação de Sistemas Espaciais do programa de pós-graduação do INPE, ministrada pela Prof $^{a}$. Dr ${ }^{a}$. Ana Maria Ambrosio. O grupo era formado por mestrandos e doutorandos atuantes no mercado de trabalho que não possuiam conhecimento prévio da disciplina sobre métodos de geração de casos de teste baseados em MEFs.

A ferramenta foi disponibilizada para os alunos da disciplina. Além de aulas sobre modelagem em MEFs, uma palestra sobre métodos de geração baseados em MEFs foi ministrada pelo Prof. Dr. Adenilso Simão. A palestra foi complementada pela apresentação da mestranda sobre a ferramenta JPlavisFSM, que apresentou as funcionalidades básicas 
da JPlavisFSM com um exemplo de uso. Posteriormente, uma nova visita ao INPE foi realizada com o intuito de promover uma discussão sobre a ferramenta, em que os alunos apresentaram um resumo de seus trabalhos, bem como as dificuldades encontradas durante a utilização da ferramenta. O objetivo consistiu em utilizar a JPlavisFSM como apoio a atividade de modelagem e geração de testes de sistemas reais, analisando as dificuldades enfrentadas e fornecendo um feedback sobre o desempenho da ferramenta. Os trabalhos desenvolvidos foram:

\section{Vending machine;}

2. Pêndulo invertido;

3. Mundo dos Blocos (Planejamento Automatizado);

4. Resolução de Conflitos de Trajetória em Unmanned Aircraft System;

5. Unidade de Telemetria e Telecomando do Computador de Bordo da Plataforma Orbital;

6. Verificação da função de alternância entre controladores de um sistema redundante;

7. Analix-1 (Simulador do Satelite CBERS-3).

Todos os trabalhos refletiam aplicações reais de diversos contextos. Os trabalhos 1 , 4, 5, 6 e 7 correspondem ao domínio de sistemas embarcados, sendo os trabalhos 5 e 7 específicos da área aero-espacial e os trabalhos 4 e 6 do domínio aeronáutico. O trabalho 2 corresponde a um problema clássico da área de sistemas de controle, aplicado a guindastes usados para carga em estaleiros e um meio de transporte urbano com duas rodas, conhecido como Segway. O trabalho 3 modela um problema clássico da área de inteligência artificial, que estuda o processo de busca de sequência de ações para que sejam alcançados os objetivos estabelecidos por meio de métodos computacionais.

Em cada trabalho, foi modelada uma única MEF que descrevia o seu respectivo sistema, submetendo-a à JPlavisFSM para a geração de testes. Algumas características das MEFs geradas são descritas na Tabela 4.3, como número de estados e transições que cada MEF possui, se ela é completa ou parcialmente especificada e se era possível obter uma sequência de separação aplicando a funcionalidade 'auto-completar'.

O número de estados e transições ajuda a entender a dimensão das MEFs criadas e, de certa forma, o grau de abstração utilizado para a modelagem do sistema. MEFs muito pequenas geralmente utilizam de um alto grau de abstração, uma vez que os sistemas modelados não são triviais. Por sua vez, MEFs muito grandes apresentam alto grau de complexidade para o seu entendimento e/ou podem acrescentar transições pouco significativas, que apenas são modeladas para atingir a completude da especificação. 
Tabela 4.3: Características das MEFs geradas nos trabalhos.

\begin{tabular}{|c|c|c|c|c|}
\hline Trabalho & Estados & Transições & Especificada & Auto-completar \\
\hline \hline 1 & 4 & 8 & parcial & não \\
\hline 2 & 5 & 19 & parcial & não \\
\hline 3 & 13 & 117 & completa & sim \\
\hline 4 & 5 & 17 & parcial & não \\
\hline 5 & 4 & 44 & completa & sim \\
\hline 6 & 3 & 8 & parcial & não \\
\hline 7 & 6 & 14 & parcial & não \\
\hline
\end{tabular}

O fato de uma MEF ser parcial ou completa determina a aplicabilidade do método W, que é restrito a MEFs completamente especificadas. Para as MEFs que foram classificadas como parcialmente especificadas não foi possível obter sequências de separação utilizando a funcionalidade 'auto-completar', o que inviabiliza a aplicação de métodos que geralmente são considerados aplicáveis a MEFs parciais, como o HSI e SPY. A não geração de conjuntos de testes por métodos tradicionais da área de teste baseado em MEFs aponta para uma dificuldade encontrada por alguns testadores em modelar MEFs parciais e minimais. Parte da dificuldade pôde ser justificada pelo pouco conhecimento teórico sobre os métodos de geração e como as sequências de separação são obtidas. Porém, a atividade de modelagem não é uma tarefa simples e agrega conhecimento específico sobre o sistema a ser modelado e como essa modelagem pode ser feita.

Metodologias para auxílio à modelagem, como a CoFI (Ambrosio et al., 2005, 2007), podem representar uma solução para a fase inicial de criação das MEFs. A JPlavisFSM foi analisada pelos usuários que a consideraram um bom apoio a atividade de teste e, também, forneceram o feedback necessário para algumas correções e melhorias quanto à usabilidade da ferramenta. Um documento detalhado sobre o estudo de caso está em elaboração e deve ser publicado na biblioteca do INPE como relatório técnico.

\subsection{Considerações finais}

Neste capítulo, foi apresentada a nova ferramenta JPlavisFSM, desenvolvida com intuito de prover novas funcionalidades apontadas como necessárias frente a versão original da ferramenta Plavis/FSM. O objetivo da ferramenta JPlavisFSM consiste em fornecer subsídios para a aplicação do teste baseado em MEFs, por meio de um ambiente flexível e amigável, que disponibilize uma interface gráfica prática ao usuário e a automatização da geração de casos de testes. 
Para avaliar e validar a ferramenta, estudos de casos foram conduzidos durante o presente trabalho. O desafio envolvido na condução dos estudos de caso consiste na identificação da aplicabilidade da técnica de teste baseada em modelos em diferentes aspectos, como em diferentes graus de conhecimento por parte dos testadores sobre as técnicas de modelagem baseadas em MEFs e os métodos de geração de casos de teste. A aplicabilidade da ferramenta também foi avaliada como forma de apoio ao ensino aos métodos de geração e como apoio a geração para sistemas reais e mais complexos.

No próximo capítulo, é discutido o estudo realizado durante o presente trabalho para avaliar a aplicabilidade dos métodos de geração de casos de teste no contexto de sistemas reais, utilizando o módulo de comunicação do ITASAT-1 como exemplo. 


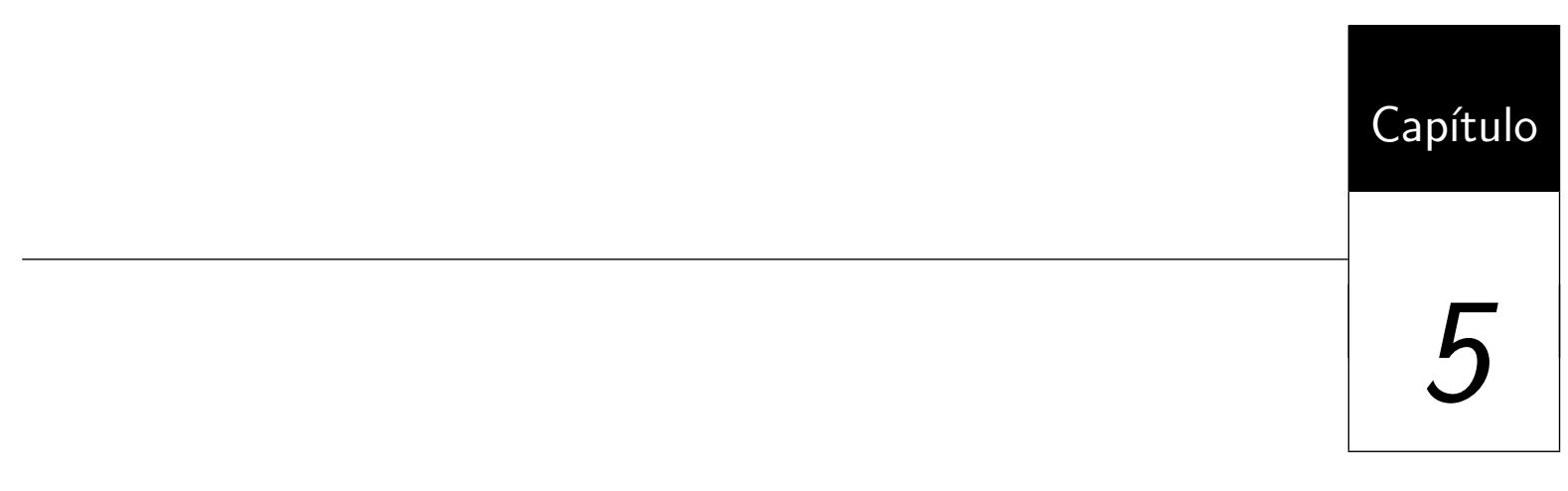

Estudo de Caso: ITASAT

\subsection{Considerações Iniciais}

Para analisar a aplicabilidade da técnica de teste baseada em MEFs, foi realizado um estudo de caso para aplicar o teste baseado em MEFs em um sistema embarcado real. Foi escolhido o Módulo de Comunicação do ITASAT (Seção 3.5), como sistema alvo do teste e, então, aplicada a metodologia CoFI (Seção 3.4.1) para guiar o processo, uma vez que a metodologia foi definida dentro do escopo de sistemas espaciais. O objetivo foi avaliar os benefícios e as dificuldades enfrentados durante todo o processo de teste baseado em MEF e a colaboração provida pela ferramenta JPlavisFSM.

Na Seção 5.2, é apresentada uma visão geral sobre o processo de teste realizado no satétlite ITASAT-1. Na Seção 5.3, são apresentadas as fases de identificação e modelagem pertinentes à aplicação da metodologia CoFI. Na Seção 5.4, é abordada a fase de geração de casos de testes apoiada pela ferramenta JPlavisFSM. Na Seção 5.5, são exibidos os resultados obtidos ao final do estudo de caso. 


\subsection{Planejamento do Processo de Teste}

O foco do estudo de caso realizado no ITASAT foi investigar quais os prós e contras do teste baseado em MEFs no contexto de teste de software embarcado. Na Figura 5.1, pode-se observar os passos da metodologia CoFI, usada para guiar a modelagem das funções de comunicação do satélite ITASAT-1.

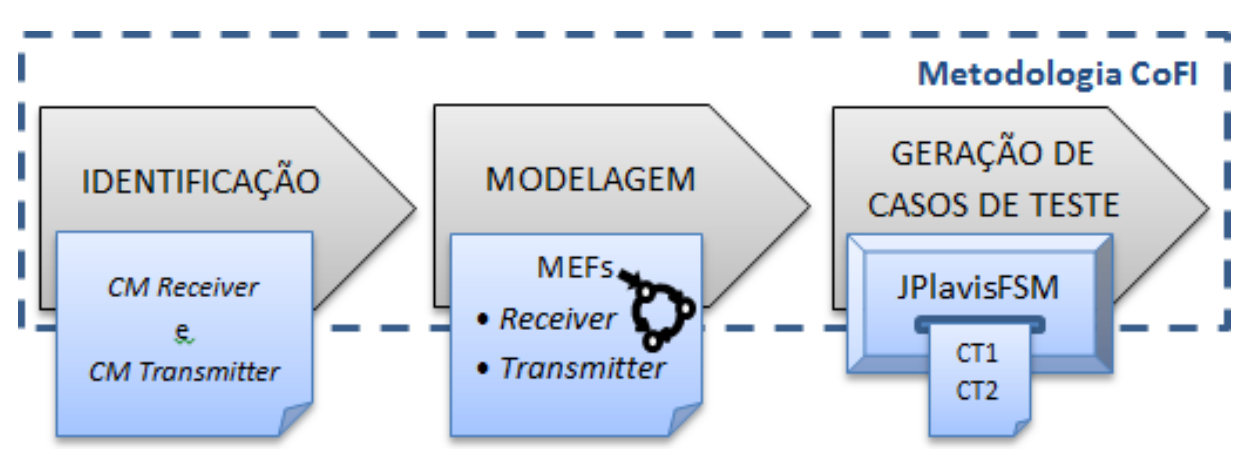

Figura 5.1: Processo de desenvolvimento do estudo de caso.

A CoFI é uma metodologia de teste de software definida com objetivo de reduzir custos e diminuir o número de incidentes em missões espaciais, utilizada em projetos realizados no INPE e no ITA e pertinente ao contexto dos testes do módulos de comunicação do satélite ITASAT-1.

\subsection{Identificação e Modelagem}

A primeira atividade realizada foi o estudo dos requisitos do software embarcado do módulo de comunicação do satélite ITASAT-1, composto por duas partes: transmissão e recepção de dados, denominados CM Receiver e CM Transmitter. Na fase de identificação de serviços da metodologia, o software de transmissão foi identificado como um serviço e o software de recepção como outro. A partir do documento de especificação de ambas partes do módulo de comunicação (Receiver e Transmitter), foram extraídas as entradas e saídas do software, assim como as exceções que podem acontecer durante o seu funcionamento (exceções especificadas). Como a atividade de teste realizada considerava apenas o software responsável pela comunicação, nenhuma falha de hardware foi modelada. Quanto à modelagem das entradas não esperadas, prevista pela CoFI, todos os eventos presentes no modelo foram analizados e nenhum comportamento anormal foi identificado, pois o software não permite que sejam executadas entradas no estado errado.

Para o software do CM Receiver foram identificadas 12 entradas e 13 saídas, distribuídas em cinco MEFs que modelam seu comportamento completo, sendo uma MEF 
responsável pela modelagem do seu comportamento normal e as demais, pelo comportamento diante das exceções especificadas. Para o CM Transmitter foram identificadas 19 entradas e 12 saídas que determinam o funcionamento do software, modeladas em três MEF, sendo uma para o comportamento normal e 2 para as exceções especificadas. As MEFs principais que descrevem o comportamento normal do CM Receiver e do CM Transmitter são apresentadas na Figuras 5.2 e 5.3, respectivamente.

A princípio, uma das limitações encontradas para a modelagem do software foi a existência de timers que tratavam eventos de timeouts durante o processo de comunicação. Como MEFs tradicionais não possuem características que permitam a modelagem de eventos temporizados, como MEF estendidas ou temporizadas (TFSMs - Timed Finite State Machines) (El-Fakih et al., 2009), esses eventos devem ser abstraídos no modelo. A Metodologia CoFI orienta que timers sejam modelados como dispositivos externos que são inicializados por um evento de saída gerados pelo software e que enviam um evento de entrada para a MEF que indica o estouro de tempo (timeout).

Para o sistema de comunicação, eventos de timeout são geralmente lançados quando nenhuma resposta esperada é gerada, ou seja, representam eventos de exceções especificadas. Para o comportamento normal, o software sinaliza os eventos (de saída) que inicializam os timers. Nas MEFs geradas, pode-se observar os eventos de saída, como StartTimerA e StartTimerC e, como eventos de entrada, EndTimerA e EndTimerC.

Outra limitação encontrada na utilização de MEFs foi a necessidade de se associar um evento de entrada a um evento de saída. Como no software do módulo de comunicação, algumas entradas não geram saídas que possam ser observadas, alguns eventos de saída foram definidos de modo a abstrair o comportamento que descreve o fim de um estado, como a saída 'Terminate' na MEF do Receiver (Figura 5.2) e 'Empty' na MEF do Transmitter (Figura 5.3). Por outro lado, alguns estados devem ser ativados por meio da combinação de duas (ou mais) entradas ou geram mais de um evento de saída em uma mesma transição. A solução para esta caracterísitca foi definir uma entrada ou saída que represente esse comportamento composto, como no caso do evento de saída 'ACKandStartTimerC' na MEF do Receiver.

\subsection{Geração de Casos de Teste}

Após o levantamento dos requisitos e definição dos serviços, entradas e saídas gerais do módulo de comunicação, utilizou-se a ferramenta JPlavisFSM como apoio nas fases de modelagem e geração de testes. A interface gráfica disponibilizada pela ferramenta auxilia no processo de criação das MEFs e análise das propriedades estruturais, importante para o direcionamento da modelagem. Analisando as propriedades estruturais, é possível atender 


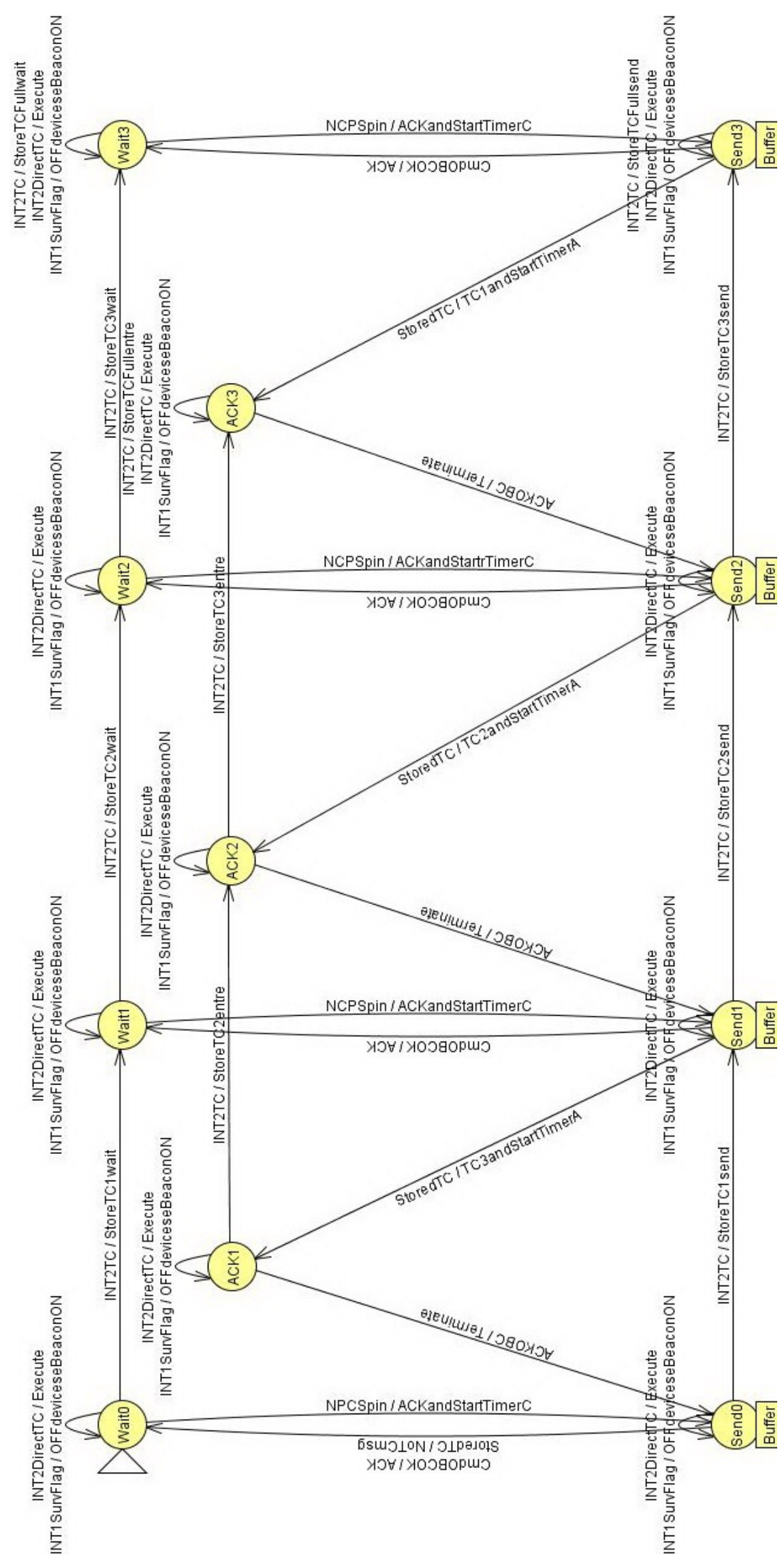

Figura 5.2: MEFs do comportamento normal do CM Receiver. 


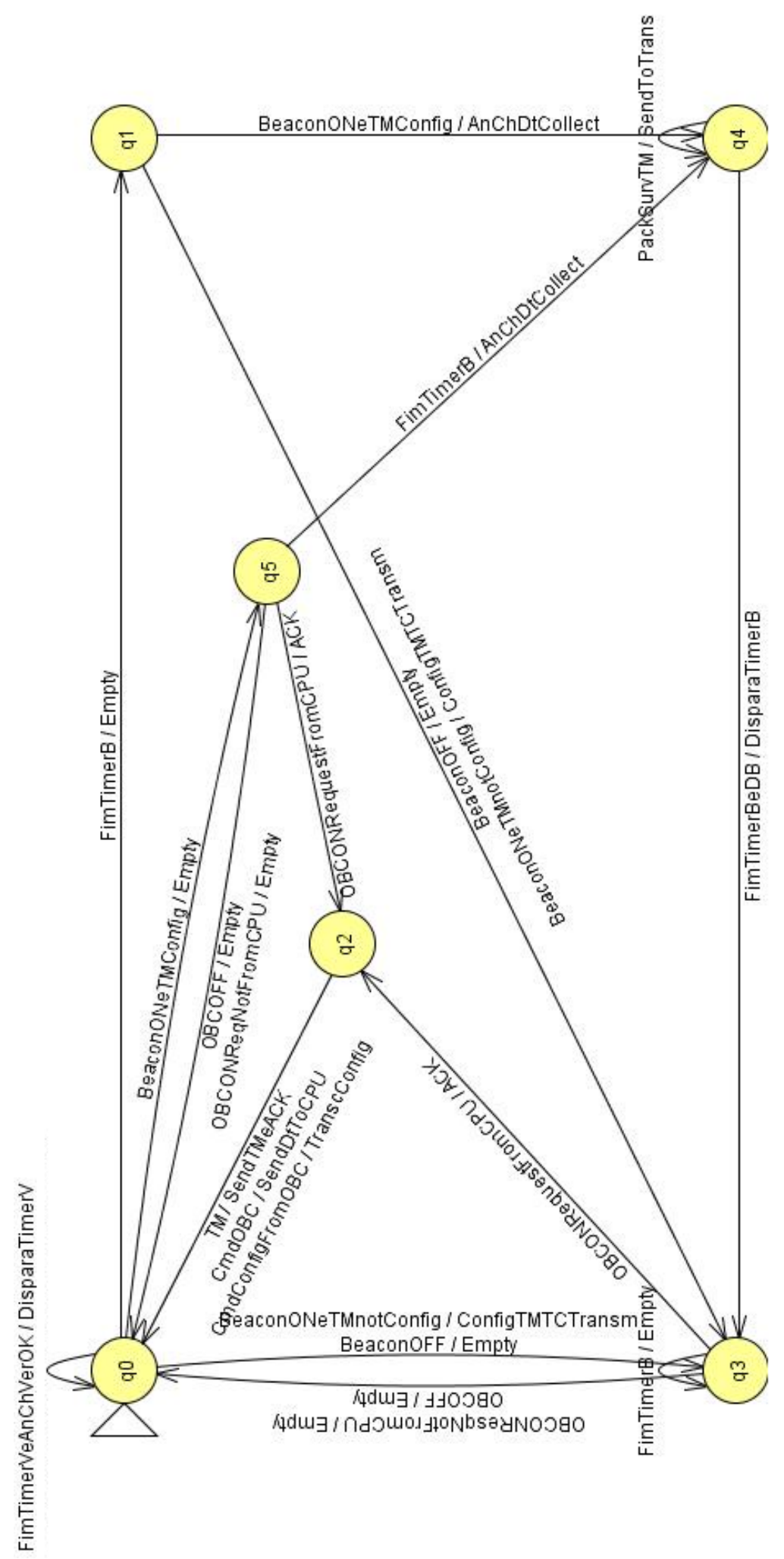

Figura 5.3: MEFs do comportamento normal do CM Transmitter. 
Tabela 5.1: Número de testes gerados por método para cada uma das MEFs.

\begin{tabular}{|c|c|c|c|c|c|c|}
\hline MEF & $\mathrm{W}^{*}$ & UIO & HSI & HSI* & SPY & SPY* \\
\hline \hline R_N & 234 & 48 & 38 & 78 & 22 & 40 \\
\hline R_Ex1 & 356 & 44 & 34 & 89 & 26 & 42 \\
\hline R_Ex2 & 201 & 37 & 27 & 67 & 21 & 40 \\
\hline R_Ex3 & 201 & 37 & 27 & 67 & 21 & 40 \\
\hline R_Ex4 & 201 & 37 & 27 & 67 & 19 & 37 \\
\hline T_N & 316 & 21 & - & 184 & - & 72 \\
\hline T_Ex1 & 316 & 21 & - & 184 & - & 72 \\
\hline T_Ex2 & 335 & 19 & - & 158 & - & 61 \\
\hline
\end{tabular}

mais facilmente aos requisitos necessários para a utilização de alguns dos métodos de geração disponibilizados na ferramenta. Esta funcionalidade permite ao usuário maior flexibilidade, uma vez que dispensa a necessidade de se ter experiência na identificação destas propriedades, que não são trivialmente observadas.

A partir das MEFs geradas, foram estudados quais os métodos de geração disponibilizados pela JPlavisFSM que poderiam ser executados no cenário atual. Na Tabela 5.1, é descrito o número de testes gerados por método para cada uma das MEFs criadas. As MEFs iniciadas pela letra ' $\mathrm{R}$ ' correspondem ao software $C M$ Receiver e pela letra ' $\mathrm{T}$ ', do CM Transmitter; o final ' $\mathrm{N}$ ' corresponde às MEFs que modelam o comportamento normal do sistema e o final 'Ex', às MEFs que modelam as exceções especificadas dos sistemas. Para viabilizar a utilização de alguns dos métodos de geração nas MEFs criadas, foi aplicada a funcionalidade 'auto-completar', descrita pelo caractere '*' ao lado do nome do método.

\subsection{Análise dos Resultados}

O Método W, apesar de ser o mais tradicional dentre os métodos presentes na literatura, pode ser aplicado apenas em MEFs completamente especificadas, o que restringe a possibilidade da sua aplicação prática. Os demais métodos puderam ser aplicados na maioria das MEFs, exceto nas MEFs do CM Transmitter que não possuem sequências de separação e, consequentemente, não permitem a execução dos métodos HSI e SPY originais (sem a utilização do 'auto-completar').

A JPlavisFSM permite o cálculo do conjunto mínimo de teste composto pela combinação dos conjuntos gerados por todos os métodos. A ferramenta elimina todas sequências idênticas ou que sejam prefixos de outras. Na Tabela 5.2, é possível observar o número 
total de testes representado pela soma dos testes gerados por todos os métodos da ferramenta, o conjunto mínimo calculado, o número de mutantes para cada uma das MEFs e o seu respectivo escore de mutação atingido.

Tabela 5.2: Resumo dos testes.

\begin{tabular}{|c|c|c|c|c|}
\hline MEF & Conjunto Total & Conjunto Mínimo & Mutantes & Escore de Mutação \\
\hline \hline R_N & 342 & 285 & 1852 & 1.0 \\
\hline R_Ex1 & 460 & 408 & 1720 & 1.0 \\
\hline R_Ex2 & 286 & 264 & 1320 & 1.0 \\
\hline R_Ex3 & 286 & 263 & 1357 & 1.0 \\
\hline R_Ex4 & 284 & 265 & 1357 & 1.0 \\
\hline T_N & 593 & 432 & 775 & 1.0 \\
\hline T_Ex1 & 593 & 432 & 775 & 1.0 \\
\hline T_Ex2 & 573 & 454 & 591 & 1.0 \\
\hline
\end{tabular}

É importante considerar qual o objetivo da atividade de teste. O número de testes gerados é consideravelmente extenso e cabe ao testador decidir qual estratégia adotar. Por exemplo, o testador pode escolher executar o conjunto mínimo de testes ou um conjunto gerado apenas por um dos métodos da ferramenta. A análise do escore de mutação atingido pode ser um indicador da adequação do conjunto ao objetivo de teste definido. É responsabilidade da esquipe de testes determinar quanto o software deve ser testado.

Para a viabilização da modelagem baseada em MEFs, muitos conceitos do software devem ser abstraídos. Ao final do processo proposto pela Metodologia CoFI, obtem-se um conjunto 'abstrato' de teste que deve passar ainda por uma fase de pós-processamento. Algumas entradas devem ser substituídas por um conjunto de entradas reais, como a entrada 'INT2DirectTC' que corresponde a 23 diferentes telecomandos que devem ser tratados pelo módulo de comunicação. A geração de casos de testes é automática, mas o pós-processamento e a execução dos testes não é uma atividade trivial. Um relatório técnico sobre o estudo de caso completo foi elaborado e deve ser publicado no INPE.

\subsection{Considerações Finais}

Neste capítulo, foi apresentado o estudo de caso que descreve a experiência sobre a elaboração de testes para um sistema embarcado, no caso, módulo de comunicação do ITASAT-1. Foi possível identificar que a fase de modelagem e geração de casos de teste não é simples de ser desenvolvida; porém, com apoio da metodologia CoFI e da ferramenta JPlavisFSM pode-se reduzir o tempo envolvido na atividade. Observou-se que existe a necessidade de 
uma fase adicional após a geração dos casos de teste, para o pós-processamento da informação gerada, de forma a traduzir os casos de testes teóricos gerados pela JPlavisFSM para casos de testes reais. A implementação de um script de teste pode ser útil para automatizar a fase de execução e análise dos resultados ao final da atividade de teste.

No próximo capítulo, são apresentadas as conclusões obtidas, bem como as limitações e dificuldades encontradas durante a condução deste trabalho de mestrado e os trabalhos futuros relacionados. 


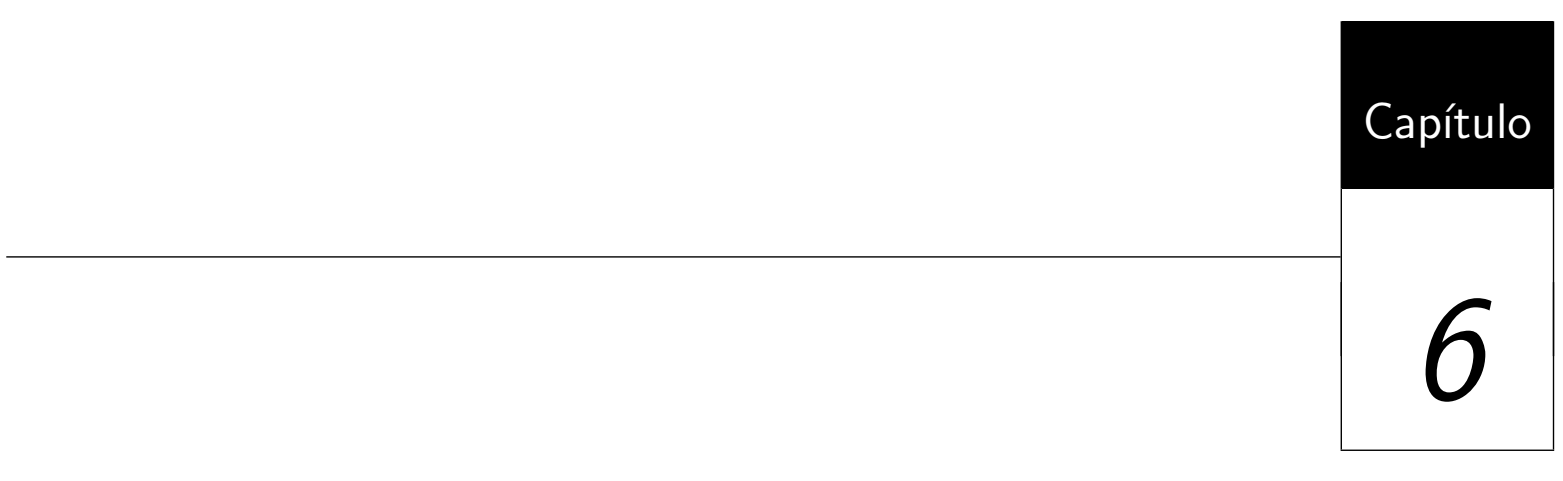

\section{Conclusões}

A área de teste baseado em modelos tem sido amplamente explorada por proporcionar a condução das atividades de desenvolvimento e teste em paralelo, além de prover facilidades para a verificação da especificação devido ao formalismo agregado. Máquinas de estados finitos, por sua vez, correspondem a um dos modelos mais usados e pesquisados na área devido à sua simplicidade conceitual e expressividade na descrição do comportamento de sistemas. Por meio de MEFs e com apoio de ferramentas apropriadas, a geração de casos de testes para avaliar os comportamentos esperados de um sistema é automatizada, reduzindo o custo da atividade.

O formalismo das MEFs fornece embasamento matemático para a especificação de métodos que garantam a geração automatizada de conjuntos de teste completos. $\mathrm{Na}$ literatura, foram propostos diversos métodos de geração baseados em MEFs, tais como os métodos W, UIO, HSI e SPY. A automatização dos métodos de geração de casos de teste consiste em um importante subsídio para a aplicação da técnica de teste baseada em MEFs, pois o processo envolvido torna-se transparente ao usuário final.

Neste trabalho, o objetivo principal consistiu em investigar a aplicabilidade da técnica de teste baseada em MEFs, bem como dos métodos de geração de casos de teste encontrados na literatura. Para isso, a ferramenta JPlavisFSM foi desenvolvida como subsídio para auxiliar a aplicação da técnica, a partir dos conceitos presentes na plataforma Plavis. 
Na Seção 6.1, são descritas as contribuições realizadas pelo presente trabalho. Na Seção 6.2, são listadas as limitações encontradas durante a condução das atividades propostas. Na Seção 6.3, são discutidas as possibilidades para trabalhos futuros.

\subsection{Contribuições}

A principal contribuição deste trabalho de mestrado foi prover alguns subsídios para a aplicação de métodos de geração de casos de teste em aplicações reais, por meio da condução dos três estudos de casos apoiados pela JPlavisFSM. A ferramenta foi desenvolvida durante o presente trabalho como subsídio para a aplicação automatizada dos métodos de geração baseados em MEFs.

A JPlavisFSM foi inspirada nas características presentes na ferramenta Plavis/FSM, como áreas para desenvolvimento das MEFs e sessões de teste que disponilizavam métodos de geração de casos de teste e análise de mutantes. Outras funcionalidades foram agregadas à JPlavisFSM, como a disponibilização de mais métodos de geração, ambiente gráfico para a edição de MEFs e a feramenta n-Complete como meio de avaliação, complementar a análise de mutantes, dos conjuntos de teste gerados.

A partir do novo ambiente, foi possível explorar a técnica de teste baseada em MEFs sob diferentes visões, identificando os seus benefícios e limitações em cada caso. Três estudos de caso foram realizados com o objetivo de analisar principalmente: (1) o desempenho da ferramenta e das novas funcionalidades implementadas, tais como a capacidade de adicionar novos métodos em tempo de execução; (2) a aceitação da JPlavisFSM por parte dos seus usuários; (3) a viabilidade de se conduzir a atividade de teste baseada em MEFs em sistemas reais. Para isso, optou-se por explorar usuários em diferentes cenários, que variavam em relação ao grau de conhecimento teórico sobre MEFs, familiaridade com a interface da JPlavisFSM e objetivos diante da ferramenta.

No primeiro estudo de caso feito na disciplina de graduação, o foco foi avaliar a utilização de métodos externos à ferramenta, considerando que os alunos possuiam familiaridade com a interface de edição de MEF e conhecimento intermediário sobre os métodos de geração baseados em MEFs. Esse estudo de caso caracteriza o cenário utilização da ferramenta como apoio a atividade de análise de novos métodos implementados, demonstrando a flexibilidade da ferramenta. Para o segundo estudo de caso, realizado na disciplina de pós-graduação, o foco era a execução de teste em um sistema real, em que o usuário possuia pouco conhecimento sobre métodos de geração e pouca familiaridade com a ferramenta. Nesse caso, o estudo reflete o cenário de testadores profissionais que desejam explorar a técnica de teste baseado em MEFs em seus sistemas. Em ambos os cenários, não foi caracterizada nenhuma dificuldade em relação a utilização da ferramenta 
em seus projetos. A JPlavisFSM foi apontada como um apoio significativo às atividades desenvolvidas. Os estudos realizados também forneceram dados para a realimentação da JPlavisFSM, que foi aprimorada durante a condução deste trabalho.

O terceiro estudo, realizado com o ITASAT, proporcionou um maior entendimento sobre os benefícios e as dificuldades envolvidas durante todo o processo de teste. Foi observada a visão de um testador com um sistema real para ser modelado e testado. A fase de modelagem corresponde a uma importante etapa da atividade de teste e não é passível de automatização, cabe ao testador identificar os requisitos do sistema e traduzi-los em estados e eventos de entrada e saída. A metolodolgia CoFI auxilia no processo de identifação; porém, é necessário conhecimento prévio sobre as funcionalidade do sistema e o seu comportamento. Para que a modelagem seja facilmente aplicada na fase de geração de teste, ela deve ser realizada de forma consciente para que algumas propriedades estruturais da MEF sejam atendidas. O conhecimento do testador sobre essas propriedades torna-se um ganho adicional para o sucesso da modelagem.

\subsection{Dificuldades e Limitações}

O presente trabalho apresentou algumas dificuldades e limitações quanto à condução dos estudos de caso, em especial, no estudo de caso com o ITASAT.

Como o projeto do ITASAT-1 está em fase de desenvolvimento, uma dificuldade enfrentada foi o fato de os documentos de especificação sofrem alterações para a adequação dos requisitos necessários para a sua implementação. Durante a fase de identificação dos serviços da metodologia CoFI, os documentos utilizados para a análise do requisitos do módulo de comunicação sofreram alterações significativas, que alteravam o comportamento do sistema. Foram necessárias algumas iterações com a equipe do ITASAT para o fechamento da modelagem. A utilização da metodologia auxiliou no processo uma vez que a modularização do comportamento do software facilitou o processo de entendimento e aquisição das informações.

A simplicidade conceitual, que agrega grande potencial computacional para as MEFs, implica na necessidade de altos níveis de abstrações durante a fase de modelagem. A complexidade do sistema envolvido também dificulta a identificação dos eventos de entrada e saída, bem como os estados que caracterizam o seu comportamento. Como discutido na Seção 5.2, algumas entradas modeladas não geram saídas que possam ser visualizadas pelo usuário. Em outros casos, mais de uma saída ocorre sem a necessidade da definição de um par (entrada, saida). Além disso, MEFs não possuem recursos para a modelagem de eventos temporizados, frequentemente presentes em sistemas embarcados e reativos. 
Em grande parte das MEFs geradas durante este trabalho, não foi possível aplicar os métodos de geração disponíveis na JPlavisFSM, uma vez que as MEFs geradas não eram reduzidas e, portanto, não possuiam sequências de separação. A princípio, essas MEFs poderiam ser reduzidas em apenas um estado, com transições com origem e destino para esse mesmo estado; porém, a ordem do acontecimento das transições é um fator determinante para a modelagem correta do comportamento do sistema. Como não existe a possibilidade de as entradas ocorrerem em mais de um estado, não há como diferenciar os estados pelas sequências de entradas, pois não existe saída definida a ser comparada.

\subsection{Trabalhos Futuros}

Em relação à ferramenta JPlavisFSM, algumas adaptações podem ser desenvolvidas para melhorar sua usabilidade. Na versão atual, a ferramenta pode ser utilizada integralmente em ambiente Linux. Para Windows, apenas o método $\mathrm{W}$ foi disponibilizado e a ferramenta n-Complete também deve ser incorporada. Algumas funcionalidades sugeridas pelos usuários das disciplinas do ICMC e INPE podem ser incorporadas, como a flexibilização da linguagem de programação utilizada para desenvolvimento de métodos externos para serem acoplados à ferramenta, que está restrita a linguagem Java.

Quanto à adequação do modelo e dos métodos ao domínio de sistemas embarcados, uma possibiliade seria a utilização de máquinas de estados finitos temporizada (TFSM do inglês, Timed-Finite State Machines). Alguns trabalhos encontrados na literatura estudam a definição de métodos de geração baseados em TFSM. Uma opção seria adaptar a interface atual da JPlavisFSM para permitir a criação deste tipo específico de MEF estendida e disponibilizar métodos de geração para TFSM, como o HSI para TFSM proposto por El-Fakih et al. (2009).

Pode-se investigar a possibilidade de se estender algum outro método tradicional para TFSM, que possuam propriedades interessantes para sistemas embarcados, como a geração de sequências únicas de teste. Para alguns sistemas, a necessidade de se realizar o comando de reset antes da execução de cada caso de teste pode ser uma operação crítica ou muito cara.

Outro ponto que pode-se dar continuidade é a execução dos casos de testes gerados pela JPlavisFSM no software do módulo de comunicação do ITASAT-1. Deve-se analisar qual o conjunto que deve ser aplicado e, então, realizar o pós-processamento necessário para a execução. Os resultados obtidos podem colaborar com a qualidade do software desenvolvido e fornecer base para uma avaliação mais criteriosa sobre a aplicabilidade dos testes gerados pela técnica baseada em MEF, identificando qual o número de testes 
CAPÍTULO 6. CONCLUSÕES

significativos gerados, ou seja, quais puderam ser executados realmente e quais foram capazes de revelar algum defeito no sistema. 
CAPÍTULO 6. CONCLUSÕES 


\section{Referências Bibliográficas}

Aho, A. V.; Dahbura, A. T.; Lee, D.; Uyar, M. U. An optimization technique for protocol conformance test generation based on uio sequences and rural chinese postman tours. In: Proceedings of the $8^{\text {th }}$ Symposium on Protocol Specification, Testing, and Verification, IFIP, 1988, p. $75-86$.

Ambrosio, A.; Martins, E.; Vijaykumar, N. L.; Carvalho, S. A methodology for designing fault injection experiments as an addition to communication systems conformance testing. In: Proceedings of the First Workshop on Dependable Software - Tools and Methods, Yokohama, Japan, 2005.

Ambrosio, A.; Mattiello-Francisco, F.; Santiago, V. A.; Silva, W.; Martins, E. Designing fault injection experiments using state-based model to test a space software. In: Bondavali, A.; Brasileiro, F.; Rajsbaum, S., eds. Third Latin-American Symposium on Dependable Computing (LADC). Lecture Notes in Computer Science (LNCS) series, Morelia, México: Springer, Berlin. 2007, p. 170-178, 2007.

Barbosa, E. F.; Chaim, M. L.; Vincenzi, A. M. R.; Delamaro, M. E.; Jino, M.; Maldonado, J. C. Teste estrutural. In: Delamaro, M. E.; Maldonado, J. C.; Jino, M., eds. Introdução ao Teste de Software, Elsevier, p. 47 - 74, 2007.

Berger, A. S. Embedded systems design: An introduction to processes, tools and techniques. Lawrence, KS, USA: CMP Books, 2001.

Binder, R. Testing object-oriented systems: Models, patterns, and tools. Addison-Wesley, 2000.

Borcsok, J.; Chaaban, W.; Schwarz, M.; Sheng, H.; Sheleh, O.; Batchuluun, B. An automated software verification tool for model-based development of embedded systems 
with simulink. In: XXII International Symposium on Information, Communication and Automation Technologies (ICAT 2009), Sarajevo, Bosnia and Herzegovina: Elf Publishing, 2009, p. $1-6$.

Causevic, A.; Sundmark, D.; Punnekkat, S. An industrial survey on contemporary aspects of software testing. In: $3^{\text {rd }}$ International Conference on Software Testing, Verification and Validation (ICST 2010), Los Alamitos, CA, USA: IEEE Computer Society, 2010, p. $393-401$.

Chow, T. S. Testing software design modeled by finite-state machines. IEEE Transactions on Software Engineering, v. 4, p. 178 - 187, 1978.

Conrad, M.; Fey, I.; Sadeghipour, S. Systematic model-based testing of embedded automotive software. Electronic Notes in Theoretical Computer Science, v. 111, p. 13 26, proceedings of the Workshop on Model Based Testing (MBT 2004), 2005.

Delamaro, M. E.; Barbosa, E. F.; Vincenzi, A. M. R.; Maldonado, J. C. Teste de mutação. 2007a.

Delamaro, M. E.; Maldonado, J. C.; Jino, M. Conceitos básicos. In: Delamaro, M. E.; Maldonado, J. C.; Jino, M., eds. Introdução ao Teste de Software, Elsevier, p. 1 - 7, 2007b.

Ebert, C.; Jones, C. Embedded software: Facts, figures, and future. Computer, v. 42, n. 4 , p. $42-52,2009$.

Ebert, C.; Salecker, J. Embedded software - technologies and trends. IEEE Software, v. 26, n. 3, p. $14-18,2009$.

El-Fakih, K.; Yevtushenko, N.; Fouchal, H. Testing timed finite state machines with guaranteed fault coverage. In: Proceedings of the $21^{\text {st }}$ International Conference on Testing of Software and Communication Systems and $9^{\text {th }}$ International FATES Workshop, TESTCOM '09/FATES '09, Berlin, Heidelberg: Springer-Verlag, 2009, p. 66-80 (TESTCOM '09/FATES '09, ).

Fabbri, S. C. P. F.; Maldonado, J. C.; Masiero, P. C.; Delamaro, M. E. Proteum/FSM: A tool to support finite state machine validation based on mutation testing. In: Proceedings of the $19^{\text {th }}$ International Conference of the Chilean Computer Science Society, Washington, DC, USA: IEEE Computer Society, 1999, p. 96 - 104.

Fabbri, S. C. P. F.; Vincenzi, A. M. R.; Maldonado, J. C. Teste funcional. In: Delamaro, M. E.; Maldonado, J. C.; Jino, M., eds. Introdução ao Teste de Software, Elsevier, p. 9 $-25,2007$. 
Fujiwara, S.; Von Bochmann, G.; Khendek, F.; Amalou, M.; Ghedamsi, A. Test selection based on finite state models. IEEE Transactions on Software Engineering, v. 17, p. 591 - 603, 1991.

Gönnenc, G. A method for the design of fault detection experiments. IEEE Transactions on Computers, v. C-19, n. 6, p. 551 - 558, 1970.

Harel, D. Statecharts: A visual formalism for complex systems. Science of Computer Programming, v. 8, p. $231-274,1987$.

Hennie, F. C. Fault detecting experiments for sequential circuits. Annual IEEE Symposium on Foundations of Computer Science, p. 95 - 110, 1964.

Hierons, R. M.; Ural, H. Reduced length checking sequences. IEEE Transactions on Computers, v. 51, p. $1111-1117,2002$.

Hierons, R. M.; Ural, H. Optimizing the length of checking sequences. IEEE Transactions on Computers, v. 55, p. 618 - 629, 2006.

IEEE Ieee standard glossary of software engineering terminology. 1999.

ITASAT Itasat-1: Acdh software specification. 2011.

ITU-T CCITT specification and description language. 1993.

ITU-T Revised ITU-T specification and description language. 2002.

Kang, B.; Kwon, Y.-J.; Lee, R. A design and test technique for embedded software. IEEE Computer Society, 2005, p. 160 - 165.

Maldonado, J. C. Critérios potenciais usos: Uma contribuição ao teste estrutural de software. Tese de Doutoramento, DCA/FEEC/UNICAMP, Campinas, SP, Brasil, 1991.

Martinez, J.; Merino, P.; Salmeron, A.; Malpartida, F. UML-Based model-driven development for HSDPA design. IEEE Software, v. 26, n. 3, p. 26 - 33, 2009.

Marwedel, P. Embedded system design. Netherlands: Springer, 2006.

Mathur, A. P. Foundations of software testing, v. 1. Pearson Education, 2008.

Naito, S.; Tsunoyama, M. Fault detection for sequential machines by transition tours. In: Proceedings of the $11^{\text {th }}$ IEEE Fault Tolerant Computing Conference (FTCS 1981), IEEE Computer Society, 1981, p. 238 - 243. 
Petrenko, A.; Boroday, S.; Groz, R. Confirming configurations in efsm testing. IEEE Transactions on Software Engineering, v. 30, p. 29-42, 2004.

Petrenko, A.; Yevtushenko, N. Testing from partial deterministic fsm specifications. IEEE Transactions on Computers, p. 1154-1165, 2005.

Petrenko, A.; Yevtushenko, N.; Lebedev, A.; Das, A. Nondeterministic state machines in protocol conformance testing. In: Proceedings of the $6^{\text {th }}$ International Workshop on Protocol Test systems VI (IFIP TC6/WG6.1), Amsterdam, The Netherlands, The Netherlands: North-Holland Publishing Co., 1993, p. 363-378.

Pontes, R. P.; Morais, M.; Véras, P. C.; Ambrosio, A. M.; Villani, E. A comparative analysis of two verification techniques for deds: Model checking versus model-based testing. In: $4^{\text {th }}$ IFAC Workshop on Discrete Event System Design (DEDS), Valencia, Spain, 2009, p. $70-75$.

Sabnani, K.; Dahbura, A. A protocol test generation procedure. Computer Networks and ISDN Systems, v. 15, n. 4, p. 285 - 297, 1988.

Sato, L. S.; Saotome, O.; Timm, C.; Fernades, D.; Yamaguti, W. Itasat-1: Brazilian university microsatellite for payload test and validation in low earth orbit. In: Proceeding of the $8^{\text {th }}$ Symposium on Small satellites for Eath Observation, Berlin, Germany, 2011.

Seo, J.; Ki, Y.; Choi, B.; La, K. Which spot should i test for effective embedded software testing? In: Proceedings of the $20082^{\text {nd }}$ International Conference on Secure System Integration and Reliability Improvement, Washington, DC, USA: IEEE Computer Society, 2008, p. $135-142$.

Sidhu, D.; Leung, T.-K. Formal methods for protocol testing: a detailed study. IEEE Transactions on Software Engineering, v. 15, n. 4, p. 413 - 426, 1989.

Simão, A.; Petrenko, A.; Yevtushenko, N. Generating reduced tests for fsms with extra states. In: Proceedings of the 21 $1^{\text {st }}$ IFIP WG 6.1 International Conference on Testing of Software and Communication Systems and 9th International FATES Workshop, TESTCOM '09/FATES '09, Berlin, Heidelberg: Springer-Verlag, 2009, p. 129 - 145 (TESTCOM '09/FATES'09, ).

Simão, A.; Petrenko, A. Checking completeness of tests for finite state machines. IEEE Transactions on Computers, v. 59, n. 8, p. 1023 -1032, 2010. 
Simão, A. S.; Ambrósio, A. M.; Fabbri, S. C. P. F.; Amaral, A. S. M. S.; Martins, E.; Maldonado, J. C. Plavis/fsm: an environment to integrate fsm-based testing tools. 2005.

Srivastava, S.; Singh, A. Testing of embedded system using fault modeling. 2009, p. $177-180$.

Sung, A.; Choi, B. An interaction testing technique between hardware and software in embedded systems. APSEC 2002, Washington, DC, USA: IEEE Computer Society, 2002, p. 457 - 464 (APSEC 2002, ).

Tian, P.; Wang, J.; Leng, H.; Qiang, K. Construction of distributed embedded software testing environment. Washington, DC, USA: IEEE Computer Society, 2009, p. $470-$ 473.

Ural, H.; Wu, X.; Zhang, F. On minimizing the lengths of checking sequences. IEEE Transactions on Computers, v. 46, n. 1, p. 93 - 99, 1997.

Vuong, S.; Chan, W.; Ito, M. The uiov-method for protocol test sequence generation. In: Proceedings of the $2^{\text {nd }}$ International Workshop Protocol Test Systems, Berlin, Germany, 1989, p. $161-175$. 